Portland State University

PDXScholar

Dissertations and Theses

Dissertations and Theses

$12-4-1998$

\title{
Cost-Benefit Analysis of Physician Assistants
}

Roderick Stanton Hooker

Portland State University

Follow this and additional works at: https://pdxscholar.library.pdx.edu/open_access_etds

Part of the Health Policy Commons, and the Public Administration Commons Let us know how access to this document benefits you.

Recommended Citation

Hooker, Roderick Stanton, "Cost-Benefit Analysis of Physician Assistants" (1998). Dissertations and Theses. Paper 4029.

https://doi.org/10.15760/etd.5913

This Dissertation is brought to you for free and open access. It has been accepted for inclusion in Dissertations and Theses by an authorized administrator of PDXScholar. Please contact us if we can make this document more accessible: pdxscholar@pdx.edu. 
COST-BENEFIT ANALYSIS OF PHYSICIAN ASSISTANTS

by

\title{
RODERICK STANTON HOOKER
}

A dissertation submitted in partial fulfillment of the requirements for the degree of

\author{
DOCTOR OF PHILOSOPHY \\ in \\ PUBLIC ADMINISTRATION AND POLICY
}

Portland State University

1999 


\section{DISSERTATION APPROVAL}

The abstract and dissertation of Roderick Stanton Hooker for the Doctor of Philosophy in Public Administration and Policy were presented December 4, 1998, and accepted by the dissertation committee and the doctoral program.

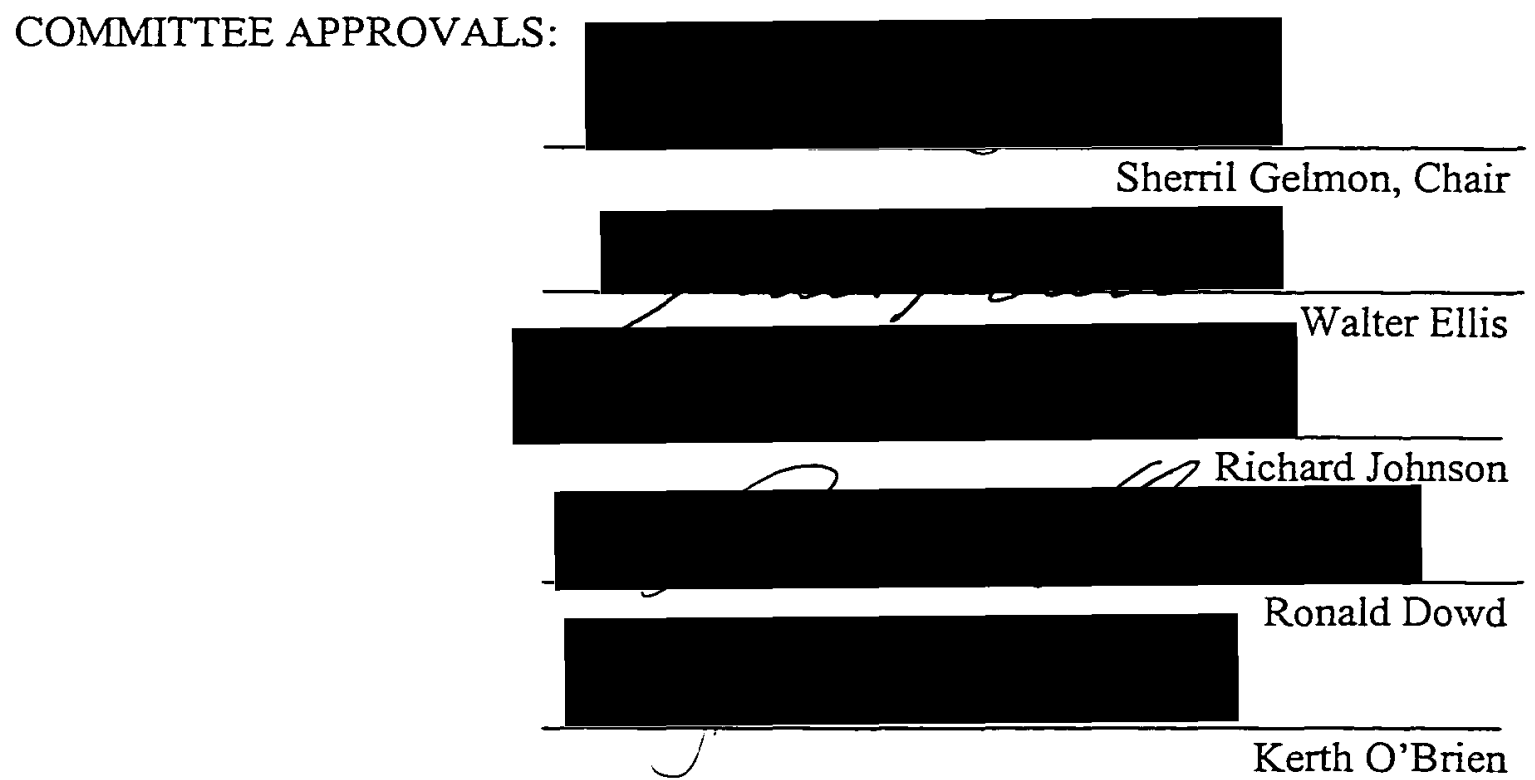

Representative of the Office of Graduate Studies

DOCTORAL PROGRAM APPROVALS: $/$
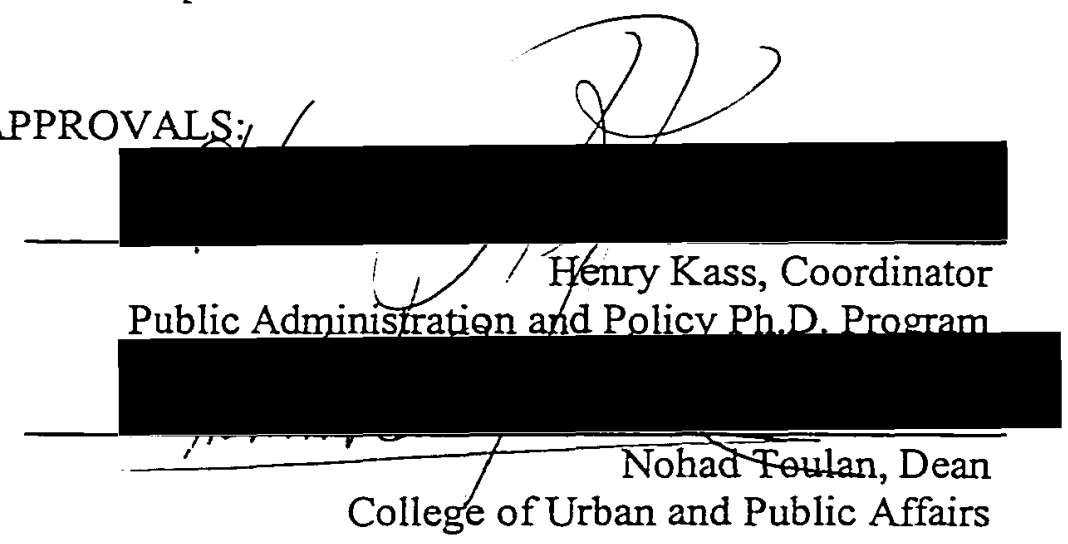


\begin{abstract}
An abstract of the dissertation of Roderick Stanton Hooker for the Doctor of Philosophy in Public Administration and Policy presented December 4, 1998.
\end{abstract}

Title: Cost-Benefit Analysis of Physician Assistants

This study examined if physician assistants (PAs) are cost-beneficial to employers. In an era of cost accountability, questions arise about whether a visit to a PA for an episode of care differs from a visit to a physician, and if PAs erode their cost-effectiveness by the manner in which they manage patients.

Four common acute medical conditions seen by PAs and physicians within a large health maintenance organization were identified to study. An episode approach was undertaken to identify all laboratory, imaging, medication and provider costs for these diagnoses. Over 12,700 medical office visits were analyzed and assigned to each type of provider and medical department. Patient variables included age, gender, and health status. A multivariate analysis identified significant cost differences in each cohort of patients.

In every condition managed by PAs, the total cost of the visit was less than that of a physician in the same department. This was significant for episodes of shoulder tendinitis, otitis media, and urinary tract infections. In no instance were PAs statistically different from physicians in use of laboratory and imaging costs. In 
each instance the total cost of the episode was less when treated by a PA. Sometimes PAs ordered fewer laboratory tests than physicians. There were no differences in the rate of return visits for a diagnosis between physicians and PAs. Patient differences were held constant for age, gender, and health status.

This study affirms that PAs are not only cost-effective from a labor standpoint but are also cost-beneficial to those who employ them. In most cases, they order resources for diagnosis and treatment in a manner similar to physicians for an episode of care, but the cost of an episode of an illness is more economical overall when the PA delivers the care. This study validates the federal policy of support for primary care PA education and suggests that PA employment should be expanded in many sectors of the health care system. These findings and the results of this cost-benefit model are evidence of its validity in predicting health care costs. 


\section{ACKNOWLEDGEMENTS}

This study has benefited from the ideas, suggestions, and support of many people. Support in kind was provided by the Kaiser Permanente Center for Health Research in Portland, Oregon. Final preparation of this analysis was made while I was a visiting researcher at this organization. I am grateful to the many people within the Center for Health Research who gave of their time and expertise so I could finish this study. Mark Hornbrook, $\mathrm{PhD}$, volunteered very early on in my career to lend Center support for my work. One person in particular at the Research Center, Dr. Gregory Nichols, suggested some ways to organize the data for easier analysis.

The idea for the study evolved from many conversations with those who preceded me in the study of the health workforce. In particular Richard Johnson and Donald Freeborn, senior investigators at $\mathrm{CHR}$, provided invaluable opportunities not only to learn first hand about the research process, but also to participate in the development of important research studies on health organizations and the health workforce. I especially appreciate the insights they shared on the important inputs in health care delivery.

The late Jane Cassels Record has been my inspiration from the first time I met her in 1977. Her seminal work on the economics of nonphysician provider employment was the stepping stone for my work in this same area. 
I am greatly indebted to and wish to thank the members of my dissertation committee: Professors Gelmon, Ellis, Johnson, Dowd, and O'Brien.. They have provided much support, encouragement, and very able assistance throughout the course of this project. In particular, I am extremely grateful to my mentor and friend, Dr. Richard Johnson, not only for tutoring me in the theory of workforce economics but also for his continuing support of my work when I would get discouraged. His thoughtful and extensive comments on earlier drafts have immeasurably improved this study. Professor Sherril Gelmon gave willingly of her time as the chair of my committee and was pleasant beyond the call of duty when presented with yet another draft to wade through. She is an expert in the health workforce and serves as a model if I should ever sit on a similar committee.

Other acknowledgements go to fellow Public Administration and Policy classmates. Twelve of us set off on this voyage together in the early 1990s and we learned a lot from each other. Three in particular are my friends Charlene Rhyne, Rick Van Orden, and Christine Slusarenko. They were there to lend support when spirits began to flag. The freedom to express ideas, share frustrations, and explore constructs with friends is an under-appreciated resource in this process. Since they are on the same course I hope I can be there when they need me.

Dr. Stephen Crane at the American Academy of Physician Assistants has been a friend and shared my interest in this subject. His expertise in the economics of physician assistant employment has been the source of many ideas that were 
incorporated in this study. My appreciation also goes to my friend, Dr. P. Eugene Jones, an expert on statistical methodology who saw an early draft and made many comments that helped me to focus more on the issue. Probably no one knows more about nonphysician employment than my good friend Professor James Cawley at The George Washington University. For years we have bounced countless ideas off one another seeking theories that could explain some of the phenomena we've observe in health care delivery. Jim will never know the innumerable kernels of ideas he lent behind in our talks - ideas I was able to incorporate in this study.

Finally, there is no greater tribute I can give than my appreciation to the tireless work that my wife, Donna Lux Hooker, provided in reading, questioning, editing and reading again this work. Her keen eye for unfounded statements that kept me ever improving endless drafts of this document. She has endured my work while trying to be a wife, and mother, as well as husband and father - when I was too distracted to hear what was being asked or said by my wife and children. Lindsay and Tyler, I won't do this again. But more importantly I would not have stayed the course had Donna not given the support I needed to start back to school once again, read my papers, give me the time to read, and then help me back on the horse when I fell off. This dissertation is dedicated to her and we share the mantle of accomplishment for its completion. 
ACKNOWLEDGEMENTS

LIST OF TABLES__ vii

LIST OF ABBREVLATIONS viii

PREFACE — ix

CHAPTER I: INTRODUCTION TO THE STUDY PROBLEM ___ 1

Data Reviewed __ 9

Purpose of the Study _ـ 10

Theoretical Basis for the Study__ 10

Cost-Effectiveness Analysis___ 11

Cost-Benefit Analysis ___ 11

Research Question__ 12

Research Approach _ 14

Assumptions Used in the Study___ 14

Chapter Summary __ 18

CHAPTER II: REVIEW OF THE LITERATURE___ 19

Economic Theories and Policy Analysis Perspectives _ 20

Health Maintenance Organization__ 24

Physician Assistant Literature 26

PAs as Substitutes or Complements _ 30

Practice Arrangements ___ 32

Delegation _ 34

Consultation__ 37

Supervision__ 39

Clinical Productivity __ 41

Cost of PAs

Employment of PAs _ 52 
Compensation to Production Ratio 54

Substitution Ratios 56

Conclusion to Chapter $I$ 60

CHAPTER III : DATA AND METHODS 62

Hypothesis 63

Cost-Benefit Analysis Criteria 65

Study Site 67

Electronic Medical Record 72

Definition of an Episode of Care 74

Study Population Selection 76

Data Sources, Variables, and Cost Model 86

EpicCare End User Database 86

Medications 87

Laboratory Information System (LIS) 88

Radiology Information and Management (RIM) 90

Health Status 91

Sociodemographics 92

Admission, Discharge, and Transfer (ADT) 93

Emergency/Urgency Care Database 94

Provider Attributes 94

Outpatient Utilization 96

Research Population 96

Medical Record Verification 98

Analysis Model 100

Chapter Summary 104

CHAPTER IV: RESULTS 105

Providers 106 
Patient Attributes 108

Multivariate Analysis__ 126

Urinary Tract Infection__ 127

Bronchitis__ 129

Otitis Media 130

Shoulder Tendinitis___ 132

Summary of Results _ 135

CHAPTER V: DISCUSSION__ 137

Interpretation of Results _ 140

Bivariate Results _ 141

Multivariate Results__ 142

Policy Implications _ 147

CHAPTER VI: CONCLUDING REMARKS___ 151

Study Limitations — 152

Suggestions for Further Study __ 155

Executive Summary__ 158

BIBLIOGRAPHY_L 161

APPENDIX A - DIFFERENTLAL DIAGNOSES__ 170

APPENDLX B - REGRESSION ANALYSIS__ 185 


\section{LIST OF TABLES}

TABLE 1 THE DELEGATION OF OFFICE VISITS TO PAS 36

TABLE 2 PHYSICLAN SUPERVISION OF PAS AND NPS 40

TABLE 3 PA PRODUCTIVITY IN AN HMO SETTING 45

TABLE 4

TABLE 5

TABLE 6

$T A B L E 7$

TABLE 8

TABLE 9

CLINIC PRODUCTIVITY WHEN A PA IS ADDED 46

PA OUTPATIENT VISITS PER DAY 49 VISITS PER DAY BY YEARS OF EXPERIENCE 50 VISITS PER DAY BY FIELD OF PRACTICE 51 COMPENSATION TO PRODUCTION RATIO 55

TABLE 10 COST-EFFECTIVENESS OF PAS 59

TABLE 11 DLAGNOSES SELECTED FOR STUDY 79 LABORATORY ORDERS AND COSTS 89

TABLE 12 IMAGING ORDERS AND COSTS 91

TABLE 13 VARIABLES IN COST-BENEFIT ANALYSIS 97

TABLE 14 CRITERLA FOR POPULATION SELECTION 99

TABLE 15 SELECTING THE RESEARCH POPULATION 101

TABLE 16 TYPE OF PROVIDER BY DIAGNOSIS 107

TABLE 17 VISITS BY PATIENT ATTRIBUTES 110

TABLE 18 URINARY TRACT INFECTION PATIENTS 114

TABLE 19 SHOULDER TENDINITIS PATIENTS 114

TABLE 20 ACUTE OTITIS MEDIA PATIENTS 115

TABLE 21 ACUTE BRONCHITIS PATIENTS 115

TABLE 22 MEDICAL OFFICE VISIT ORDERS 119

TABLE 23 MEAN COSTS FOR AN EPISODE OF CARE 121

TABLE 24 COSTS FOR BRONCHITIS 122

TABLE 25 COSTS FOR OTITIS MEDIA 123

TABLE 26 COSTS FOR UTI 124

TABLE 27 COSTS FOR TENDINITIS 125

TABLE 28 MULTIVARIATE REGRESSION COST MODEL 134 vii 


\section{LIST OF ABBREVATIONS}

AAPA

ADT

ANOVA

CDS

CIS

CNM

CPT

CRNA

CT

ECG

ED/UC

ENT

FP

HMO

ICD-9

IM

KARE

KPNW

LIS

$\mathrm{MD} / \mathrm{DO}$

MIPS

MGMA

MOV

MRI

MSE

NP

NWP

OM

OTA

PA

PPRC

PT

RIM

SAS

SPA

TOPS

UTI
American Academy of Physician Assistants

Admissions, Discharge, and Transfer Database

Analysis of Variance

Chronic Disease Score

Clinical Information System

Certified Nurse Midwives

Current Procedural Terminology

Certified Registered Nurse Anesthetist

Computerized Tomography

Electrocardiogram

Emergency Department/Urgency Care

Ear, Nose, and Throat

Family Practice

Health Maintenance Organization

International Classification of Diseases: $9^{\text {th }}$ edition

Internal Medicine

The Kaiser Appointment and Record of Encounters

Kaiser Permanente Northwest

Laboratory Information System

Physician

Membership Information and Processing System

Medical Group Management Association

Medical Office Visit

Magnetic Resonance Imaging

Mean Squared Exponent

Nurse Practitioner

Northwest Permanente, PC

Otitis Media

Office of Technology Assessment

Physician Assistant

Physician Payment Review Commission

Physical Therapy

Radiology Information and Management System

an integrated system of software for statistical analysis

Strategic Positioning and Assessment

The Outpatient Pharmacy System

Urinary Tract Infection 


\section{PREFACE}

Examining the economics of physician assistant labor has been an interest of mine since 1977. This was when I met the late Jane Record, $\mathrm{PhD}$, an economist with the Kaiser Permanente Center for Health Research. She had presented some findings from her seminal study of the cost-effectiveness of physician assistants - a study funded by the Department of Health Education and Welfare. I was so impressed with her work I asked if I could join her group. This was research I found not only interesting but also a rare opportunity to examine an emerging health provider occupation unique to American health care delivery. Dr. Record advised I first find a job as a PA. Shortly after that brief meeting, I came to work as a physician assistant in the Department of Internal Medicine with Kaiser Permanente in Portland, Oregon, and within a year I was involved with some of her studies. Unfortunately, Jane Record died in 1980. I never lost the desire to continue some of her work.

Since 1978 I have been a clinical PA in primary care and rheumatology. In spite of Dr. Record's untimely death, I was able to continue my interest in the health workforce as an adjunct researcher at the Center for Health Research, specifically, the economic aspects of nonphysician clinicians who provide services that are similar to physicians - physician assistants, optometrists, mental health workers, podiatrists, nurse practitioners, nurse midwives, nurse anesthetists, and certified nurse anesthetists. Many people have influenced my work. At the Center for Health Research my mentors, have been Richard Johnson, $\mathrm{PhD}$, Donald Freeborn, $\mathrm{PhD}$, Mitch Greenlick, $\mathrm{PhD}$, and Mark Hombrook, $\mathrm{PhD}$. They have instilled in me the need for excellence in searching for the truth in social research. I have appreciated their willingness to share their opinions and expertise whenever called upon and their advice, solicited or otherwise.

The impetus to seek another degree was the frustration of not being the principal investigator of studies I wanted to undertake. Few granting agencies will consider funding a non-doctoral degree principal investigator. I began my doctoral 
studies in the early 1990 s by taking one course a term - it has been a long haul. The doctorate program in Public Administration and Policy at Portland State University was an ideal fit. I had a Master's degree in Business Administration and was interested in organizational theory. After taking the required courses in the Public Administration and Policy track, I was free to enroll in a number of other courses that had relevancy in health policy - my main interest and the direction of my future research.

Kaiser Permanente has been the ideal laboratory for observing the dynamics of health care delivery. The health plan structure, the people who serve it, the broad-based membership, and the ability to experiment with cost-effective strategies without compromising the safety of the patients has made my role as observer a unique one. Unique because I am a part of it on a daily basis but because I am able to step back periodically to critique through researcher eyes. Kaiser Permanente is a complex organization and that it exceeds where others have failed is testimony to its organizational make-up, leadership and mission. The introduction of PAs into its structure in 1970 is an example of how this organization has been ahead of the curve in innovative strategies. In this case the department of internal medicine wanted to hire a PA so it could learn more what a PA is and what he could do. Within a year they had hired four additional PAs.

One particular example of organizational commitment to innovation that made this study possible is the single medical record policy. In the early 1990 s the Northwest Division of Kaiser Permanente enacted the world's largest computerized and comprehensive health care record system. This system has resulted in considerable reduction of medical record handling, at the same time improving the accuracy of the notation in the medical record, improving the delivery of care and decreasing unnecessary costs from duplication and error alone. It is an extraordinary system and I am proud to have been some small part of it both from the user and analyst side. As a consequence of utilizing this system this study is one in a growing number of comprehensive studies in health services research that take 
advantage of extraordinary accurate and contemporary health care databases.

Almost every aspect of an episode of care can be accounted for with this system. In all faimess, however, more and better studies are to come. This is an organization and a system that has yet to meet its potential to create one of the finest models of health care delivery in the world. It is a humbling experience to have had the fortune and privilege to work within Kaiser Permanente and to be a small cog in the greater scheme of things. I only hope this paper does some justice to the system.

Roderick S. Hooker, PA

Portland, Oregon 


\section{COST-BENEFIT ANALYSIS OF PHYSICIAN ASSISTANTS}

\section{CHAPTER I}

INTRODUCTION TO THE STUDY PROBLEM 


\section{CHAPTER I}

\section{INTRODUCTION TO THE STUDY PROBLEM}

The introduction of physician assistants (PAs) in the United States to assist the primary care physician in the mid-1960s represented a change in health care delivery. The traditional method of medical care provision had the physician in charge of patient care and a base of support staff, nurses, and allied health members carrying out the physician's orders \{Starr 1982\}. With the advent of the physician assistant many of these physician responsibilities were delegated, allowing the physician more time to spend with more complex patient problems or to practice more efficiently \{Jones 1994 \}. Although the initial setting was a solo practitioner primary care office, within a short time PAs were providing care in various settings including rural clinics, urban međically underserved areas, hospitals, emergency departments, and the military.

The need to distribute primary care to rural and medically underserved areas remains one of the more pressing issues of health care delivery in this country \{PPRC 1994\}. Because of the need to improve this situation, the federal government began underwriting PA training programs in the 1970s through a series of public laws and policies. For example, Public Law 95-210, enacted in 1977, encourages the employment of PAs and advance practice nurses in rural areas by means of reimbursement through Medicare and Medicaid. The intent was 
to use PAs to improve access to primary care - a less expensive altemative to training more physicians \{OTA 1986\}. This experiment in health policy appears to be working based on the wide distribution of PAs in different sectors of the health workforce. What is not fully understood is the degree of benefit PAs bring to society over and above what physicians provide. This study is intended to move closer to answering that important question.

As of 1998 there are over 35,000 graduates of PA programs throughout the United States. Over one-third of practicing PAs are working in communities of less than 10,000 people, and over $50 \%$ are in the three disciplines of primary care (General Internal Medicine, Family Practice, and General Pediatrics) \{AAPA 1996b\}. This distribution of PAs is a remarkable achievement in policy enactment and dispersal of a new health profession. However, in spite of this achievement, a number of obstacles prevent the full utilization of PAs. These obstacles, mostly on the state level, are in the area of full insurance reimbursement for PA services, prescriptive privileges in some states for PAs, and access to certain populations such as institutional patients and in certain jurisdictions \{Henderson 1994; Sekscenski 1994; Cohen 1996\}.

Prescribing and reimbursement obstacles persist for various reasons. In regard to reimbursement, insurance companies may not want to pay out more refunds for medical services and some see an opportunity to limit reimbursable services just to physicians as a means of controlling costs \{PPRC 1993a; 1993b; 1994\}. However, the insurance barrier is starting to erode. With medical 
insurance reform and more uniform policy development in the industry, reimbursement issues are becoming less restrictive for the PA $\{$ Henderson 1994\}.

Prescribing still remains a significant barrier for a large segment of the PA profession since states control this through legislation \{Henderson 1994\}. PAs were first authorized limited prescribing privileges in Colorado in 1969 \{Silver 1971\}. When this authority was enacted, PAs in Colorado could order drugs without consulting their supervising physicians as long as the physician reviewed and approved the order. New York authorized prescribing privileges to PAs in 1972; Maine, New Mexico, and North Carolina followed in 1973. By 1979, PAs had prescribing privileges in 11 states \{Weston 1984\}. In 1998 PAs are authorized by statute or regulation to prescribe in 44 states, the District of Columbia, and in most federal facilities including the military and facilities serving veterans \{AAPA 1998a\}.

For prescribing PAs the underlying principle in these jurisdictions is one of dependence on the physician who have delegated this authority. With few exceptions--such as dentists and veterinarians, and in some states podiatrists, optometrists, and nurse practitioners--the legal right to prescribe is still the exclusive domain of the physician. In Oregon and Washington, enabling legislation allows PAs to prescribe in a manner similar to physicians. In Maryland and Louisiana, PAs are prohibited from prescribing altogether \{AAPA 1998\}. In spite of the fact that prescribing is a state legislative act, the main influence in 
delegating this legislation is one of physician authorization and acceptance $\{$ Cohen $1996\}$.

Barriers to full PA utilization remain due to physician attitudes more than public safety issues \{Gara 1990\}. When the federal government reviewed the use of PAs it found them a "safe and economical" means of improving health care delivery in the United States \{OTA 1986; 1990\}. With mounting evidence demonstrating that PAs are cost-effective, the issue seems to be less about their labor cost and more about whether they are cost beneficial to physicians or the institutions that employ them \{Moore 1994; Johnson 1978; Golladay 1976\}.

This study examines one issue that has limited full utilization of PAs - the cost-benefits of PAs in the delivery of care. The lack of research on this issue has allowed physicians, who influence state policies and laws in the use of PAs, to justify inhibiting the full utilization of PAs in certain states.

\section{Background}

Two primary goals of federal and state health care reform in the mid-1990s are universal coverage and cost containment \{Laham 1993\}. With a focus on these goals, discussion about the optimal make-up and distribution of the health workforce has been rekindled by workforce planners and policy makers \{Osterweis 1996; Weiner 1996\}. While national health reform did not take place 
as planned by the Clinton government, these issues remain central in the minds of health policy reformers \{Schroeder 1996\}.

One important aspect is the potential "substitution" of non-physician providers such as physician assistants and advance practice nurses (nurse practitioners [NPs], certified nurse midwives [CNMs], and certified registered

nurse anesthetists [CRNAs]) for physicians (Cawley 1996; Bednash 1996; Cromwell 1996\}. The growing presence of nonphysician providers has made substantial changes in the way health care delivery is being discussed \{Meikel 1992a; 1992b; Einsenberg 1994; Schroeder 1996\}. In spite of the benefit that PAs appear to bring to health care delivery in terms of efficiency, a number of barriers exist. Why the barriers are present is not always obvious to the politically naïve observer.

\section{Statement of the Problem}

Interest in physician substitution exists because of the ongoing concern about health expenditures, such as physician costs, and the search for an optimal level of health care input that balances quality with cost effectiveness. Certain managed care systems are using PAs more intensely than the fee-for-practice sector. In some HMOs, up to one-third of primary care staffing is PAs \{Larson 1994; Hart 1997\}. Some see the use of PAs as a benchmark or potential standard for more contemporary models of medical practice \{Weiner 1994; Weiner 1996\}. 
A third reason for physician substitution is the increased need for dealing with chronic disease and prevention, areas in which PA/NPs have ability and interest, and a niche often unfilled by physicians \{Crandall 1984; Cooper 1995\}. There is a potential need for PAs in hospitals as house officer (resident physician or residents) workloads are increased and specialty resident numbers are reduced \{Riportella-Muller 1995\}. Reform proposals and recommendations by policy bodies, including the Clinton Health Security Act, and the Balanced Budget Act of 1997 have suggested that national workforce policy should move towards increasing the participation of PAs and NPs in the health care system \{White House 1993; Schroeder 1996\}.

Advocates of PAs and NPs have quoted studies that support the claim that PAs and NPs can do 70 to 90 percent of primary care physician tasks and, by implication, replace similar numbers of generalist physicians \{Weiner 1994; Record 1981\}. As health workforce planners attempt to forecast the health care needs of the US society in the next five, ten, and twenty years, accurate data detailing what PAs can and cannot provide in terms of physician services will become a necessity \{Franks 1993; Weiner 1994; Cooper 1995; Goodman 1996\}.

A number of questions must be addressed in forecasting a mix of providers in the workforce. Are physician assistants cost effective? Are they productive enough to be considered replacements for physicians? If they are cost effective, are they cost beneficial? To whom do the benefits accrue? Do the benefits of 
using physician assistants accrue to the employer, the patient, or society as a whole?

This dissertation examines the central health policy issue of physician assistant economics and the downstream financial impact of utilizing PAs in clinical practice (cost-benefit analysis). Health workforce policymakers are interested in what happens to the output of a physician's practice, inpatient service, or an outpatient clinic when a PA is added to the clinical staff \{Moore 1994; Franks 1993; Weiner 1994; Cooper 1995; Goodman 1996\}. Questions are being asked about the outcomes of care in terms of access to patient care services, the level of quality of care, and practice revenues and productivity when PAs are part of the equation \{Moore 1994\}. Information to address these questions is widely dispersed and the following review of the literature in Chapter II is an attempt to summarize the data into one coherent body.

While the contributions of PA practice are determined by multiple influences, many which are difficult to measure, there are a number of PA clinical performance characteristics that have been described in health services research. Many of the findings, some performed years ago, still appear to be valid. For example, numerous studies have shown that, within their spheres of practice competency, PAs provide lower cost health care that is comparable, and in some instances superior to, that provided by physicians \{OTA 1986; Schneider 1977; Greenfield 1978\}. While PA cost effectiveness has not been conclusively demonstrated in all clinical practice settings $\{$ McCibbin 1978\}, substantial 
empirical and health services research evidence confirms the findings that PAs are cost effective in most of the settings studied (Cawley 1986; Record 1980; Romm 1979\}. Regardless of the lack of extensive economical studies it is fairly apparent that utilization in clinical settings would be unlikely if PAs were not cost effective.

Evidence indicates that the organizational setting is closely related to the productivity and possible cost benefits of PA utilization. Scheffler (1979) documented that PAs employed in institutional settings are more productive than those in private practice are in that they see more patients in the same period of time. Record and colleagues (1981) noted correlation among productivity, delegation of tasks, and organizational size and proposed that economies of scale, and cost savings incentives were the likely explanations for the observations of PA cost effectiveness in the health maintenance organization (HMO) setting.

\section{DATA REVTEWED}

This part of the introduction reviews the limitations and generalization of data from the major studies that have examined PA productivity. The cost effectiveness results are discussed. Next the applicability of cost effectiveness 
analysis to physician assistant employment and medical care labor is assessed. Finally, the beneficiaries of physician assistant employment are reviewed.

\section{Purpose of the Study}

The purpose of this study is to examine the cost-benefits of employing PAs from the employer's perspective. This study directly addresses policy and opinions that limit PAs utilization in various settings. The attitudes of some physicians and researchers are that PAs may be cost effective in the short run but not beneficial in the long run $\{$ Moore 1994\}. If they are not cost-beneficial as theorized then perhaps their use is being overemphasized. Thus the basis of this study is to examine this particular question - are PAs cost-beneficial to those who employ them?

Implicit for health workforce planners is the question of how much overlap a PA may have with a physician in the same setting. While a number of studies contribute to our understanding of cost-effectiveness and PA utilization, a comprehensive review has failed to find any examination of cost-benefit work in either the PA or the NP literature \{Hooker 1997; Mahoney 1988\}.

\section{Theoretical Basis for the Study}

The policy evaluation approaches for this study are the economic theories of cost-effectiveness, cost-benefit analysis, substitution and complement \{Russell 
1996; Weinstein 1996; Siegel 1996\}. These theories represent the basis for developing policy concerning physician assistant employment and deployment in the American health workforce.

\section{Cost-Effectiveness Analysis}

Cost-effectiveness analysis is based on the desire to achieve policy objectives in the least costly way \{Heineman 1990; Miller 1993\}. This form of analysis compares alternative policies that might be used to achieve the same or very similar objectives. In cost-effective analysis, the results are usually expressed as the net costs required to produce a certain unit of output $\ldots$ - usually related to the variation in utilization rates. One example would be comparing the labor cost of using a PA and a physician for hypertension management of patients if both providers followed hypertension guidelines. These two different providers may produce the exact same effect for a cohort of patients but the salary of one is substantially less than the another. The cost-effective strategy would be to select the least expensive provider that produces the same result. Choosing between two different antihypertensive medications that each produce the same net effect would be another cost-effective strategy.

\section{Cost-Benefit Analysis}

Cost-benefit analysis is an extension of cost-effectiveness evaluation and is based on the relationship between the benefits and costs of a particular policy with 
all costs and benefits expressed in monetary terms \{Russell 1996; Weinstein 1996; Siegel 1996$\}$. Such analysis helps answer the fundamentally important question of whether the benefits of a policy are at least worth its costs. The typical result is a measure of 'net benefits' which is the difference between the total monetary input costs of an intervention and the consequences of that intervention, also valued in monetary terms. For example, hypertension strategies are often analyzed in terms of cost-benefit analysis since the cost of an intervention may be a few dollars but the net savings in a preventable illness like stroke, myocardial infarction, or renal failure may be ten times that amount. In a medical office setting that employs a PA, the PA is less expensive than a physician from a labor standpoint. However, if the PA orders lab, $\mathrm{x}$-rays, frequent return visits, ignores other medical problems, and prescribes more expensive medications for an episode of hypertension, the cost benefits of this employment will reveal a less than optimal cost-effectiveness. Potentially the PA could negate all of his or her cost-effectiveness by practicing medicine differently than a physician.

\section{Research Question}

The research question this study addresses is: Are physician assistants cost beneficial to their employers? One measure of cost will be to compare the management of an illness by a PA with the management of the same illness by a physician while holding a number of important variables constant. 


\section{Hypothesis}

The hypothesis for this study is that $P A s$ are cost-beneficial to employers for delivering primary care medical services for common acute conditions. The premise is that PAs provide care that is largely indistinguishable from physicians. They may erode some of their cost-effectiveness by ordering a few more resources on average for an episode of care but in the aggregate they remain cost beneficial to their employer when compared to physicians. This cost benefit to the employer is primarily in the reduced labor cost or lower salary than physicians. To test this hypothesis a number of variables need to be controlled. The most important variables include age, gender, and comorbidities of patients. Most studies can control for age and gender, but very few have attempted to control for comorbidities or health status. This study will incorporate a health status score for all patients in the study population with the intent of holding constant some of the differences that exist for different types of patients \{Von Korff 1992; Johnson 1994\}. This is a new method of adjusting patient differences by chronic disease comorbidities and has not been widely applied to this type of research.

The significance of the study is that by building on research that has demonstrated PA cost-effectiveness, the results are expected to show that benefits can be accrued to the employer of PAs. The belief is PAs can provide the same outcome of care as physicians for an episode of an illness but at significant cost 
differences based on labor alone. The results of this study have implications for workforce analysis.

\section{Research Approach}

The approach to this study incorporates a secondary data analysis of care provided by both physician assistants and physicians within one organization. A number of selected diagnoses will be analyzed as episodes of care using a unique database that records all ambulatory health care encounters in an electronic format in a large health maintenance organization in the greater Portland, Oregon area. These diagnoses will be sorted by type of provider and compared as to cost of care for each type of provider. This will be demonstrated by holding a number of variables constant and examining costs of care using an episode approach. Costs will include medical office visits, laboratory, imaging, medication, and other resources. To control for types of patients the population will be adjusted by age, gender and by comorbidities. Analysis will include cost-effectiveness techniques and cost benefit methodology. The methodology chapter describes the research design and the proposed data analysis in greater detail.

\section{Assumptions Used in the Study}

A number of assumptions and limitations arise from a study of this magnitude. The use of a single organization as a source of data, using a very large 
database of all member visits over one year, and identifying all providers who provide care for this populations allows a number of advantages for reaching conclusions. But there are also inherent limitations. Organizations provide care differently not only in different regions of the country but within the same region. Policies goverming how physician assistants are utilized can differ significantly among organizations. Finally, the author of this study is a PA as well. Therefore conclusions drawn from this study need to be stated with caution as the findings may not be generalizable.

An electronic medical record, called EpicCare, is a database instituted by KPNW in 1993 and currently used on a scale unlike any in the country. EpicCare's primary attribute is that it electronically captures every aspect of a patient's ambulatory medical encounter with KPNW including medical office visit, laboratory work, nursing interactions, correspondence, telephone calls, equipment, pharmacy dispenses, referrals to nonprimary care specialists, and hallway consultations. This is the broad panoply of services that goes into the mix of ambulatory visits and the focus of this study. Analysis of EpicCare data had not been widely undertaken at the time of this writing, although the raw data is being shifted into a well-established, end-user relational database named System 1032 (S1032) which lends itself to large based data analysis.

The population studied is the Portland based Kaiser Permanente health plan membership for 1997. This membership is assumed to be representative of the population it draws upon with the exception of the very wealthy and very poor. 
This is a fairly confident assumption since three studies have examined this membership and have found it reflective of the Portland, Oregon/Vancouver, Washington, metropolitan area \{Freeborn 1994\}.

Only episodes of care with a single diagnosis at the time of the initial encounter will be analyzed. This approach is to avoid mismatching the resources for one encounter with that of another diagnosis. The assumption is that the resources used for a particular encounter are the usual resources for that condition. A preliminary examination of the data found that this was the case in most primary care encounters.

All conditions are identified by ICD-9 (International Classification of Diseases - Ninth Edition) codes. This classification is considered one of the strengths of this study since it uses a widely accepted method of identifying conditions seen universally. While ICD-9 codes help to standardize conditions, the codes fail to identify the severity of the disease. Attempts to assign severity of conditions abstracted from the medical record, or even assigned by the clinician, do not correlate well and tend to lack external validity. The assumption for this study is that within a large population dataset, the severity of the condition is spread fairly equally between types of providers.

Other economic assumptions for physician assistants include:

- Care for these diagnoses are tasks delegated by the supervising physician. This is an economic term that implies that the PA is trained 
and experienced in managing these diagnoses. The basis of PA education is primary care based and the training process includes exposure to a wide assortment of common and uncommon primary care diagnoses. The diagnoses for this study are common conditions and are easily managed by all PAs \{AAPA 1979\}.

- Consultation with the supervising physician for these episodes did not take place. This broad assumption is made to avoid assigning supervision costs to the encounter. The diagnoses under study are commonly seen, uncomplicated, and all PAs are experienced in managing these conditions without consultation \{AAPA 1993\}.

- The PA and physician were under the same organizational influences and restraints in caring for these patients, including recommended guidelines for certain conditions \{Hooker 1993\}.

- Patients had equal access to PAs and physicians and the patients were undifferentiated in 1997. It is policy that within this organization and at all times patients are provided a choice of providers. No triaging takes place for common primary care conditions. Evidence exists that patients are equally satisfied with both providers and usually do not choose one over the other for acute primary care conditions \{Hooker $1993\}$. 
Finally, the area of cost-benefit analysis is an economic technique that is new to this area of health workforce analysis. Cost benefit analysis needs to be defined in terms of who the beneficiary is. In this study the analysis will be with the employer as the beneficiary although implications of benefit, both direct and indirect, are made for the patient as well.

\section{Chapter Summary}

Although physician assistants have been part of the American health workforce for three decades, many economic questions still remain that are potential barriers for full utilization. Some of these economic questions center on what are the short term and long term benefits of PA employment. If we are to understand the benefits of utilizing PAs we need to base our understanding in the economic theory of cost effectiveness and by extension cost benefit analysis. This is undertaken in Chapter II, a review of the literature. 


\section{CHAPTER II}

\section{REVIEW OF THE LITERATURE}




\section{REVIEW OF THE LITERATURE}

The following review of the literature addresses the range of economic understanding of physician assistants. In organizing the literature, the areas of policy analysis development as a science and the economic theory of cost effectiveness are reviewed. This review is followed by a historical focus on whether the care and revenue they provide justify the employment of PAs as a laborsaving effort. This area of health workforce merits attention due to the lack of literature consolidation, and because virtually nothing is known about costbenefit analysis of PAs.

Another purpose of this literature review is to examine the federal health policies that have guided placement of physician assistants in society. Placing the current role of the PA in the American health work force in historical perspective will do this. The literature on physician assistants is grounded in the disciplines and theories governing economics, law, medical sociology, organizational theory, health care management, and health services research.

\section{Economic Theories and Policy Analysis Perspectives}

Broadly speaking policy analysis techniques have their origin in World War II. Chief among these techniques was operations research, which was later tied into the broader analytic perspective of systems analysis. Operations research tended to be heavily quantitative and focused on narrow, specific problems such as 
the optimum deployment of defense weaponry, personnel, and materials. Working within a framework of normative consensus, analysts could concentrate on the technical aspects of problems and were able to produce noteworthy results.

The relevance of social analysis to public policy was brought to public attention in the Supreme Court's decision in Brown v. Board of Education (1954). In arriving at their decision to rule racial segregation in public education unconstitutional, the Court commissioned social science studies on the effects of racial segregation on children and society at large \{Heineman 1990\}. In a majority opinion, Chief Justice Earl Warren drew on these and previous studies accepting the idea, advanced earlier by Pound and Dewey, that courts should use the social sciences to implement reforms. Whether social science analysis persuaded the Court to overturn segregation or whether it merely served the more symbolic role of bolstering an already determined decision is unclear. But the role of analytical expertise in the cause of social reform became established as a result of it $\{$ Heineman 1990\}.

In the 1960 s, the contribution of analytical techniques to better decision making was furthered by analysis of management and policy issues in the military. Cost-benefit analysis, operations research, linear programming, and budgeting systems are still used today. This gave rise to modern policy analysis and was further refined during the Johnson administration and the Great Society initiative $\{$ Heineman 1990\}. 
In sociology, an applied orientation to the study of society was implemented by scholars like Paul Lazarsfeld, who demonstrated that analytical techniques, especially those utilizing survey research, had uses in private industry and public policy \{Lazarsfeld 1984\}. Lazarsfeld's activities provoked debate among sociologists favoring a more theoretical stance for their discipline, and those wishing to see sociological ideas and analyses applied in society.

The discipline of economics rapidly outdistanced other social science disciplines in status as an important source of ideas and methodologies for public policy. John Maynard Keynes's ideas had provided economic theory with coherence and what has been termed a "robustness" that enabled it to retain applicability in the uncertain conditions of the real world. Additionally, within the framework of their general theories, economists were successful in innovating quantitative techniques, such as cost-benefit analysis, that expanded alternative approaches to problems.

As cost-benefit analysis became more widely used there needed to be a better understanding to whom the benefits accrued. When HMOs or government programs evaluate an intervention, they consider the costs they will experience in providing or paying for it. Costs incurred by patients or other costs, such as for outpatient medications or home care after hospital discharge, may be irrelevant from their perspective. They may also disregard some outcomes. For example, it may matter little to the HMO or government program how soon patients return to work after an illness, although it may matter a great deal to individuals, their 
employers, or the government agency responsible for disability payments \{Russel $1996\}$.

Cost-effectiveness analysis is a method for evaluating the outcomes and costs of interventions designed to improve health. The results are usually summarized in cost-effectiveness ratios that demonstrate the cost of achieving a unit of health effect for diverse types of patients and for variations of the intervention. In a cost-effectiveness ratio, changes in health due to an intervention, compared with a specific alternative, are captured in the denominator; and changes in resource use, compared with the same alternative and valued in monetary terms, are captured in the numerator \{Russel 1996\}.

An evaluation of health benefits in monetary terms introduces elements of cost-benefit analysis. Some values of health care, which often influence choices about health services, cannot be quantified by cost-effectiveness analysis. Cost-benefit analysis is a complementary form of cost effectiveness analysis that values all effects in monetary terms. It is an opportunity to compare interventions that are lost by relying solely on cost-effectiveness analysis. As an analytic technique in policy analysis the program or programs of interest are compared alongside each other by adding up all costs, then benefits are examined and valued. Next, costs are subtracted from benefits. If several options are being considered or studied then the one with the greatest net benefit is considered the most effective \{Heinman 1990\}. 


\section{Health Maintenance Organizations}

Because this study will be conducted using data from an $\mathrm{HMO}$, a brief synopsis of HMOs follows. The forerunners of HMOs were prepaid group practices and were first developed on a large scale around the middle part of the 20th century \{Starr 1982; Kongstvedt 1995\}. Although organized medicine resisted accepting HMOs for years, they were eventually endorsed as part of national health policy with the passage of the Health Maintenance Act of 1973 (Public Law 93-222). This Act attempted to stimulate the growth of prepaid health care by providing start-up funding, prohibiting enforcement of restrictive state legislation, and requiring that major employers offer their employees the opportunity to join HMOs that met federal requirements. However, organized opposition saddled the law with stipulations and limitations that restricted the growth of HMOs. In 1976 and 1978, the Health Maintenance Act was amended, removing these restrictions. Thus, the widespread and rapid growth of HMOs has essentially taken place only since the early 1980s \{Kongstvedt 1995\}. The Kaiser Permanente Health Plan began in 1933 and stands out as one of the successful pioneers of prepaid medical care. It has become the largest HMO in the country with over nine million members as of 1998 .

All HMOs share a number of behavioral characteristics: 
- Contractual responsibility to provide or assure the delivery of a specific range of health services, including physician and inpatient hospital services;

- Service to a defined population which has voluntarily enrolled in the plan;

- Receipt of a fixed periodic payment from enrollees which is independent of the use of services (although there may be minor charges related to such use); and

- Assumption of at least part of the financial risk or gain in the provision of services \{Luft 1981$\}$.

The HMO Act served to codify these basic tenets of prepaid medical care by requiring capitation-based payment, community rather than experience rating, the enrollment of members who could use only participating providers, and comprehensive benefits that would promote the maintenance of good health by covering basic health services with a minimum of copayments and deductibles $\{$ Hale 1988\}.

Next to the federal government, HMOs are the largest employer of PAs \{AAPA 1996b\}. They have been utilizing PAs since 1970 and many studies have been conducted on staffing to population ratios that rely heavily on HMO efficiency as a guide \{Cooper 1995; Weiner 1996; Hart 1997\}. To put these studies in a proper context for economic analysis an understanding of the literature on physician assistants is needed. 


\section{Physician Assistant Literature}

The literature on physician assistants is fairly extensive, and has been reviewed and summarized by various authors at various times. A few of these summaries bear mentioning. The 1986 Office of Technology Assessment Case Study \{OTA 1986\}, and the 1991 National Health Service Corps Policy Paper \{NHSC 1991\} are the two most cited and the most extensive. Both conclude that the introduction of the PA and the NP into the American health work force has been an important and justified health experiment and should be supported. They practice in medically underserved and rural areas and improve access for a wide range of populations.

In the 1970s and 1980s, much of the literature on PAs and NPs examined these two occupations alongside each other or together. While there is a great deal of overlap in what the PA and NP occupations provide in traditional primary care physician services, there are also some fundamental differences. Physician assistants tend to have heterogeneous backgrounds with such former professions as corpsmen, pharmacists, physical therapists, and nursing \{Simon A 1998\}. Nurse practitioners on the other hand, tend to have homogeneous backgrounds in that almost all are Registered Nurses with a Bachelor Degree. While $25 \%$ of PA programs grant a graduate degree almost all NP programs grant Masters degree, usually in nursing. The PA profession is made up equally of men and women, 
while the NP profession is predominantly female (90\%) \{AAPA 1998b;

Washington Consulting Group 1994\}.

Finally, NPs consider their role as an extension of the nursing act, and believe they may practice independent of a physician \{Mahoney 1988; Safriet 1992\}. PAs, on the other hand, regard their role as dependent upon physicians not only for their employment but also for responsibilities delegated to them \{Jones 1994; AAPA 1996a; Simon A 1998\}. Little is known whether these preparations have any bearing in how they provide services.

Because the literature is more available about how PAs provide care, this study will confine the analysis of providers to physicians and PAs. The main reason for not including NPs in this analysis is that the PA is trained by the physician approach to medical care. PAs approach the patient using the physician as a model and this makes comparisons with physicians more logical. The NP is guided by nursing theories and believes the provision of care is an extension of the nursing act \{Mahoney 1988\}. Gilliam offers the best explanation, stating that: "While PAs and NPs were once thought to be virtually interchangeable, the divergence of the two professions has been such that all similarities have, for all intents and purposes, disappeared." $\{$ Gilliam p168\}. Another important reason is the scope of this study. Confining this study to only two types of providers (PAs and physicians) allows more numerous analytic comparisons to be made between the particular groups. 
There are important definition considerations regarding the way we think about substitution, complement, and delegation. Substitution, in this regard, is the replacement of traditional physician services, while complement is the enhancement of care \{Baumol 1991; Record 1981\}. This distinction is important depending on the policies under consideration. If the objective is to estimate the number of generalist physicians to be trained, then the physician requirement needs to be reduced by the number of PAs expected to substitute for physicians. If the question is how many PAs are expected to be employed and need to be trained for future health care settings, it is necessary to consider estimates of the substitution (or complement) role PAs will perform in select settings.

The performance of physician assistants in the delivery of medical care services has been studied extensively since in the early 1970s. During this time there was an intense effort to document what was generally regarded as a labor savings device for physicians. Motivations for this research varied. Some researchers wanted to document the PA's effectiveness while others thought the stories of PA utilization were overstated and wanted to refute them. Few emerging professions have been subjected to such scrutiny. Spitzer notes:

“...the introduction of physician assistants has been a responsible policy and ... that many other innovations mediated by medical practitioners have gained widespread acceptance with much less rigorous prior evaluation than was given to ... physician assistants" $\{$ Spitzer 1984\}. 
In the first summary of PA studies a General Accounting Office report in 1975 noted that generally no difference could be found in the care by the physician or the PA \{GAO 1975\}. From that time on, the impact of physician assistants on access to health care services, quality of care, and physician and patient acceptance continued to be measured with positive results. However, the precise degree of productivity and cost effectiveness of the utilization of physician assistants has remained difficult to determine. The downstream benefits of PA employment are unclear and the vast majority of PA productivity studies have viewed the PA as a physician substitute rather than as a member of an interdisciplinary health care team \{Scheffler 1996\}.

Almost all the economic research on PAs examines the cost effectiveness of PA employment. Cost effectiveness analysis is an economic technique designed to compare the positive and negative consequences of a specific resource allocation. Basically, it seeks to measure the comparable effects of a particular investment versus its cost. In labor this is usually in terms of productivity and in health care this technique is commonly applied to new medical technologies, diagnostic and laboratory tests, health facilities, delivery systems, drug treatment and immunization programs.

It is a complex task to apply cost-effectiveness analysis in general to the delivery of medical care services and specifically to the provider of such services. It is difficult to accurately measure the content of a medical encounter, given variations in such factors as severity of illness, types of treatment, patient 
preferences, extent of use of diagnostic tests, level of provider training, and the site and mode of care delivery. Add to these factors the differences in the type of provider delivering a similar service and different styles of task delegation. It is obvious that efforts seeking to determine cost effectiveness are methodologically difficult and quite expensive.

\section{PAs as Economic Substitutes or Complements}

Many studies have examined the role of the PA, and many researchers have tried to answer the question of whether PAs substitute for or complement physician services. In the classical economic definition, a substitute replaces a service with something in kind. For example, a kidney machine or a donated kidney replaces a person's original kidney so both are substitutes for the original organ. A bicycle substitutes for an automobile (although not a perfect substitute, it is, nonetheless, a substitute).

A complement is something that enhances the service being provided. Butter complements a piece of toast. A nurse is generally thought to complement a physician's service \{Feldstein 1988 \}.

Paul Feldstein (1991) points out that in medical care it is not always easy to know when an input is a complement or a substitute based only on the task to be performed. A PA may be as competent as a physician to perform certain tasks. However, if the PA works for the physician, and the physician determines the 
performance or directs the task, the PA is a complement and will increase the physician's productivity. If, on the other hand, the PA performs the same task and is operating relatively independently of the physician, then the PA is a substitute for the physician in providing that service. The essential element in determining whether input is a complement or a substitute is who controls the use of that input \{Feldstein 1991\}. Substitutability, as the term is used here, implies that quality of care is not jeopardized. In examining the literature on this question, Sox concluded that a PA is able to "provide the average office patient with primary care that compares very favorably with care given by the physician" (Sox 1979\}.

Most studies examining cost effectiveness of PAs have suffered some flaws based on methodology problems. For the most part, there have been small sample sizes, experiences were analyzed in only one type of ambulatory setting, nurse practitioners or nurses were compared to PAs instead of physicians, the focus was on primary care functions, or the srudies were incomplete in regard to revenue generation and cost data \{Lawrence 1978\}. Furthermore, the majority of these studies were performed in the 1970s while the role of the physician assistant was still developing. Finally, no study has examined what is the cost benefit of employing PAs. Do they have other effects to society that show that their employment lowers overall cost?

Given satisfactory quality and patient acceptance, the substitutability of PAs for physicians depends upon the volume of services delegated and the degree to which the productivity of PAs matches the physician's in performing the 
delegated services. The delegation and productivity numbers can be combined to produce a physician/PA substitution ratio. If, for example, $50 \%$ of the physician's services are delegated to a PA, and the PA's productivity is half that of the physician, it will take one PA to substitute for half of a physician, and the substitution ratio will be .50 physician/1 PA, or .50 .

From the bulk of published studies evaluating physician assistant performance, it is clear that anywhere from 60 to 100 percent of the services performed by primary care physicians can be provided by physician assistants without consultation (substitution) \{Ott 1979; Mendenhall 1980; Johnson 1985; Scheffler 1979; Tirado 1990; Page 1975, Record 1980; Hooker 1993\}. The most rigorous of all PA economic studies showed that the substitution ratio of traditional primary care medical office visits is .83 , suggesting that it takes one physician assistant to substitute for eight-tenths of a physician $\{$ Record 1980\}.

\section{Practice Arrangements}

A medical practice is an administrative and economic relationship composed of the health care setting and all of the parts that allow it to function. It can be a group practice, solo practice, hospital outpatient clinic, managed care organization, or any of various administrative arrangements for medical care provision. The initial concept of the PA in the early 1970s was of the PAjoining a solo physician practice. Studies have looked at estimates of PA productivity to determine the practice arrangements which could best utilize the clinical services of a PA in a solo practice (Nelson 1977\}. 
In the past, activity analyses were used to develop a model of primary care practice organization. The attempt was to document what the primary care physician did most of the time. Estimates of productivity consisted of listing the majority of tasks that fully describe most typical primary care practices. From this list, a model was developed estimating that the introduction of a PA could increase medical practice productivity anywhere from $49-74$ percent. That is, a physician usually producing 147 office visits per week may increase that number to 256 visits per week simply by hiring a PA. Nelson (1977) found that when PA providers were studied in solo and small group medical practices, they increased practice productivity (as measured by the number of office visits) by $12 \%$ during the first year after their introduction and $37 \%$ during their second year in the practice $\{$ Nelson 1975\}.

Reinhardt found that physicians who practiced in groups could manage more patient care visits than those working in solo practices could. He noted that medical care services delivered by groups of physicians exhibited clear economies of scale. Within groups, patterns emerge where the mean level of clinical productivity for each health care professional working in the practice serves to increase the total productivity output of the practice as more personnel who can substitute for a portion of the physician are added \{Reinhardt 1972\}.

Economies of scale are often quite large in the HMO setting that lends itself to experimentation in innovative methods of delivering health care services. In spite of this, measures of physician assistant productivity are remarkably 
consistent and transcend findings observed in studies in HMOs, rural private practices, urban ambulatory care clinics, and geriatric settings \{Hansen 1992; Frick 1986\}. Scheffler found that PAs spend more of their time in patient care when working closely with three or fewer physicians in general medicine \{Scheffler 1977\}.

\section{Delegation}

"Delegation" refers to the percentage of primary care medical responsibilities or tasks that can be safely handled by a physician assistant under optimal conditions. This is typically derived from a panel of experts reasoning from a set of medical criteria. The term "delegability" was adopted by Record to refer to the maximum level of delegation that can be achieved without threat to quality of care $\{$ Record 1980$\}$.

A review of the literature examining the issue of delegation of PAs identified ten studies that used office visits as an output measure. The findings of these studies are summarized in Table 1. In the aggregate, the range of delegation is extremely broad -- from six to 99 percent -- with considerable overlap of the delegation level among settings.

In one study at Kaiser Permanente, a multidisciplinary panel of health professionals developed a set of medical principles focusing on patient complaint and medical history to determine the limits of PA substitutability. The team examined a random selection of medical records from an outpatient utilization 
database for one year of clinical experience to identify the office visits that would have been triaged to PAs had the panel's medical criteria been in effect. The team found that the PA-appropriate medical office delegability rate was 83 percent of the total in adult primary care during the study period $\{$ Record 1978$\}$. A number of conservative assumptions were used to conduct this study in the late 1970s: significant illnesses such as cancer, renal failure, congestive heart failure, and similar progressive illnesses would be triaged to physicians; all patients would be given a choice of a physician or a PA at time of appointment; no patient would be seen more than twice in a row by a PA for the same diagnosis. PAs and physicians were assigned the same number of appointments each day. The outcome was that $83 \%$ of all patients seen in primary care by primary care physicians could be managed without supervision by a physician assistant $\{$ Record 1978$\}$. No other study has been as rigorous, used as large a pool of physicians and PAs, or had as many encounters to examine. These studies are summarized in Table 1.

Because of the economy of scale, large practices seem to be more likely to use PAs and other nonphysician providers. In these settings, physicians tend to delegate a larger percentage of medical services. Breslau, Wolf, and Novack further support the positive correlation of size and delegation. They studied 70 primary care teams and found delegation of technical tasks to be 24 percent greater in large medical organizations than in small office-based practices. Delegation of patient-care tasks was also six percent greater in large organizations Breslau $1978\}$. 


\section{TABLE 1}

THE DELEGATION OF OFFICE VISITS TO PAs:

A SUMMARY OF THE LITERATURE

\begin{tabular}{|c|c|c|c|c|c|}
\hline Reference & $\begin{array}{l}\text { Study } \\
\text { Period }\end{array}$ & Setting & Patients & $\begin{array}{c}\text { Method of } \\
\text { Triage }\end{array}$ & $\begin{array}{c}\text { Level of } \\
\text { Delegation }\end{array}$ \\
\hline Record 1978 & $\begin{array}{l}1971- \\
1973\end{array}$ & $\mathrm{HMO}$ & $\begin{array}{l}200,000 \\
\text { health plan } \\
\text { enrollees }\end{array}$ & $\begin{array}{l}\text { By } \\
\text { receptionist }\end{array}$ & $79 \%$ \\
\hline Record 1980 & 1972 & HMO & $\begin{array}{l}200,000 \\
\text { health plan } \\
\text { enrollees }\end{array}$ & $\begin{array}{l}\text { By } \\
\text { receptionist }\end{array}$ & $83 \%$ \\
\hline Pondy 1973 & 1972 & $\begin{array}{l}\text { HMO } \\
\text { Group, } \\
\text { Solo (2), } \\
\text { Institution }\end{array}$ & N/A & Not described & $\begin{array}{l}81 \% \text { HMO } \\
36 \% \text { Group } \\
39 \% \text { Solo } \\
24 \% \text { Solo } \\
\end{array}$ \\
\hline Miles 1976 & $\begin{array}{l}1971- \\
1974 \\
\end{array}$ & Solo & $\begin{array}{l}27,000 \text { rural } \\
\text { Appalachia }\end{array}$ & N/A & $33 \%$ \\
\hline Henry 1974 & $\begin{array}{l}1971- \\
1972 \\
\end{array}$ & $\begin{array}{l}\text { Satellite \& } \\
\text { Independent }\end{array}$ & $\begin{array}{l}3,500 \text { in rural } \\
F L\end{array}$ & $\begin{array}{l}\text { All patients } \\
\text { seen by PA }\end{array}$ & $80 \%$ \\
\hline Riess 1976 & 1974 & $\begin{array}{l}\text { Satellite \& } \\
\text { Independent }\end{array}$ & $\begin{array}{l}5,300 \text { in rural } \\
\text { Pacific } \\
\text { Northwest }\end{array}$ & $\begin{array}{l}\text { All patients } \\
\text { seen by PA }\end{array}$ & $90 \%$ \\
\hline $\begin{array}{l}\text { Watkins } 1978 \\
\text { (unpublished) }\end{array}$ & 1977 & $\begin{array}{l}\text { Emergency } \\
\text { Department of } \\
\text { an institution }\end{array}$ & $\begin{array}{l}200,000 \\
\text { health plan } \\
\text { members }\end{array}$ & $\begin{array}{l}\text { Triaged } \\
\text { appropriate } \\
\text { patients to PA }\end{array}$ & $45 \%$ \\
\hline Ott 1979 & 1975 & Solo \& Group & $\begin{array}{l}\text { Nine practice } \\
\text { settings }\end{array}$ & $\begin{array}{l}\text { By receptionist } \\
\text { to CHAs }\end{array}$ & $99 \%$ \\
\hline Ekwo 1979 & $\begin{array}{l}1977- \\
1978\end{array}$ & $\begin{array}{l}\text { Solo, Group \& } \\
\text { Satellite }\end{array}$ & $\begin{array}{l}19 \text { primary } \\
\text { care practices } \\
\text { in Iowa }\end{array}$ & By receptionist & $87 \%$ \\
\hline Weiner 1986 & 1975 & 3 HMOs & $\begin{array}{l}\text { Over } 300,000 \\
\text { health plan } \\
\text { members }\end{array}$ & $\begin{array}{l}\text { Varied by } \\
\text { health plan }\end{array}$ & $\begin{array}{r}47 \% \\
15 \% \\
6 \% \\
\end{array}$ \\
\hline
\end{tabular}

Note: $\mathrm{CHA}=$ Child Health Associates. 
In a study of the potential for substituting PAs and/or NPs for resident physicians at two New York City hospitals, Knickman conducted a time-motion study analyzing physician clinical tasks under two different models. One study used a traditional model in which the physician resident is the primary medical manager; the other used an alternative model in which a PA or NP performs baseline patient care monitoring. In the traditional model, residents spent almost half their time on tasks they could not delegate. However, the study found that, under the alternative practice model $80 \%$ of the resident's time was delegable $\{$ Knickman 1992\}.

The results of the hospital substitution study are applicable to many U.S. teaching hospitals. A recent survey of 144 teaching hospitals found that more than $60 \%$ of the medical directors surveyed reported experience with PA or NP employees in their hospitals. One-third of the hospital departments said they were planning to increase the number of PAs and NPs they employ \{Riportella-Mueller $1995\}$.

\section{Consultation}

“Consultation" occurs when a PA requests a physician's assistance in a specific medical office visit. It differs from delegation in that it is not the physician's decision to assign to the PA some subset of the physician's service. The consultation rate is a portion of the total delegated medical office visits the PA 
is responsibie for. There are many circumstances that determine a consultation rate because the consultation can take many forms with varying time and cost results. Signing a prescription, verifying a radiograph finding, or approving a proposed medical management plan may take the supervisory physician only a minute or two. However, it may take a prolonged time if a complicated case needs to be reviewed and the physician needs to examine the patient as well. The time spent in consultation with the PA can decrease the time the physician has for his or her own tasks and decreases the overall productivity of the PA-physician team. A newly graduated PA will seek more consultations from a physician than a PA who has been practicing primary care for five years. In a state that forbids PA prescribing or dispensing, the PA may have to consult with the physician on every patient who needs a prescription.

The consultation rate is the amount of consultations of any kind over the total number of visits assigned to the PA in a given period of time. It may be closely related to the level of delegation in a certain specialty or a particular practice style if the physician wants to use the PA as his or her personal assistant. In other circumstances, willingness to delegate a broad range of services to a PA may be based upon the assumption that consultation will be infrequent or that the PA needs little supervision. It is, therefore, important to know the consultation rate as well as the delegation level when the cost effectiveness of PAs is being analyzed. Because consultations are often informal, little is known about the PA consultation rate. Generally, the consultation rate tends to be lower for 
experienced PAs. Many variables control this rate, such as the relationship with the physician, time, availability, and patient mix. When the PA and physician share an office, the consultation rate is higher than when they are separated by distance or office layouts that inhibit consuitations. Time-motion studies documenting every minute of the physician/PA relationship over a prolonged period of time are needed to understand the importance of this labor assessment.

\section{Supervision}

"Supervision" is a state-legislated term that is the legitimate basis of the PA profession. It also has an economic assignment. Competent supervision is essential for quality of patient care. But it also carries with it some restriction of delegated tasks and loss of physician productivity due to the employer administrative tasks associated with this relationship. The amount of time devoted to supervision depends largely on the relationship between the PA and the physician. Little study has been devoted to this important aspect. In 1992 the Veterans Administration surveyed over 100 supervising physicians of physician assistants and nurse practitioners (Alexander 1992\}. The time spent supervising a PA or NP in this system ranged from 9.2 to 16.1 hours/week based on a workweek of approximately 30 hours of direct patient care (Table 2). One of the shortcomings of this study is that although assigned the role of supervising the PA 
TABLE 2

PHYSICIAN SURVEY MEAN RESPONSES TO QUESTIONS ON SUPERVISION OF PAS AND NPS

\begin{tabular}{|c|c|c|}
\hline Activity & $\begin{array}{r}P h \\
S u p \\
P A \\
(n=75) *\end{array}$ & $\begin{array}{l}\text { ian } \\
\text { or of } \\
N P \\
(n=34\end{array}$ \\
\hline Hours/Week Physician Spends in Direct Care & 33.0 & 29.7 \\
\hline Hours/Week Physician Supervises PA/NP & 16.1 & 9.2 \\
\hline Percent Time PANP “Takes First Call” for Physician & 20.2 & 26.4 \\
\hline \multicolumn{3}{|l|}{ Percent Time Supervision Involves: } \\
\hline Overseeing Medical Procedures & 23.7 & 27.2 \\
\hline Checking Orders with PANP & 25.7 & 41.5 \\
\hline Other Activities & 50.6 & 31.3 \\
\hline
\end{tabular}

Source: Alexander 1992 (p. 446).

Note: *Number of responding physicians in parentheses. First Call means the PANP responds to telephone request for a medical staff member to see a patient after hours. 
or NP, the supervising physicians were also engaged in patient care, usually in the same setting. Therefore the amount of administrative time taken away from patients to supervise the PA or NP was not accurately recorded.

In one large HMO that employed both PAs and NPs the supervising physician patient load was decreased by 10 percent per day. This $10 \%$ was designated as administrative time and was inserted into the schedule to compensate the physician for supervising the PA or NP and for reviewing a set of medical records used by the PA/NP at the end of the day \{Hooker 1991\}

\section{Clinical Productivity}

Record (1980) defined productivity this way:

"In theory, productivity is a simple concept: it measures changes in the total output that occur when small changes are made in one factor of production, with all other factors and circumstances held constant. Because these conditions can be met in the real world only rarely, productivity numbers are almost always rough estimates. Certainly that is the case with respect to [PAs] \{Record 1980\}."

The findings on PA productivity reflect the changing policy concerns of the American health care system. Initially, emphasis relied upon documentation of increased access to services, usually within the organizational framework of solo practice in rural areas. Later investigations focused on issues of cost and delegation in organized health settings. An important contribution to health 
services research has been the documentation of the multifaceted effects of PAs on clinical productivity, meaning the overall output of a clinic or medical office when a PA is added to the staffing mix. A common measure of productivity, one that can positively affect access to health care, is the number of patient visits performed in a clinical setting. Generally, PA productivity can be compared to physician productivity in two other ways: 1) on the basis of tasks PAs are qualified to perform, and 2) on the full range of tasks performed by a physician. The comparison of the range of these tasks is sometimes known as the functional delegation $\{$ Record 1981\}. The question is whether the productivity of PAs compares favorably with physicians.

In virtually every study done on productivity, PAs compare favorably to physicians \{Crandall 1984; Scheffler 1996\}. In fact, there is evidence in some settings that PAs see more patients per annum than do physicians Hooker 1993; Hooker 1986$\}$. For most practices the utilization of PAs results in higher clinical productivity rates. What influences this productivity depends upon such variables as the range of task delegation, practice case-mix, the health care delivery system, the context in which the PA performs the clinical service, and institutional policy on how PAs are managed and utilized, to name only a few of the variables.

One study looked at nine medical practices that employed PAs. When these practices were compared to control practices, it was found that the physicianPA team practices increased clinical productivity by 40.4 percent (as measured by the number of office visits), while the control practices increased only 1.3 percent 
during the same time period \{Smith KR 1973\}. Another study assessed the impact of a PA in a small practice on the distribution of physician time. After employing a PA in primary care, a larger proportion of physician time was spent in seeing older, more seriously ill, or hospitalized patients, and in communicating with patients $\{$ Nelson 1977$\}$.

A small-scale study of the cost effectiveness of nonphysician health providers was conducted in another type of ambulatory care setting. This report describes the performance of four PA/NP providers and five family practice physicians. The authors compared measures of the practice costs of both types of health providers working in a University Student Health Clinic (a type of prepaid systern) and in a fee-for-service Family Practice Clinic. Total hours worked, numbers of patients seen, revenue generated, and provider salaries were collected for the nine primary care providers over a 49-week period. In the Student Health Clinic, the average cost for salaries for each patient visit was $\$ 5.49$ for PA/NP services and $\$ 8.53$ for each visit to the physician. In the Family Practice Clinic, revenue generated per dollar of salary was $\$ 2.68$ for PA/NPs, versus $\$ 2.62$ for family physicians making PAs slightly more productive as revenue generators $\{$ Hansen 1980\}.

Mathematical models have been developed to explore the most efficient contribution of health care personnel in different settings. These settings include private group practices, urban medical centers, military settings, managed health care settings such as health maintenance organizations \{Hooker 1993; Golladay 
1976; Golladay 1973; Zechauser 1974; Schneider 1977; Cyr 1985; Ortiz 1979) and tertiary centers $\{$ Harbert 1994\}. These models provide the theoretical documentation for the clinical productivity of PAs with estimates ranging from 50 to 95 percent of physician productivity. The theoretical and carefully documented empirical approaches are similar in their assessments of PA clinical productivity. Hooker studied the hourly, daily, and annual productivity of PAs, NPs, and physicians in the primary care departments of internal medicine, family practice, and pediatrics in a large HMO. He found that PAs see approximately the same number of patients as physicians hourly and daily but PAs saw 29 percent more annually. This is due in part to PAs being primarily outpatient based, while physicians had hospital responsibilities that took them away from the medical office (Table 3). Physicians also had more vacation and compensatory time off as well. In a different study on the same population patient visits to physicians and PAs tended to be similar in 90 percent of the cases (the functional delegation level), but differed in illnesses that are associated with a hospitalization such as acute cardiac illnesses, cerebral accidents, and cancers \{Hooker 1993\}. 
TABLE 3

PA CLINICAL PRODUCTIVITY IN AN HMO SETTING

\begin{tabular}{|lcc|}
\hline \multicolumn{1}{|c}{ Department } & Patients/Hour & Patients/Day \\
Family Practice & & \\
Physicians & 2.39 & 17.4 \\
Physician Assistants & 2.61 & 19.0 \\
Internal Medicine & & \\
Physicians & 3.10 & 22.5 \\
Physician Assistants & 2.97 & 21.5 \\
Pediatrics & & \\
Physicians & 3.14 & 16.5 \\
Physician Assistants & 3.07 & 22.3 \\
& & \\
\hline
\end{tabular}

Source: Hooker 1993 (p 58) 
While some practices employ PAs to meet increasing demand, others employ PAs to relieve physicians of excess workload. Kane noted that after hiring PAs, more patients in the practice were seen by appointment instead of over the schedule and more patients in the practice had specific plans for follow-up management \{Kane 1978\}. Other researchers reached similar findings ( Table 4). The differences in productivity in each study is because adding one PA does not mean that the number of patients seen annually is double what it was when the physician was the only provider. The physician may not be working as intensely as before, or the PA(s) added may not be keeping up with the average number of patients previously seen.

\section{TABLE 4}

PHYSICIAN PRODUCTIVITY WHEN A PA IS ADDED TO THE CLINIC

\section{Study by First Author \\ PA : Physician Ratio \\ Percent Productivity}

Greenfield 1978

$1: 1$

$92.0 \%$

Cyr 1985

$1: 1$

$80.1 \%$

Hooker 1993

$1: 2$

$110.0 \%$

Note: Productivity is defined as the percent of patients seen in an outpatient setting when a PA is added compared to a physician's average patient load. First and second study performed in a private solo practice; third study performed in an HMO. 
Physician assistant clinical productivity compares favorably to that of physicians, particularly in organized ambulatory care settings that utilize team approaches and structured division of medical care staffing. While it seems likely that similar levels of PA clinical productivity exist for physician assistants working in other types of patient care settings; performance measures in newer practice areas (such as inpatient hospital settings) have not been performed. Additional studies examining levels of PA clinical performance characteristics are needed since the content of clinical care (the specific medical tasks) delivered by physician assistants differ within various clinical settings.

The population base is one of the many variables difficult to control in comparing productivity of PAs in different settings. Many significant differences exist among groups of PAs depending on the work setting, the type of specialty, and years of experience. However, when some of this data is aggregated, there are some interesting findings. Using data collected in the 1995 AAPA Membership Census, Kevin Kraditor, of the AAPA Research Division, examined the productivity of PAs in terms of number of outpatients seen per day, controlling for a number of variables. The tables present summary statistics on measures of outpatient productivity for groups of PAs defined in terms of work setting, years of experience as a PA, and field of practice (Tables 5,6,7). All analyses used only data for PAs whom reported being in full-time clinical practice and working for a single employer (Kraditor - personal communication, 1996). 
The findings from this study include a statistically significant difference in the number of outpatients seen per day by work setting, with the largest differences reflected by PAs working in Military Facilities or Correction Facilities. When years of experience are examined, PAs with more experience see more patients per day than PAs with less experience. Field of experience also seems to make a difference in terms of patients seen per day. The largest differences are found in emergency medicine where PAs report seeing 24.6 patients per day on average.

In terms of workweek, the vast majority of PAs report working about 40 hours per week. PAs employed in inner city clinics report fewer hours per week. Those in military facilities work more hours per week than do PAs in all other settings.

While these studies are far from conclusive, a number of observations emerge. Productivity depends on many variables. The setting and the policies within that setting are highly variable. Self-employed PAs report being the most productive of all PAs surveyed. One presumption is because they realize a potential stream of revenue from every patient seen. They are also small in number so the significance of this is uncertain. PAs who are salaried in large government facilities such as Veterans Administration Centers report the lowest number of patients seen - perhaps because less are scheduled. HMO PAs report a mean of 21 patients seen per day. This figure is similar to other reports of PA productivity in HMO studies \{Hooker 1994\}. 
TABLE 5

OUTPATIENT VISITS PER DAY BY WORK SETTING FOR PHYSICIAN

ASSISTANTS, 1995

\begin{tabular}{|lrcc|}
\hline \multicolumn{1}{c}{ Setting } & Respondents & Mean & Std Dev \\
Clinic & 763 & 21.9 & 9.6 \\
Group physician practice & 517 & 21.6 & 7.7 \\
Solo physician practice & 190 & 22.7 & 9.9 \\
HMO & 198 & 21.3 & 6.2 \\
Other managed care organization & 19 & 20.1 & 7.0 \\
University hospital & 72 & 15.0 & 13.1 \\
Hospital (non-university) & 260 & 23.7 & 10.7 \\
Inner city clinic & 116 & 19.9 & 12.2 \\
Military facility & 248 & 24.8 & 8.3 \\
Corrections facility & 51 & 23.7 & 12.4 \\
Nursing homes & 5 & 19.4 & 4.7 \\
Rural clinics & 357 & 20.2 & 8.9 \\
Self-employed PA & 10 & 35.9 & 14.5 \\
VA facility & 58 & 16.6 & 5.5 \\
Industrial facility & 109 & 20.1 & 9.3 \\
Academic facility & 44 & 22.4 & 7.9 \\
Public health facility & 33 & 21.0 & 6.8 \\
Other government facility & 27 & 23.4 & 20.6 \\
Other clinical setting & 3,091 & 10.6 \\
Total & & 21.7 & 9.5 \\
\hline
\end{tabular}

Source: American Academy of Physician Assistants, Research Division, 1996.

Note: Based on full-time employed PAs reporting outpatient visits but no inpatient or nursing home visits. Data collected from the 1995 AAPA Member Census. 
TABLE 6

OUTPATIENT VISITS PER DAY BY YEARS OF EXPERIENCE

FOR PHYSICIAN ASSISTANTS

\begin{tabular}{|lccc|}
\hline Years of Experience & Respondents & Mean & Std Dev \\
Under 1 year & 139 & 18.6 & 7.2 \\
1-3 years & 821 & 20.8 & 8.8 \\
4-6 years & 505 & 21.9 & 10.1 \\
7-9 years & 341 & 21.2 & 8.5 \\
10-12 years & 410 & 21.6 & 8.6 \\
13-15 years & 371 & 22.5 & 10.2 \\
16-18 years & 343 & 22.8 & 10.5 \\
Over 18 years & 296 & 23.3 & 10.3 \\
Total & 3,226 & 21.7 & 9.4 \\
\hline
\end{tabular}

Source: American Academy of Physician Assistants, Research Division, 1996

Note: Based on full-time employed PAs reporting outpatient visits but no inpatient or nursing home visits. Data collected from the 1995 AAPA Member Census. 
TABLE 7

OUTPATIENT VISITS PER DAY BY FIELD OF PRACTICE FOR PHYSICIAN ASSISTANTS

\begin{tabular}{|lccc|}
\hline Field of Practice & Respondents & Mean & Std Dev \\
Family/general medicine & 1836 & 22.1 & 8.2 \\
General intemal medicine & 255 & 18.9 & 8.6 \\
General pediatrics & 115 & 24.4 & 9.9 \\
Emergency medicine & 316 & 24.6 & 11.2 \\
General surgery & 6 & 18.3 & 7.3 \\
Medical specialties & 130 & 16.8 & 13.6 \\
Pediatric specialties & 33 & 18.7 & 15.1 \\
Surgical specialties & 145 & 20.0 & 10.6 \\
OB/Gyn & 88 & 20.0 & 10.4 \\
Industrial/Occupational medicine & 181 & 21.7 & 10.3 \\
Other & 173 & 21.4 & 10.6 \\
Total & & & \\
\hline
\end{tabular}

Source: American Academy of Physician Assistants, Research Division, 1996

Note: Based on full-time employed PAs reporting outpatient visits but no inpatient or nursing home visits. Data collected from the 1995 AAPA Member Census. 
In summary, the extent of PA productivity cannot be determined without reference to an array of interdependent variables that, assuming that all of them can be identified, are difficult to evaluate. The classical conceptualization of how productivity should be measured -- by observing what happens to total output when small, homogeneous units of one input (in this case the PA) are added while other inputs and the larger context are held constant -- is difficult to measure in a big practice, and virtually impossible in a small one $\{$ Record 1980$\}$.

\section{Cost of PAs}

The cost implications of the use of PAs can be viewed from two perspectives. The first is that of the entrepreneurial medical practice. It is concerned with whether or not the increase in practice revenue resulting from hiring a PA will exceed the additional costs of adding a provider, and whether it is more desirable to hire a physician or a PA. The second perspective is society's view. How is high quality care delivered at minimum cost? The societal view is that all costs, no matter where they come from, are ultimately bome by society. This societal perspective considers not only employment costs, but training costs as well.

\section{Employment of PAs}

When a PA is employed, a variety of costs need to be considered. These include salary, benefits, malpractice insurance, office space, equipment, support staff, supplies, and other direct and indirect expenses. There is little data on this 
subject so assumptions must be made. We will assume that the overhead costs (other than compensation) are no different than if a physician had been employed.

Outcome studies regarding whether a PA uses more laboratory, imaging, and drugs for an episode of care have not been published. Anecdotal reports suggest that malpractice insurance may be cheaper for the PA because the litigation rate is less than for physicians \{Wolman 1996\}. There seems to be little evidence to suggest that PAs negate any of their cost-effectiveness by the way they practice medicine.

Kane examined the practice finances before and after the employment of a PA in rural practices. There were no significant differences in changes in patient volume; however, the 10 practices that employed a PA showed an increase in revenue and in net profit per physician. On the average, the net profit increased approximately $22 \%$ for the physician employing the PA compared with $21 \%$ for the control physician. The reasons suggested for this observation was that the physician who employed the PA had been relieved of some of their primary care responsibilities. This shift enabled some physicians to reduce their revenue generating time and allowed others to pursue activities that required greater skill and interests \{Kane 1978\}. In other cases this meant more remuneration for less time, suggesting both direct and indirect financial benefit and greater efficiency from the addition of a PA. 
In contrast to other costs, the income differential for PAs and physicians is clearly quite large. Most PAs are salaried employees. Physicians, on the other hand, receive not only a stream of revenue for their own services, but also receive entrepreneurial benefit from employing a revenue-generating provider.

Based on national data $\$ 55,000$ is a reasonable average salary estimate for an experienced primary care PA in 1997 \{AAPA 1998\}. The figure for a primary care physician for the same year is approximately $\$ 129,000$ SSimon CJ 1996\}. This places the PA at .43 of the salary of a physician in primary care.

\section{Compensation to Production Ratio}

One of the better ways to examine the net value of a PA is the income generated if the employer is in private practice. Compensation is the area that is usually examined since this includes salary and benefits collectively. The most useful ratio is the amount of compensation the employer forgoes to retain the PA divided by the amount of revenue the PA returns. The smaller the ratio, the more economical the provider. The Medical Group Management Association (MGMA $1994\}$ collects this data annually (Table 8). In 1994, the compensation to production ratio for PAs was .38. In comparison, the compensation to production ratio for Family Practice physicians was $.44, .40$ for pediatricians, .41 for NPs and .48 for psychologists. This suggests that the PA is relatively more economical to employ than another physician. 
TABLE 8

\section{COMPENSATION TO PRODUCTION RATIO FOR}

\section{PHYSICIAN ASSISTANTS}

\begin{tabular}{|lccc|}
\hline & \# Providers & $\begin{array}{c}\text { \# Medical } \\
\text { Practices }\end{array}$ & $\begin{array}{c}\text { C/P Ratio } \\
\text { Mean } \\
\text { Overall for PAs }\end{array}$ \\
Organization Type & 124 & 40 & .381 \\
Single specialty & 19 & 13 & .433 \\
Multispecialty & 105 & 27 & .372 \\
Other Providers & & & \\
Family Practice Physician & 1,117 & 135 & .447 \\
Internal Medicine Physician & 883 & 134 & .447 \\
Pediatric Physician & 501 & 107 & .409 \\
Nurse Practitioner & 71 & 31 & .419 \\
Certified Nurse Midwife & 15 & 7 & .472 \\
Optometrist & 57 & 20 & .423 \\
Psychologist & 104 & 32 & .477 \\
Podiatrist & 31 & 19 & .334 \\
\hline
\end{tabular}

Source: Medical Group Management Association, 1994 (p. 98) 
While the number of nonphysician providers used for this study is not large (and may not be statistically significant), the relative ratios among providers does give an indication of the efficiency that a PA brings to a practice. Based on existing research it appears that for every dollar in revenue generated, the employer pays 38 cents to employ the PA.

\section{Substitution Ratios}

The physician/PA substitution ratio is the amount of physician service a PA can provide. It is determined primarily by the level of delegation and comparative productivity of physicians and PAs for the delegated services. A substitution ratio of 1.0 implies unity and is achieved when one physician assistant substitutes for one physician for all services. There are many anecdotes indicating that this occurs. PAs in rural and isolated clinics often function at very high levels, often replacing the physician who was previously occupying that role $\{\mathrm{DeBarth}$ 1996\}. But these are largely anecdotal accounts. Little is known about the types and numbers of patients seen annually, and how they compare to what was managed by the physician. The best studies occur in large managed care settings where some of the variables can be controlled and physicians and PAs work alongside each other seeing similar patients.

Using an urban health center as a paradigm, one study constructed production functions that would best take advantage of substituting PAs for 
physicians. It was estimated that one PA could replace at least half of a full-time physician. From data developed in a national survey of physicians, Scheffler estimated that a ten percent increase in the medical office visits output of a practice would require, on average, an increase of 3.5 percent in physician hours or 5.4 percent in PA hours $\{$ Scheffler 1979\}. These figures suggest a marginal substitution ratio of .63 , as compared to the overall .50 ratio estimated by Zeckhauser and Eliastom \{Zechauser 1974\}. Another mathematical model used data from seven HMOs to demonstrate the potential impact of PAs and NPs on physician requirements. This study found that, in adult medicine, the addition of 12.7 PANPs would permit physician numbers to drop from 16.4 to 9.7 . Thus, the 12.7 PANPs could replace 6.7 physicians. The respective substitution ratios were calculated as .53 \{Schneider 1977$\}$.

Record and colleagues estimated that if enough PAs were hired to perform all of the services for which they were considered competent by physicians in the Department of Internal Medicine at Kaiser Permanente, and if the PA and physician work weeks were equated, the substitution ratio would be .76 Record 1981 \}. Steinwachs and colleagues studied ambulatory care in another HMO and found the substitution ratio to be .38 in adult care and .48 in pediatrics \{Steinwachs 1976$\}$. The figures might have been higher if the base had been primary care, as it was in the Record study, with outpatient specialty services excluded. Hooker analyzed data that suggests the ratio was .90 in primary care 
and Page's work in the military was close to unity (one to one) as early as 1975 $\{$ Hooker 1993; Page 1975\}.

Most of the estimates of substitution ratios fall in the range of .75 , suggesting it would take, on average, one PA to substitute for three-fourths of a primary care physician. For managers, this suggests that four PAs could replace three physicians. Whether these estimates would be the same when examined 20 years later remains to be seen.

From the literature review presented above, and presented in Table 9, it appears that physician assistants can assume at least $83 \%$ of all outpatient primary care visits safely without supervision. But how cost effective is a PA? This is the question that the above computations attempt to answer. The solution is in the difference between the physician/PA substitution ratio (.83) and the PA/physician cost ratio (.43). These two numbers indicate that a PA can substitute for at least $83 \%$ of a primary care physician services at approximately $43 \%$ of the physician's direct cost in salary. If the physician's time is reduced due to supervision costs, then the figure is $52 \%$ of the physician's salary. A summary of the economic exercises is in Table 9. These figures, however, must be viewed with caution. They are based on the "best studies" (those studies considered the most rigorous in investigation), or on the average of different studies, using fairly conservative figures. Many of the studies use small numbers that may not be statistically significant, and most of the estimates were derived from studies conducted before 1980. 


\section{TABLE 9}

COST-EFFECTIVENESS OF PRIMARY CARE PHYSICIAN ASSISTANTS

Issue Examined

Delegation

Supervision

Physician/PA Substitution Ratio

PA/Physician Cost Ratio (Salary)

PA/Physician Cost Ratio (With Supervision)

Compensation to Production Ratio

PA/Physician Cost Benefit Ratio
Range

.40 to 1.0

.10 to .60

.40 to 1.0

.40 to .50

N/A

.25 to .52

unknown
Average or

Best Study

.83

.10

.75

.43

.52

.38

unknown

Note: Based on a review of the literature, using conservative estimates, and extrapolating to 1995 costs 


\section{CONCLUSION TO CHAPTER I}

Bearing in mind that the published data are suggestive but not conclusive, the cost effectiveness of physician assistants can be reasonably confirmed and measured, to a fair extent. Major studies of physician assistant productivity and cost effectiveness have shown that PAs usually generate practice revenue far beyond the cost of salaries and overhead (Mendenhall 1980; Schneider 1977; MGMA 1997\}. What seems to be missing is the next step in the economical analysis of a labor substitute are the long-term or cost benefits of this venture. While one may never be able to precisely measure cost effectiveness in every practice setting and specialty, the fact that over 30,000 PAs are currently employed is significant empirical evidence for cost effectiveness. Employers -- physicians, federal agencies, clinics, and hospitals -- would not hire them if they were not cost effective to some degree.

Reports continue to appear supporting the view that PAs are valuable additions to the health workforce. When economic principles are applied, it appears that PAs can substitute for more than three-fourths of a primary care physician in an outpatient setting. PAs require little supervision, and can safely assume the care for over 83 percent of the types of patients seen. When practice productivity is examined, it appears that PAs may be one of the most cost-effective members of the health care team, returning a greater compensation to production ratio than other nonphysician providers. 
While a number of questions have been answered as to the economic advantage of physician assistants to the American health care system, other questions emerge. What is the cost benefit to society, to physicians, and to institutions when a PA is added to the provider mix? The weakness of other studies has been the lack of control of the significant variables at the same time such as age, gender, and health status of patients when comparing care delivered by different providers.

Cost-benefit analysis is an economic evaluation technique used to determine the allocative efficiency of a health care organization when a new program is enacted. In this case, the addition of a PA as a substitute for physician services. The application of this concept is to examine the alternative of doing nothing or continuing the current practice. Cost-benefit analysis is a useful tool in setting out a decision analysis to continue with a current program or making changes in the program \{Donaldson 1990\}. Trade-offs are usually implicit in this type of analysis such as safety and quality. In the absence of such scrutiny important aspects of efficiency and equity may not be recognized. Due to scarcity of resources, decisions about what type providers should staff primary care needs to be ascertained on a cost-benefit level, at least from the employer's perspective. This study attempts to overcome some of this weakness by trying to adjust for some of the variables that have been overlooked in other studies. In the end this study will help answer the question whether PAs are cost beneficial to those organizations that employ them. 
CHAPTER III

DATA AND METHODS 
This chapter describes the population, data and methods used to conduct this study. Included are the hypothesis, a description of the study site, the study population selection process, variable definitions, and a description of the analysis models.

\section{HYPOTHESIS}

PAs are cost-beneficial to employers for delivering primary care medical services for common acute conditions.

While there is strong evidence that physician assistants (PAs) are cost-effective in most medical settings, there has been virtually no analysis of PAs from a costbenefit standpoint. Cost-benefit is defined as an extension of cost-effectiveness when all costs and benefits are expressed in monetary terms. Generally speaking, the situation dictates that the 'benefits' accrue to someone or some organization since benefits means anything that contributes to the improvement of a condition. When dealing with changes in health care delivery, improvement or benefits can be regarded from different perspectives: i.e., a patient's perspective, an employer's perspective, or as a benefit to society. Since PA utilization represents changes in traditional health care delivery, this can be viewed as an improvement in cost-effective labor. Because

PAs tend to be employees and not independent practitioners, this study examines them 
as a cost-benefit from the employer's view. A favorable cost-benefit study shows either a reduction in cost, an increase in benefit, or both. In this case the premise is that PAs can achieve the same health benefit as physicians but at a lower. In other words they add some benefit that is above and beyond what a physician provides. That benefit is believed to be a reduction in cost of health care delivery without compromising the safety of the patient. From a policy perspective, the federal government has supported PA education through various public laws and initiatives. It is the major employer of PAs. The efficiency and utilization of PAs may be further clarified using a cost-benefit approach.

We know from a number of studies that PAs are economical from a labor standpoint $\{$ Hooker 1997$\}$. They safely perform either the same or similar tasks as a physician, with comparable patient satisfaction levels. These cost-effectiveness studies are described in Chapter II. Whether PAs negate any of their costeffectiveness by using more resources than physicians over the course of an illness episode is not known. For example, do PAs have the patient return more often for an acute condition than physicians do, order more laboratory tests, more imaging studies, differ in medication written, or use any other resource in the management of an illness more frequently than the physicians they are associated with? The literature provides little information in this regard. The theory and basis for the hypothesis of this study is that PAs tend to use the medical model they are trained in and mirror those they are most associated with -- physicians. Therefore, the research question for this study is: Are PAs cost-beneficial to their employers? Since the majority of PAs are in primary care (Internal Medicine, Family Practice, Pediatrics) nationally, and since most 
primary care episodes are acute conditions, the basis of this study is to test the hypothesis: PAs are cost-beneficial to employers for delivering primary care medical services for common acute conditions.

Systematic and nonsystematic observations suggest that PAs tend to practice in the same manner as physicians. They have been trained by physicians in medical school settings, are employed by physicians, work alongside physicians and within, a short span of time, they tend to practice the same way - at least for most conditions. This study will test this hypothesis by examining four frequently seen acute primary care episodes of illness and compare the care delivered between PAs and physicians while holding a number of important variables constant.

\section{Cost Benefit Analysis Criteria}

The underlying goal of cost-effectiveness/cost-benefit analysis is to find which alternative provides maximum aggregate benefits for a given level of intervention of resource use $\{$ Sloan 1996$\}$. This study sets out to determine which alternative, physicians or PAs, provides the same benefit at the lower cost. Several formal methods use certain elements of cost-benefit analyses. For example, cost-of-illness analysis attempts to measure the social costs associated with a particular disease. The basic steps in cost-benefit analysis are as follows:

- Define the intervention. An intervention is compared to an alternative intervention, which could be the status quo. In this case the nature of the 
intervention is the substitution of one type of provider for another - PAs for physicians - in the treatment of acute primary care conditions.

- Identify relevant costs. These are usually direct costs but can include indirect costs to the patient in terms of lost wages and travel expenses. Because this is a study shaped as a benefit to the employer, the relevant costs are the allocation costs the health plan needs to set aside to cover the cost of the intervention.

- Identify relevant benefits. These include the net benefits to the recipient of the intervention. In this case it is the employer or organization, which are one and the same. The net benefits are the aggregated cost savings accrued by employing a PA to manage common primary care conditions. All relevant benefits are identified.

- Measure costs. This requires attaching a monetary value to all components of costs, which entails placing a value on medical inputs. Costs are usually expressed in present-value terms. For this study, all costs are in 1997 dollars and are considered current.

- Measure benefits. In the case of cost-benefit analysis, measuring benefits entails converting all benefits into dollars. The benefits from the incorporation of PAs into this organization are substantial and are computed in the discussion section.

- Account for uncertainties. This entails using any means possible to control for or eliminate uncertainties from the analysis and in the measurement of 
costs and benefits. Only by reducing or eliminating these uncertainties can the robustness of conclusions be tested. This study makes considerable effort to reduce a number of uncertainties by applying stringent criteria, using a large sample size, and controlling for many variables.

Although the basic steps in a cost-benefit analysis are outlined above, various authors point out that there is no consensus as to the best method for conducting costbenefit studies, even at the conceptual level \{Sloan 1996; Weinstein 1996\}. That is, in every step shown above, different analysts may use different methods to complete the task. In part, this reflects an imperfection in the method itself. The method in this study was selected by reviewing the literature, as well as by obtaining a consensus from discussion with dissertation committee members, economists, and other health services researchers. Any uncertainties are accounted for and attempts are made to control for them. Again, this is done in large part by using rigorous selection criteria.

\section{STUDY SITE}

The study site is the Northwest Division of Kaiser Permanente (KPNW), a large not-for-profit group-model health maintenance organization (HMO) that has been in existence since 1942. The region of KPNW under study is located in Portland and Salem, Oregon, and in Southwest Washington. The study draws upon a health plan population of 420,000 members in 1997 , the year of the data collection. The medical staff is composed of over 550 physicians, 75 PAs, 80 NPs, 12 nurse midwives 
and is supported by 5,000 employees. The health plan is the insurance organization that contracts with employers to provide health care services on an annual basis. It owns and operates 20 medical offices, one hospital, and contracts with 7 other hospitals. The health delivery organization is designed to deliver virtually all health care services under the same administrative system. All health plan members are fully insured for hospital care without deductibles and nearly all members have pharmacy benefits, with copayments ranging from nothing to 50 percent of drug cost. Ambulatory care copayments range from zero to five dollars. These minimal copayments mean the prescriber tends not to be influenced by the cost of the appropriate medication for the patient.

The KPNW membership resembles the demographic composition of its service area, and the service area is demographically similar to the United States population as a whole in terms of age, gender status and socioeconomic strata \{Greenlick 1988; Freeborn 1994\}. Knowing that the membership is reflective of the population it draws upon in certain important parameters allows for greater generalization about the population as a whole. Another feature of a health plan population such as KPNW is that a great deal is known about it. The Kaiser Permanente Center for Health Research has studied the membership extensively since 1963 . Over 200 studies have been published on some aspect of the organization or delivery of health care services through this research institution. As a consequence many statements about the membership can be made with confidence due to the extensive understanding about the health behavior of the membership. 
The medical group, Northwest Permanente, PC, is a separate for-profit entity that contracts on an annual basis with the not-for-profit health plan to deliver physician-type services for the health plan's members. The medical group administers physicians and PAs separately from the health plan management structure. This organizational arrangement where the physician group is an administrative body independent from the health plan is what generally distinguishes group-model HMOs from staff-model HMOs.

The medical group contracts with the health plan to provide physician-type services in the health plan's twenty medical offices. In addition to outpatient services the physicians staff all hospitals. Influences for cost containment and quality of service from these three different organizational entities - medical group, health plan, hospitals - that are intricately involved with each other. For example, if the hospital needs to reduce hospitalization rates or length of stay for its members, it needs to renegotiate the contract with the medical group. Any change in hospital care will result in a shift of physician services and patient care to the outpatient setting where most physicians and all primary care PAs reside. The medical group, Northwest Permanente, then decides what the staffing arrangements should be in the medical offices - more physicians or more PAs. The need to have and increase the employment of PAs in the outpatient setting is balanced by the need to use more expensive physicians in the inpatient setting. Concerns are then raised whether PAs can and should be taking on the more complex patients that are being shifted to the ambulatory setting. 
Unlike many capitated health plans and fee-for-service medical practices, the judgment of physicians and PAs, in the management of certain medical procedures, are not subject to precertification screening and reimbursement-based restrictions. Practitioners can initiate most medical procedures without authorization. However, in some years, physician income is somewhat influenced (plus or minus $10 \%$ ) by the overall financial performance in providing services to the membership. Essentially both physicians and PAs are affected by institutional policies fairly equally and may experience market pressures through mechanisms such as annual facility budgets. This means that patients are treated the same by PAs and physicians under the same organizational influences. Cost-effectiveness strategies are on-going and many efforts are in place to improve efficiency. One strategy is to limit administrative time as a means for more providers available for medical service. In turn more patients may be seen, access for patients is improved, and the membership is more satisfied.

The employment of PAs within Kaiser Permanente has been ongoing since 1970 \{Lairson 1974\}. Originally introduced to complement physician services and improve productivity, by the mid-1970s PAs were managing their own panels of patients in addition to assisting physicians. By 1980 virtually all PAs within Kaiser Permanente were seeing patients largely unselected or undifferentiated (i.e., not triaged) in the primary care departments of internal medicine, family practice, and pediatrics. In a study examining the differences among patients seen by physicians and PAs in internal medicine and family practice, a 90 percent overlap was found in diagnoses and frequency of disorders \{Hooker 1986\}. Based on broad groupings of diagnoses, PAs and physicians treat patients in similar proportions for trauma, acute 
disorders, and many chronic conditions such as diabetes and hypertension. The few differences that emerge between types of providers are in diagnoses that are often associated with a hospitalization, such as cancer, myocardial infarction, cerebral vascular accidents, and renal failure $\{$ Hooker 1986\}. In these cases of hospitalassociated diagnoses, physicians tend to see more patients with these disorders than PAs do.

Primary care consists of the departments of internal medicine (IM), family practice (FP), and general pediatrics (Peds). These three departments provide the bulk of primary care services to adults and children for the health plan. The specific aims of this study is to explore whether the type of provider (PA or physician) makes a difference in the aggregate, how patients are managed for an episode of an illness, and the costs associated with these management strategies.

This study takes place within a single HMO during a 12-month period. By using one organization, many variables can be controlled, such as organizational influences, setting differentiation, prescribing practices, formulary constraints, laboratory and imaging policies, and internal referrals -- variables that are important in understanding provider similarities and differences in styles of care and outcomes. A one-year period of study was selected to control for any seasonal variability that might influence patient access. A long-established policy to avoid differentiation or triaging of patients to or away from one type of provider helps avoid selection bias, one of the more important variables to hold constant when examining types of providers. The one factor that has confounded physician variation studies is patient health status. 


\section{Electronic Medical Record}

An important aspect of this study is the use of a single medical record for all medical office visits (MOVs). A further enhancement of the single medical record is that the electronic entry of MOVs or encounters and resources used to manage patients is contained in one computerized medical record. The comprehensive computer-based medical record used in KPNW is EpicCare, developed by Epic Systems of Madison, Wisconsin. EpicCare essentially computerizes all outpatient documentation, ordering, and messaging processes into one electronic record that can be retrieved at a computer workstation. Providers use this system to document encounters; code diagnoses and procedures; maintain problem lists; order laboratory tests, medical supplies, and imaging studies; and send prescriptions electronically to the pharmacy for dispensing. Over 800 practitioners (physicians, PAs, NPs, and other clinicians) use this system. Over 3,500 support personnel (nurses, laboratory technicians, physical therapists, etc.) have EpicCare accounts and access it to interact with the providers of record in the same electronic format. The EpicCare account allows tracking of all entries by the person making the entry. In the primary care section over 300 primary care clinicians in 20 separate medical offices use this system in their delivery of care $\{$ Chin 1997 . This data forms the main source of information for the primary care visits that are investigated in this study. 
The data maintained by EpicCare is comprehensive and incorporates both coded and discreet data as well as narrative information. Attributes captured by EpicCare include:

- Diagnoses (ICD-9-CM - coded with optional descriptor modification)

- Problem lists, generated from the ICD-9-CM - coded diagnoses

- Past history, generated from ICD-9-CM - or CPT codes

- Medication lists, active and inactive, and continuously updated as ordered

- Orders: laboratory (cytology, clinical laboratory, pathology); imaging (Xray, MRI, CT, nuclear medicine, mammography, ECG); prescriptions, immunizations, and injections; internal referrals; recommended interval return visit

- Results: laboratory, imaging, and consult reports

- Reason for visit, vital signs, examination room procedures, assessment, treatment plan, and recommended return interval

- Telephone encounters, reason for call, and letters

- Annotated images for clinical notes

- Record of immunizations, allergy agents, smoking status

- Progress or narrative notes: this includes progress, telephone advice, and care-plan notes, as well as patient encounters. 
Providers enter the information relevant to the patient encounter, including the reason for the visit, diagnosis, orders, medications, referrals, chart notes, past history, and problem lists. They also enter both coded data and narrative information. All entries are done at the computer workstation using keyboard entry, with a dictation option for the subjective and objective portion of the encounter. Field defaults, selection lists, string-matching, and synonym-matching lists can be used to facilitate data entry. System template texts may be used with a few keystrokes for commonly occurring encounters \{Krall 1997; Chin 1997; Krall 1998\}.

Definition of an Episode of Care An episode of care is a series of related events in the course of a continuous experience with an illness or medical condition \{Donaldson 1996\}. Some conditions, such as diabetes and rheumatoid arthritis, are lifetime episodes. Other conditions such as upper respiratory infections, poison oak dermatitis, and influenza are acute self-limited conditions and are usually seen once for some form of symptomatic relief. For the purposes of this study, only acute episodes will be tracked and will consist of the four conditions under study that have a definable beginning and end. They differ somewhat from acute self-limited conditions in that ignoring the symptoms may lead to worsening of the condition.

The selection of an episode approach has a number of rationales. An episode methodology can be used to compare costs of treating specific cases across different providers over time. This has administrative applications in integrated health delivery organizations, for other providers who have responsibility for providing 
comprehensive care for patients, and for monitoring patterns of resource use by type of episode. The episode approach provides the most appropriate basis for planning and budgeting given the expected incidence of disease \{Weinstein 1996\}. An episode methodology also provides the most appropriate method for measuring and comparing patient care output of HMOs and fee-for-service physicians and PAs. Such comparisons have typically been difficult to conduct because of the intrinsic differences in the organization of medical practice under these two forms of health care delivery \{Weinstein 1996\}.

For this study an acute episode commences when the diagnosis is first entered into EpicCare. No diagnoses with similar symptoms (known as differential diagnoses, which are listed in Appendix A) may precede the initial encounter within a month. From the first time the subject had a diagnosis of interest to this study (Table 10) that subject will be tracked to see what, if any, other diagnoses emerge. If a diagnosis from the differential diagnoses list is entered within 30 days before the first encounter, and within 30 days of the last encounter, that encounter is deleted from the study. If the encounter fulfills these two screening tests the encounter is added to the research population. An exclusion also occurs when more than one diagnosis exists at the same time at any visit within the episode. It is necessary to delete episodes with comorbidities treated at the same time because resources used in the management of an illness cannot be reliably assigned to the diagnosis of interest. Finally, to maintain consistency in care assigned to one type of provider, if a different provider sees the patient for subsequent visits, that case will be excluded as well. The intent of this study is to analyze provider differences. Seeing more than one provider during an 
episode will confuse which provider (or type of provider) offers the greater costeffectiveness or cost-benefit. The criteria for this study are detailed in the section on data sources and outlined in Table 14.

\section{STUDY POPULATION SELECTION}

The research population is identified from the KPNW membership population through a series of steps that involve applying stringent criteria for a well-defined sample selection. In 1997, there were 2.6 million contacts, or encounters, that were recorded in EpicCare. These data are stored in the relational database software System 1032 (S1032). This database is used to identify the health record numbers of those with a diagnosis of interest. Since there were over 2,000 different diagnoses with separate ICD-9 codes entered in 1997, a set of criteria was used to select a group of diagnoses that would have the most significance for study and reduce the amount of uncertainty inherent in a large study. The criteria are as follows:

- Acute medical conditions: The condition must represent an acute problem that usually has a short duration -- a defined episode with a beginning and an end. Acute episodes of illness represent the majority of conditions seen in primary care practices \{Donaldson 1998; National Ambulatory Medical Care Survey 1998$\}$. 
- Primary care conditions: The condition should be seen frequently enough in primary care for it to have some meaningful economic impact. It should be seen often in the departments that make up primary care, and it should be seen as a single diagnosis - an important point for assigning resources to an MOV. If two or more diagnoses were recorded for a visit, it would require too many assumptions and rules to accurately and reliably assign the resource to the correct diagnosis. The diagnosis should also be a condition for which PAs are trained and are experienced to diagnose and treat without supervision.

- Diverse types of diagnoses: Diversity of conditions means involving different organ systems without overlapping of symptoms. Effort was made to identify different etiologies and to select conditions involving different parts of the body.

- Provider variation in management: Treatment styles within the HMO allow for substantial variations in the use of resources for a condition. One of the concerns in examining provider practice variations is whether there is any prescriber discretion in selection of a medication for a particular condition. If all urinary tract infections (UTIs) were treated with the same protocol, there would be little need to examine this economic scenario since the medication would be the same. In reality, wide variations exist in how patients with a UTI are approached by physicians in their use of medical resources such as their choice of antibiotics and other medications. 
In $1997 \mathrm{KPNW}$ clinicians were subject to few absolute restrictions in their choice of drugs or other treatments. Although this HMO maintains a formulary - a selection of medications that are preferred over others within the KPNW pharmacies -- in 1997 it was not binding on prescribers; clinicians could prescribe non-formulary medications if desired. Diagnoses that are commonly seen but approached differently by physicians and PAs provide more ability to detect variations in resource use.

- Study population size: A 220 case size study population is necessary for minimum statistical analysis of each diagnosis. A preliminary review of the 1997 EpicCare database found that each of the selected diagnoses had over 4,000 unique encounters that would meet the criteria for selection. Acute otitis media, for example, comprises over 3 percent of the 2.6 million MOVs for the health plan.

- No triage: Inclusion of an undifferentiated condition means that the patient has an equal probability of seeing a PA or physician for care. Patients making an appointment or presenting for care are likely to be assigned the next available provider if none is specified. This lack of triage policy persists within the KPNW organization and it seems to be consistent across all medical offices.

Two sources of data were reviewed for diagnosis selection. The first was the most frequently seen diagnoses over the last decade as reported in the National 
Ambulatory Medical Care Survey NAMCS 1998\}. The second was a list of over 2,000 distinct diagnoses, arranged by frequency, with accompanying ICD- 9 codes that were recorded in the KPNW EC database in 1997. From these two sources, four acute conditions emerged that fulfilled the above selection criteria for this study. They are displayed in Table 10. These four diagnoses represented over four percent of the 2.6 million KPNW encounters in 1997. This order of magnitude affords a large study population. The selection of these diagnoses also represents a large cost to the health plan making this study more meaningful if cost surpluses can be identified. Small adjustments in the total cost of treating these diagnoses represents substantial potential savings on an annual basis.

TABLE 10

DIAGNOSES SELECTED FOR STUDY

\begin{tabular}{|l|c|c|}
\hline \multicolumn{1}{|c|}{ Diagnosis } & ICD-9 CODE & Number \\
\hline Acute urinary tract infections & 599.0 & 121,319 \\
\hline Otitis media, suppurative \& acute & $382 \& 382.9$ & 119,847 \\
\hline Bronchitis, acute & 466.0 & 63,835 \\
\hline Shoulder tendinitis, acute & 726.11 & 9,583 \\
\hline Total & & 314,584 \\
\hline
\end{tabular}

Source: EpicCare End User Database

Note: Number represents the total number of episodes out of 2.6 million KPNW encounters in 1997. 
These four conditions (UTI, OM, acute bronchitis, shoulder tendinitis) are seen at approximately equal rates for PAs and physicians because there is no differentiation when the patient asks for an appointment in primary care. One important consideration in selection was whether variability in treatment could be identified to allow differences to emerge in the analysis as the literature suggests \{Peterson 1997\}. Conversations with physicians, PAs, nurses, patients, laboratory personnel, and appointment clerks suggest there are many provider differences in patient work-ups and in treatment of these conditions making this a study of interest. Because these conditions are managed completely within the health plan, the ability to capture all of the resources used in an episode of an illness makes this study possible. Finally, all four of these conditions can relapse if ineffectively or inadequately treated, and the literature suggests that virtually all episodes can be considered ended if a return visit for the same diagnosis did not occur within 30 days \{Hooton 1996; Christakis 1998; Gonzales 1995$\}$. Some comments about the specific diagnoses follows:

Acute Urinary Tract Infections (UTI). UTIs are acute bacterial infections usually confined to the urinary bladder and occur predominately in females beginning in the late teens and continuing throughout life. While UTIs occur in all ages, the incidence drops in each decade of life. The vast majority of women who develop UTIs have them in early and middle age. When treatment is not available, pyelonephritis and significant chronic renal disease may occur. The treatment strategy is to reduce the symptoms and cure the patient. Obtain a urinalysis is the usual approach for determining the presence of pus and/or bacteria in the urinary tract 
system. Management may consist of a broad-spectrum inexpensive antibiotic. Sometimes the urine is cultured for bacterial sensitivity to the antibiotic \{Hooton 1996; Barry 1997\}. Occassionally an oral analgesic is prescribed to decrease the sensitivity of the urethra for the first few days of treatment. Practice variations include treating some women with only the symptoms present, and in others a urinalysis is ordered without culturing the urine for the specific organism and sensitivity to select antibiotics \{Fargason 1995\}. Other variations in practice include treating empirically, screening the urine in the office without sending the patient to the laboratory, and scheduling a return patient visit for a repeat urine test to verify the treatment success. There is consensus in the literature as well as among KPNW infectious disease specialists that a relapse of a UTI is defined by the diagnosis of another UTI within 30 days \{Hooton 1996; Barry 1997\}. In reality, few episodes of UTI last more than 3-5 days when the patient takes antibiotics, so this assumption is fairly conservative. Finally, UTIs are seen frequently in all three departments that comprise primary care, improving the opportunity to compare PAs and physicians within and across departments.

Otitis Media, Suppurative \& Acute (OM). OMs are middle ear infections that are a frequent finding in infants and young children such as preschoolers. Adolescents and adults may develop OM but this is not commonly seen. These two middle ear conditions are recorded in EpicCare as the most frequent diagnoses in KPNW. "Suppurative" is a medical term indicating that pus is present. The two diagnoses are 
combined as one disease entity because a review of medical records found these diagnoses are used interchangeably as synonyms for the same condition. Both are treated the same and neither have an implication of some other diagnosis emerging or predicting different outcomes. The symptoms and observation of an infected middle ear establish the diagnosis. Most episodes of OM are treated with a brief course of a broad spectrum antibiotic such as penicillin or sulfa. Failure to treat may lead to repeated infections, hearing loss, perforation of the eardrum, or spread of the infection to the mastoids. Children are the usual patients, so the majority of conditions are seen in either the pediatric department or family practice. Some cases occur in internal medicine improving the opportunity to compare department cost differences in the management of OM. Most episodes of OM tend to resolve within a few days when treated with antibiotics. A relapse of OM usually occurs within two weeks. Any repeat encounter of OM after 30 days is considered a new episode \{Christakis 1998 \}. These assumptions are supported by a canvass of four KPNW pediatricians and two KPNW infectious disease specialists as well as a review of the literature (Roark $1995\}$.

Bronchitis, Acute. Bronchitis is usually a bacterial infection that involves the bronchioles, the middle part of the respiratory tract between the trachea and the end of the airway. It is diagnosed by a history of productive cough containing purulent sputum, and the detection of rhonchi or wheezes on ascultation of the lungs with a stethoscope. Sometimes a fever may be present. Some acute conditions of bronchitis 
require a chest $\mathrm{x}$-ray for verification; other cases are treated by symptoms alone \{Oefinger 1997\}. Practice styles vary in that some practitioners will rule out pneumonia by ordering a chest radiograph. Other providers may require sputum specimens to be submitted for culture, bacterial sensitivity to antibiotics, or for detection of the presence of cancer cells \{Gonzales 1995\}. Most conditions resolve within two weeks, so an episode of bronchitis is considered resolved if the patient does not reappear within 30 days. Patients of both genders and all ages are seen in internal medicine, family practice, and pediatric departments. Antibiotics and cough suppressants are the usual mode of treatment but some patients are treated with bronchodilators alone or with antibiotics, suppressants, and bronchodilators in combination. The diagnosis of acute bronchitis differentiates this condition from chronic or relapsing bronchitis.

Shoulder Tendinitis, Acute. Tendinitis involving the shoulder is an acute pain condition that involves an inflamed supraspinatus or biceps tendon. It is usually brought on by overuse and usually affects adults. Both genders are at risk. It tends to last a few weeks to a few months if left untreated. Treatment may be antiinflammatory medications taken orally or a corticosteroid injection alongside the inflamed tendon sheath \{Goupille 1996\}. Practice styles can vary among individual practitioners. Variations in management and treatment include imaging studies (x-ray, $\mathrm{CT}$, or $\mathrm{MRI}$ ) of the chest or shoulder, narcotic analgesics, and referral to the Department of Physical Therapy for care as well as recommending return visits to the 
referring clinician. Personal experience with this condition as well as discussion with Internists, Family Practitioners, Orthopedists, Physical Therapists, and Rheumatologists lead to the conclusion that an episode of shoulder tendinitis can be assumed ended if the patient does not make a return visit for the same condition within 30 days. Practice styles include changing antiinflammatories when one fails to help the patient, and referring the patient to a physical therapist, rheumatologist or orthopedist for management \{Rush 1994; van der Windt 1995\}.

Because this is a study comparing the allocation cost of an illness managed by two different types of providers and not an epidemiological study, verification of the diagnosis or examination of the medical record to see if criteria were satisfied for the diagnosis was not necessary. Nor was level of service or acuity of the condition seen by providers determined for this study. The incidence and treated prevalence of these conditions is well established. Since acuity and level of service remain largely subjective terms, they were ignored. Instead, interest was focused on the impact of managing these conditions from the employer/health plan's perspective. Cost of an illness is the most important input in a cost-effectiveness analysis and is the basis of this study. Some cost-benefit analyses have suffered in quality since they fail to assign all inputs or appropriate monetary values to the input such as the internal or allocation costs of a vertically integrated system \{Hodgson 1994\}. This study intends to overcome those limitations by not only assigning the significant inputs but also using the allocation costs at KPNW where all inputs have been assigned a monetary value. 


\section{Differential Diagnoses}

Finally, a list of 'differential diagnoses' was created for each diagnosis (OM, UTI, bronchitis, and shoulder tendinitis). Differential diagnoses are conditions that may share some of the same symptoms as the diagnosis of interest. This list was developed by reviewing the literature and textbooks for differential diagnoses of all four conditions. Next, a list of all diagnoses entered in EpicCare in 1997 was arranged in order of frequency. This frequency distribution of all diagnoses identified the likelihood of the differential diagnoses for each of the conditions of interest occurring. By lnowing what the range of differential diagnoses are from the literature, and how often they occur within KPNW, a list of 20 to 30 differential diagnoses for each diagnosis of interest was developed that might compound an episode of an illness. These differential diagnoses are considered important since any of the conditions under study could evolve into another diagnosis at a subsequent visit. Thus the original diagnosis could be lost to follow-up. By identifying these differential diagnoses in a preceding or subsequent visit, the initial diagnosis of interest could be eliminated from analysis since it represented a different condition or ICD-9 code. For example, a patient could present with fever, cough, and wheezes on ascultation. The diagnosis of acute bronchitis could be made at the time of the medical office visit thus beginning an episode based on the medical record. The patient could then present two weeks later with the same symptoms but now a chest $\mathrm{x}$-ray reveals some consolidation in the lungs and the diagnosis of pneumonia is made. This would be considered an 
episode of pneumonia based on the first visit and not bronchitis - therefore it would be eliminated from consideration in this study. A list of these differential diagnoses is presented in Appendix A. The selection criteria require that differential diagnoses be screened within 30 days on either side of a first encounter of the diagnosis of interest.

\section{DATA SOURCES, VARIABLES, AND COST MODEL}

The data for this study comes from a number of sources, which are described below. All costs are allocation costs used throughout the system and come from the same accounting system.

EpicCare End User Database: The main source of information for the patient encounter is the EpicCare End User Database. This database collects all information at the time of the encounter and maintains it in a relational database program. This database contains over 80 variables. The variables for this study are:

- Date of medical office visit (MOV)

- Type of provider (PA or physician) and individual provider number

- Diagnosis generated by ICD-9 code

- Orders (laboratory, imaging, pharmacy, etc.).

- Medication

- Health record number 
Medications: The Outpatient Pharmacy System (TOPS) records all information about the pharmacy encounter. In 1997 alone there were over two million outpatient prescriptions dispensed by KPNW pharmacies. Over 90 percent of all prescriptions written by KPNW prescribers are filled at a KPNW pharmacy, including those for members without a prepaid drug benefit. What prescriptions were ordered, what was dispensed, cost of the drug, and to whom it was dispensed are all recorded. Each file contains over 25 variables. While KPNW has a formulary of recommended medications, clinicians may prescribe any marketed drug. TOPS also records prescribed over-the-counter medications, such as insulin and niacin, to monitor adverse effects. Injections administered by nurses in the injection rooms are added to the pharmacy record. All pharmacy encounters are linked to the patient through the health record number. The following are pertinent data for this study:

- Patient's health record number

- Gender

- Age

- Individual provider (prescriber) number

- Internal drug product code (name, strength, dosage form)

- Brand-name or generic-name drug

- Therapeutic class

- Date dispensed

- Drug cost (acquisition cost plus handling cost) 
Laboratory Information System (LIS): The LIS provides an integrated database for the medical laboratory to support processing and reporting of laboratory procedures. Major functions of the system include order and specimen tracking, results interpretation and reporting, and cumulative patient sorting. The LIS contains all laboratory data information for an encounter, the cost to the health plan for these services, and the results of the laboratory test. For the purposes of this study, all laboratory tests ordered are linked both to the office visit of interest and to the patient through the health record number. A relational database for management and research purposes contains these elements for each procedure performed:

- Health record number

- Provider number

- Date of order

- Test ordered and results

- Laboratory cost (allocation cost)

The most frequently ordered laboratory tests for all the diagnoses in this study are aggregated and listed in Table 11. Because there was considerable overlap in tests for all four diagnoses, they were listed by code. The costs are the internal allocation costs for each test. 
TABLE 11

LABORATORY COSTS FOR KPNW - 1997

\begin{tabular}{||l|l|c|}
\hline Code & \multicolumn{1}{|c|}{ Description } & Cost \\
\hline 10005 & CBC (Complete blood count with differential) & $\$ 25.80$ \\
\hline 10020 & ABC (CBC with no differential) & $\$ 16.60$ \\
\hline 15001 & UA (Urinalysis - culture if indicated) & $\$ 14.20$ \\
\hline 15005 & UA (No Culture) & $\$ 14.20$ \\
\hline 15010 & UA (dipstick only) & $\$ 14.20$ \\
\hline 21180 & Glucose (fasting) & $\$ 13.10$ \\
\hline 21182 & Glucose (random) & $\$ 13.10$ \\
\hline 21195 & Fructosamine & $\$ 13.10$ \\
\hline 22495 & Lipid profile & $\$ 14.60$ \\
\hline 23000 & Urea nitrogen, blood (BUN) & $\$ 13.10$ \\
\hline 23050 & Creatinine & $\$ 13.10$ \\
\hline 23805 & Prostate Specific Antigen (PSA) & $\$ 17.50$ \\
\hline 24000 & AST/SGOT (Liver function test) & $\$ 13.10$ \\
\hline 26320 & T4 (Thyroid test) & $\$ 13.10$ \\
\hline 26360 & TSH (Thyroid stimulating hormone) & $\$ 17.50$ \\
\hline 50100 & Rapid Strep Test (throat culture) & $\$ 16.20$ \\
\hline 51600 & Urine culture & $\$ 20.20$ \\
\hline 53540 & Gonorrhea culture \& chlamydia DNA probe & $\$ 23.00$ \\
\hline 68000 & Trichomonas \& yeast smear & $\$ 14.20$ \\
\hline 20014 & Potassium & $\$ 13.10$ \\
\hline 05861 & Urine culture and antibiotic susceptibility & $\$ 18.75$ \\
\hline \hline
\end{tabular}

Source: Laboratory Information Services, KPNW, 1997 allocation costs

Note: Internal costs and KPNW codes 
Radiology Information and Management (RIM): RIM contains pspecific information on all patients treated in any Radiology Department, including contract services for patients seen in other hospitals. This includes all imaging services such as general radiology, computerized tomography (CT), ultrasound (US), and magnetic resonance imaging (MRI). This database collects all the imaging services and records them as Current Procedural Terminology (CPT) codes \{AMA 1997\}. The radiologist's interpretation of the results of the imaging study and costs to the health plan of each CPT code are maintained in this database as well. For this study all imaging encounters are linked to the patient's health record number at the time of the visit of interest. The database contains the following information:

- Health record number

- Gender

- Date of birth (age)

- Procedure and CPT code

- Facility

- Professional and technical fees associated with the procedure

- Procedure cost (allocation cost)

A list of all imaging orders and costs pertinent to this study are displayed in Table 12. 
TABLE 12

IMAGING ORDERS AND COSTS CREATED AT MEDICAL OFFICE VISITS

\begin{tabular}{|c|l|c|c|}
\hline CPT Code & \multicolumn{1}{|c|}{ Description } & Cost & N \\
\hline 71020 & Chest X-ray & $\$ 66$ & 245 \\
\hline 73030 & Shoulder & $\$ 66$ & 90 \\
\hline 74400 & KUB (rule out kidney stone) & $\$ 102$ & 43 \\
\hline 74425 & Intravenous Pyelogram (for kidney disease) & $\$ 165$ & 75 \\
\hline 76700 & Ultrasound Kidneys & $\$ 227$ & 8 \\
\hline
\end{tabular}

Note: $\mathrm{CPT}=$ Comprehensive Procedure and Technology

Source: KPNW Radiology internal costs

Health Status: The association of different types of comorbidities and level of health status can have a significant influence on the length of visit and degree of service provided \{Grumbach 1996\}. This is considered one of the more important variables to examine in provider practice comparisons. The ability to control for health status in other studies comparing physician variability in practice has been too difficult and expensive to undertake until now. There is need to undertake these studies since patients with multiple comorbidities are considered more complex patients requiring more clinical skill than those with none or just a few conditions \{Retchin 1997\}. One of the charges has been that PAs see less complex and less ill patients than physicians, thus making them seem more cost-effective than they really are $\{$ Moore 1994\}. At the time of this data collection, no other published study had addressed this issue either for physicians alone or comparing PAs to physicians in the management of patients. 
An approximate measure of the health status of all patients seen in this study is obtained by calculating a Chronic Disease Score (CDS) which serves as a proxy for chronic diseases or the health condition of the patient. Prescription drug data is used to calculate the CDS and assign a value to selected classes of disease-specific medications used for chronic diseases. The CDS also predicts the likelihood of hospitalization and mortality \{Von Korff 1990\}. This tool has been developed for large systems that contain detailed pharmacy information. Another strength of this study is that the CDS has been replicated for reliability and predictability with KPNW patients \{Johnson 1994\}, making it particularly valuable. All patients in the research population study will be identified for an acute medical condition of interest and included in the study sample. When all patients are screened and the research population is identified, then the patients in the study will have their health status indexed using the CDS. Some patients took many disease-specific medications during the year prior to this study, thus raising their CDS. Others will have no on-going medical condition and will have a CDS that is zero. By comparing the CDS of patients seen by both PAs and physicians we can assess whether PAs are seeing patients with a health status approximately the same as physicians.

Sociodemographics: The Membership Information and Processing System (MIPS) is the database that supplies current sociodemographic information about each patient such as age, gender, length of membership, and health plan membership eligibility. This system serves the organization's administrative and financial needs 
for tracking members. MIPS is an on-line and continuously updated inquiry and reporting system. One important role of MIPS in this study is to screen all patients in the research population to see if they were members for one year on either side of the episode. This screening attribute helps to exclude episodes of illness that might be managed from a non-KPNW source that would be lost to accurate recording of the resources for an episode. The MIPS record on each individual includes the following variables pertinent to this study:

- Health record number

- Gender

- Date of birth (age)

- Date of eligibility and termination date

- Medicare eligibility and status

Admission, Discharge, and Transfer (ADT): Both KPNW and affiliated hospitals use an automated inpatient scheduling system that serves as the basis for the discharge abstract. The $\mathrm{ADT}$ system tracks patients who are hospitalized or institutionalized. Any patient who had a hospital admission, discharge, or transfer to or from a hospital was screened for an $\mathrm{ADT}$ encounter within 30 days before or after the last encounter of an episode. If any were found, that patient was eliminated from the research population. This strategy excluded six patients whose episode of care was treated while they were hospitalized for other reasons. 
Emergency/Urgent Care Database: KPNW emergency departments and urgent care departments (ED/UC) handle more than 100,000 visits annually. Oregon and Washington hospitals are required to maintain logbooks recording emergency department use. Data for both emergency and urgent care are captured electronically in the emergency department module of ADT. Patients are registered in ADT, and member assistants enter additional information after disposition. This database will be screened to see that the study population members did not receive care from the ED/UC within 30 days preceding the first noted EpicCare contact or within 30 days of any contact for the diagnosis of interest. Eliminating patients who had an ED/UC contact preceding, succeeding, or during an episode of interest confines the episode analysis to the three departments of interest. All patients are linked to the ADT using the health record number and date of visit. Sixteen patients were eliminated from the final study population by this exclusion. Although the exclusion number was small this procedure is valuable if this model is to be used for other diagnoses.

Provider Attributes: Information on types of providers and the departments they are associated with is contained in various data sets obtained through Northwest Permanente, PC, and Kaiser Permanente administrative files. Cost coefficients for medical office visits are computed using internal or allocation costs and are based on a 1994 internal organization study entitled The Strategic Positioning Assessment Study (SPA). The SPA study estimated the cost of an office visit with different types of 
providers across all departments. This was accomplished by aggregating all of the diagnoses seen during one year and assigning costs to these diagnoses. Within a department, physicians were examined as one group of providers, PAs and NPs as a separate group. Basically, the SPA coefficient is an average cost of a visit per annum by department and provider type. The SPA coefficient ignores the intensity of the visit since it is an allocation cost. In the aggregate, the internal cost of a visit for $\mathrm{OM}$ and the cost of a visit for a hypertensive renal crisis are viewed as the same costs from the health plan on an annual basis. To obtain the provider's part of the cost of a visit the costs of resources for all visits were identified and backed out. What remained left an average provider's cost within a department. Since the cost of a medical office, staff, equipment, overhead, direct and indirect costs are the same for both physicians and PAs the differences are less than one would expect based on salary alone. These costs are strictly internal administrative costs, or allocative costs, to treat these conditions yet important costs for this analysis since this is what the health plan allocates to provide care for its members. To convert these provider-specific office visit costs to contemporary costs, the 1994 SPA coefficients were multiplied by the Consumer Price Index for Physician Services for 1995 (4.5\%), 1996 (3.6\%), and 1997 (2.9\%) \{Bureau of Labor Statistics 1998 \} to arrive at a cost of a visit in 1997 dollars by type of provider. The SPA coefficients are used as the provider specific visit cost assigned to a 15-minute visit in the study and are linked to the encounter by the provider of record for the visit. 
Outpatient Utilization: The Kaiser Appointment and Record of Encounters (KARE) database is the outpatient utilization system used to capture the MOV appointments, cancellations, and return visits. It links all appointments with a patient's health record number and a visit to a provider. While this appointment system lacks information about why the visit occurred, it helps to define the episode by identifying a return visit within 30 days. KARE allows a variable to be created to identify the number of encounters within an episode. The health record number, date and time of the appointment, provider, medical office, arrival status, department, and other attributes help define the encounter of interest for this study.

In summary, a series of large databases rich in information are utilized to address the research question. Seven databases used interactively identify the patients by age, gender, diagnosis, return visit, resources used, and provider of record. All information is linked by the patient's unique health record number. Most of the information is stored and located in System 1032 (S1032) databases.

A list of the variables used in this cost-benefit analysis is presented in Table 13. These are the principle variables used for analysis purposes.

Research Population: Criteria for the research population selection were developed to hold as many variables constant as possible. Comorbidities are considered one of the most important variables to control for at the time of the visit. If a patient had two or more diagnoses entered at the office visit, then the cost of the 
TABLE 13

VARIABLES USED IN COST-BENEFIT ANALYSIS STUDY

\begin{tabular}{|l|l|l|l||}
\hline \multicolumn{1}{|c|}{ Variable } & \multicolumn{1}{c|}{ Usage } & \multicolumn{1}{c|}{ Form } & \multicolumn{1}{c|}{ Source } \\
\hline Health Record Number & Explanatory & Continuous & MIPS \\
\hline Patient's Age & $\begin{array}{l}\text { Control } \\
\text { Covariate }\end{array}$ & Continuous & EpicCare \\
\hline Patient's Gender & $\begin{array}{l}\text { Control } \\
\text { Covariate }\end{array}$ & Dichotomous & EpicCare \\
\hline Provider Type & Independent & Dichotomous & NWP Admin \\
\hline Provider Department & $\begin{array}{l}\text { Control } \\
\text { Covariate }\end{array}$ & Dichotomous & NWP \\
\hline Medication Dispensed & Dependent & Continuous & TOPS \\
\hline Imaging Ordered & Dependent & Continuous & RIM \\
\hline Laboratory Ordered & Dependent & Continuous & LIS \\
\hline Other Resources Ordered & Dependent & Continuous & $\begin{array}{l}\text { KPNW } \\
\text { Records }\end{array}$ \\
\hline Medication Costs & Dependent & Continuous & $\begin{array}{l}\text { Pharmacy } \\
\text { Admin }\end{array}$ \\
\hline Laboratory Costs & Dependent & Continuous & Lab Admin \\
\hline Imaging Costs & Dependent & Continuous & $\begin{array}{l}\text { Radiology } \\
\text { Admin }\end{array}$ \\
\hline Chronic Disease Score & Dependent & Continuous & $\begin{array}{l}\text { TOPS } \\
\text { Database }\end{array}$ \\
\hline SPA Coefficients & Dependent & Continuous & NWP Database \\
\hline Admission, Discharge, Transfers & Dependent & Continuous & ADT Database \\
\hline
\end{tabular}


resources used cannot be accurately assigned to the visit. Therefore, only single diagnoses for an episode of care are considered. Also, only episodes of a condition treated by the same provider are examined so the resources are assigned to only one type of provider. Other criteria are listed in Table 14. While criteria selection reduces the study sample considerably, the need to control as many critical variables as possible is considered one of the more important objective of this study. The more homogeneous the patients and their diagnoses under study, the greater the validity of the results. Fortunately, the number of office visits for each diagnosis remained substantial even after applying the rigorous selection criteria. The results of the selection process provide a well-defined research population, while allowing significant provider practice differences to emerge in the analysis.

Medical Record Verification: Verification of the diagnostic episodes and management of the patient was conducted by a medical record audit. A random number generator was used to select 30 patients for each diagnosis. These medical records were reviewed and compared with the EpicCare entry. This did not reveal any obvious anomalies that would threaten the internal validity of the study nor were any significant trends identified by this process. 


\section{CRITERIA FOR POPULATION SELECTION}

\section{CRITERIA}

1. Medical office visit (MOV) - where the patient was seen for the first and subsequent episodes, in a Kaiser Permanente medical office; the encounter was entered into the electronic medical record in $199 \%$.

2. One (and only one) of the following diagnoses was entered into EpicCare for the office visit:

- Acute bronchitis

- Shoulder tendinitis

- Otitis media or suppurative otitis media

- Urinary tract infection

3. The MOV episode of interest was managed by a primary care physician assistant (PA) or physician (MD/DO) and was managed by the same provider for the whole episode. Primary care departments are:

- Internal Medicine

- Family Practice

- Pediatrics.

4. Eligible for membership in Kaiser Permanente for all of 1997

5. Less than 65 years old at time of first visit

6. Only one diagnosis per episode at each visit

7. Did not have a differential diagnosis generated within 30 days (see Appendix A for Differential Diagnoses)

8. Did not have an admission, discharge, or transfer to another institution during the episode of interest by at least 30 days.

9. Did not have any other contact with Kaiser Permanente during the episode of interest, including the Emergency Department and Urgency Care, by 30 days 


\begin{abstract}
ANALYSIS MODEL
A multiple-step analysis model is used to test the hypothesis: PAs are costbeneficial to employers for delivering primary care medical services for select acute conditions. If the hypothesis is supported by the analysis, then employing PAs is a strategy that is probably beneficial to the health plan. A cost function model, using allocation costs instead of cost estimates, will be employed since this approach comes closer to reflecting the true cost instead of cost of an episode of an illness used in other economical studies where the cost of an episode of an illness had to be estimated. By examining all of the significant inputs in an episode of care, we can investigate the relationship between the types of patients served and estimate the cost of their care more accurately. The steps in the analysis are presented below.
\end{abstract}

\title{
Step I: Selection of the Study Population
}

The first step in the analysis is to select all patients seen in 1997 from the EpicCare End User Database. Over 2.6 million encounters were entered in EpicCare in 1997. From this set of data, the diagnoses of interest were identified. This process revealed over 262,490 visits spread over the four diagnoses, and 307,031 associated orders generated for the diagnosis and/or treatment of these conditions. The selection criteria in Table 14 were applied to this population to control for a number of variables. This reduced the analysis to $12,782(4.8 \%)$ office visits for the four diagnoses of interest, and 35,591 (11.6\%) orders linked to these medical visits (see Table 15). 
TABLE 15

SELECTING THE RESEARCH SAMPLE

\begin{tabular}{|l|c|c|c|c|}
\hline & \multicolumn{2}{|c|}{ BEFORE CRITERIA } & \multicolumn{2}{c|}{ AFTER CRITERIA } \\
\hline & MOVS & ORDERS & MOVS & ORDERS \\
\hline BRONCHITIS & 47,754 & 63,835 & 1,744 & $5,989(3.6 \%)$ \\
\hline TENDINITIS & 9,583 & 13,356 & 354 & $1,040(3.6 \%)$ \\
\hline $\begin{array}{l}\text { OTITIS } \\
\text { MEDIA }\end{array}$ & 119,847 & 108,521 & 8,232 & $14,995(6.9 \%)$ \\
\hline UTI & 85,306 & 121,319 & 2,452 & $13,567(2.9 \%)$ \\
\hline TOTAL & 262,490 & 307,031 & 12,782 & $35,591(4.8 \%)$ \\
\hline
\end{tabular}

Identifying the research population size as a fraction of the population of interest is fairly straightforward since all KPNW members with a diagnosis of interest for one year were included in the selection process. A total of 12,782 visits represents approximately 5 percent of all MOVs of interest to this study. This large research population means that wide variations can emerge between types of providers and the types of patients they see.

\section{Step II: Medication Orders}

The next step is to obtain the medication dispense information for each of the visits from TOPS (or pharmacy data) along with the costs of the medication. The TOPS data contains the dispense costs (acquisition costs of the medication plus handling costs) which becomes the allocation cost of the model. At the same time the 
medication associated with each patient in the study is identified, the CDS is derived from the same pharmacy database (TOPS), and computed for each patient from the previous year medication dispensed.

\section{Step III: Laboratory and Imaging Orders}

All of the orders associated with each medical office visit are identified, assigned allocation costs in 1997 dollar amounts and calculated. These covariates and control variables are part of the multiple regression model and the analysis of variance model in the statistical analysis.

\section{Step IV: Bivariate Analysis}

In the first stage of the analysis, a $3 \times 2$ table is constructed by department (family practice, internal medicine, and pediatrics) and providers (PAs, MD/DOs), and cross-tabulated with the most important dependent variables: gender, age group, and health status (CDS). A Chi-square test is used for an analysis of the different variables by each diagnosis. The results of the bivariate analysis include mean, standard deviation, standard error, minimum/maximum, $\mathrm{t}$ test, and probability score.

\section{Step V: Regression Analysis}

In this part of the analysis model, the control variables (covariants) are added by entering them into a multivariate regression model. The intent of this part of the analysis is to determine which attributes or variables contribute to the largest

difference in total cost between PAs and physicians. The general linear model has five variables which determine the total cost (provider or visit costs, medication costs, 
imaging costs, laboratory costs, and episodes). Each variable is inserted into the model to control for the effect of the differences. The number of visits in an episode is an important aspect of this study. A cost-effectiveness study looks only at the cost of a single visit. In a cost-benefit analysis, all visits in an episode need to be identified. The results of this episode approach produce a set of statistics such as the mean total cost of an episode of a medical condition treated by a PA or physician.

The analysis of variance (ANOVA) examines the effect of the control variable on the model to determine how significant each patient variable is individually and in the aggregate to explain variations between types of providers. The outcome variable (dependent variable) is total costs. Fishers Exact Test and Pearsons Coefficient indicate the degree of variation in the analysis.

For robustness of results a small significance level will be allowed to reduce the probability of Type I errors (rejection of the null hypothesis when it is true). This is achieved by using a large sample size, reduction in variability of episodes using strict selection criteria, and using a one sided Student's $t$ test (which is more powerful than a two-sided $t$ test), and using a limited number of assumptions. The $t$-test is selected because it is the powerful for rejecting the null hypothesis using such a large population. In this case the null hypothesis $(\mathrm{H} 0)$ is stated that PAs are not costbeneficial to their employer for acute primary care conditions.

The results are discussed in the Results section and detailed in Appendix B for each set of analysis.

One-tailed tests are used at all times and statistical significance set $a$ priori at $p<0.05$. All analyses are performed using SAS statistical computing software 
package. Required study size to detect a $10 \%$ difference is estimated at 220 patients $($ alpha $=0.05$, beta $=0.10)$.

\section{CHAPTER II}

\section{SUMMARY}

In this Methods section, the plan of operation and strategy to undertake the study is outlined. The study site is a large group model HMO and the research population is defined as all members who were seen at Kaiser Permanente in 1997. Four diagnoses were selected - OM, UTI, shoulder tendinitis, and acute bronchitis. These four diagnoses make up over 4 percent of the 2.6 million encounters at KPNW. Physicians and PAs in primary care are the subjects of interest. The manner in which encounters for one of four diagnoses are managed by these clinicians provide the data for study. Seven databases and 15 variables are selected for analysis. Two important aspects of this study are assigning a health status for each patient and the use of health plan allocation costs. Strict criteria are assigned to control as many variables as possible. The results of this process produce a well-defined study population that allows enough variability in the management of care for provider differences to emerge. Another aspect of this study that makes it a valid undertaking is the size of the research population used allowing the hypothesis to be tested at a significant statistical level. This is achieved because the patient cohorts are similar in relative size, and homogeneous in descriptions. A series of steps are outlined to undertake the study. 


\section{CHAPTER IV}

\section{RESULTS}




\section{CHAPTER IV RESULTS}

This chapter reviews the results from the analysis described in the Methods section (Chapter III). The hypothesis being tested is that PAs are cost-beneficial to employers for delivering primary care medical services for common acute conditions. The premise is that there may be some differences in the types of patients being managed by PAs and physicians when examining a number of patient attributes but these differences may not be significant. The intent of the study is to adjust for these patient differences and to test for provider differences in managing these patients' conditions. This is accomplished by comparing the different variables in the cost model and by including control variables in the multivariate models to address any biases that may result from those differences. The results are summarized.

\section{Providers}

Providers are physicians and PAs, and are sometimes referred to generically as clinicians, practitioners, or prescribers. Each provider is a member of a department; the number of providers within a department varies depending on many factors. There were 12,781 patients in the study involving 305 different providers. The number and types of providers observed in this study are displayed in Table 16. Each cell in Table 16 represents one type of departmental provider and the number of providers that were identified for each diagnosis. The pediatric department has the smallest number of providers in general, and only 5 PAs are in that department. Internal medicine had the largest number of physicians in this study (117), and Family Practice had the largest 
TABLE 16

NUMBER AND TYPE OF PROVIDER BY DIAGNOSIS AND DEPARTMENT

\begin{tabular}{|l|c|c|c|c|}
\hline PROVTDER & $\begin{array}{c}\text { OTITIS } \\
\text { MEDIA }\end{array}$ & UTI & $\begin{array}{c}\text { ACUTE } \\
\text { BRONCHITIS }\end{array}$ & $\begin{array}{c}\text { SHOULDER } \\
\text { TENDINTIS }\end{array}$ \\
\hline IM PHYSICLAN & 100 & 117 & 76 & 42 \\
\hline IM PA & 17 & 17 & 16 & 9 \\
\hline FP PHYSICIAN & 79 & 79 & 61 & 41 \\
\hline FP PA & 27 & 29 & 23 & 19 \\
\hline PED PHYSICIAN & 61 & 58 & 15 & 0 \\
\hline PED PA & 5 & 5 & 4 & 111 \\
\hline TOTAL & 289 & 305 & 195 & 0 \\
\hline
\end{tabular}

Source: EpicCare End User Database and NWP Administrative files

Note: $\mathbb{I M}=$ Internal Medicine; FP = Family Practice; Ped = Pediatrics 
contingent of PAs (29). A description of these providers and how they are managed from an organizational standpoint is outlined in the beginning of Chapter III and has been described elsewhere \{Freeborn 1994; Hooker 1991; Hooker 1994\}. Overall, 305 PAs and physicians are part of the analysis (Table 16).

\section{Patient Attributes}

The first analysis involved selecting each diagnosis, and selecting the patients assigned to those diagnoses forming a cohort of patients whose attributes were summarized. The similarities and differences among the types of patients seen by PAs and physicians were then analyzed. This analysis included computing the mean age of patients, determining the number of males and females in each disease cohort, assigning CDS values, and computing mean visits per episode and percentages of each of the attributes. Results of this analysis are displayed in Table 17. The totals identify that a large number of providers and episodes of treatment were available for study.

The mean patient ages for each diagnosis are consistent with the literature, suggesting that by applying the strict criteria for this study population, age was not sacrificed as a significant variable. The patients of PAs, on average, are almost 3 years older than those of physicians for OM, UTI and shoulder tendinitis, although this was significant only for OM and UTI $(p<0.001)$. Physicians tend to see a greater percentage of older patients on average than PAs (40.2 versus 36.8 ) for acute bronchitis only $(p<0.001)$. While this difference of age is highly significant from a statistical standpoint, the difference of 3.4 years in patient groups make this 
observation limited. The differences in age are significant for children with otitis medial who respond differently to treatment than adults but minor when treating middle-age adults with the same diagnosis. Nor is there sorting by gender to see either a physician or a PA for the four conditions under study either.

The next step was to determine the health status of each patient. The CDS for each patient was computed from the pharmacy data by selecting each patient by health record number and determining a value based on the medications they take over a one year period. These are displayed by diagnosis in Table 17. CDS scores are openended unique values. A value of zero suggests that the patient uses no long-term medication and it is highly unlikely that he or she has any chronic medical condition. A value of 15 has a high correlation with someone who has multiple comorbidities such as arthritis, emphysema, diabetes, hypertension, and/or angina. Cancer would push the CDS even higher because of the types of medications dispensed for the management of malignant illness. The average CDS values for the four diagnoses vary between 0.7 and 1.8. These average CDSs are low overall and consistent with young and relatively healthy persons who occasionally have acute medical problems. The patient CDS scores for each diagnosis range from 0 to 17 with the majority near the low end and only a few with very high scores. When CDS values are compared by type of provider as well as between providers within a department, the mean health status of each cohort of patients is virtually the same and no significant differences 
TABLE 17

ACUTE PRIMARY CARE VISITS BY PATIENT ATTRIBUTES AND DIAGNOSES

\begin{tabular}{|c|c|c|c|c|}
\hline ATTRIBUTES & BRONCHITIS & $\begin{array}{l}\text { SHOULDER } \\
\text { TENDINITIS }\end{array}$ & $\begin{array}{l}\text { OTITIS } \\
\text { MEDIA }\end{array}$ & UTI \\
\hline Total Number of Patients & 1744 & 354 & 8232 & 2452 \\
\hline \multicolumn{5}{|c|}{ AGE } \\
\hline Age (mean) all patients & 39.4 & 45.6 & 10.6 & 33.2 \\
\hline Age PA patients & $36.8^{*}$ & 46.0 & $15.2^{*}$ & $35.3^{*}$ \\
\hline Age physician patients & $40.2^{*}$ & 44.5 & $12.9^{*}$ & $32.0^{*}$ \\
\hline$\%$ Adults $(18-65 \mathrm{y} / \mathrm{o})$ & $97.5 \%$ & $99.7 \%$ & $29.6 \%$ & $79.4 \%$ \\
\hline$\%$ Children $(<18$ y/o $)$ & $2.5 \%$ & $0.3 \%$ & $70.4 \%$ & $20.6 \%$ \\
\hline \multicolumn{5}{|c|}{ GENDER } \\
\hline Females & 988 & 195 & 4223 & 2242 \\
\hline Males & 756 & 159 & 4009 & 210 \\
\hline$\%$ Females seen by PA & $58.1 \%$ & $55.6 \%$ & $51.2 \%$ & $93.8 \%$ \\
\hline$\%$ Males seen by PA & $41.9 \%$ & $44.4 \%$ & $48.8 \%$ & $6.2 \%$ \\
\hline $\begin{array}{l}\text { \% Females seen by } \\
\text { physicians }\end{array}$ & $56.2 \%$ & $54.9 \%$ & $51.4 \%$ & $90.2 \%$ \\
\hline $\begin{array}{l}\% \text { Males seen by } \\
\text { physicians }\end{array}$ & $43.8 \%$ & $5.1 \%$ & $48.6 \%$ & $9.8 \%$ \\
\hline \multicolumn{5}{|c|}{ HEALTH STATUS } \\
\hline CDS (mean) & 1.84 & 1.25 & 0.66 & 1.15 \\
\hline CDS ranges & $0-19$ & $0-10$ & $0-17$ & $0-13$ \\
\hline CDS for PA patients & $1.5^{*}$ & $0.9 * *$ & 0.7 & 1.1 \\
\hline CDS for physicia patients & $1.9^{*}$ & $1.3^{* *}$ & 0.7 & 1.2 \\
\hline \multicolumn{5}{|c|}{ EPISODE VISITS } \\
\hline Mean visits per episode & 1.02 & 1.11 & 1.22 & 1.13 \\
\hline$\%$ with 1 visit (no return) & $97.5 \%$ & $89.2 \%$ & $78.2 \%$ & $86.9 \%$ \\
\hline$\%$ with 2 visits (retum) & $2.5 \%$ & $10.8 \%$ & $21.8 \%$ & $13.1 \%$ \\
\hline
\end{tabular}

Note: *Significant at $\mathrm{p}<0.001 ;{ }^{* *}$ Significant at $\mathrm{p}<0.05$ 
emerge. This observation is important because of the charge that PAs see fewer complex types of patients, at least in primary care. The implications of this finding suggest that there is little sorting out of patients by type of provider, at least for these diagnoses in this study. Whether this holds true for the majority of other acute medical remains to be seen. However, the lack of differentiation of patients by type of provider supporis other observations that supervising physicians are confident that PAs can safely manage these, as well as other conditions, without supervision \{Record 1978; Scheffler 1996\}. This bolsters the assumption that PAs are substituting for physicians regardless of the patient's age, gender, or health status - at least in this acute primary care setting.

Visits per episode is another outcome or dependent variable to examine. The reason for examining this aspect of the benefit analysis is that patient profiles may be the same for PAs and physicians, and the type of medication used may be the same for each group of providers, but PAs may have the patient return more often during an episode than physicians would. If this is the case, the cost-benefit of employing PAs in an HMO may be eroded to some extent by the cost of an additional visit. The mean number of office visits per episode ranged between 1.02 and 1.22 depending on the diagnosis (see Table 17). Within the diagnosis of interest, no patient had more than 2 visits per episode using the criteria in Table 17. On average, OM was associated with the most frequent return visits ( $22 \%$ had a return visit within 30 days). Acute bronchitis had the lowest rate of return visits $-2.5 \%$ within 30 days. When return visits by type of provider and by diagnosis were examined, no statistical difference 
emerged for any of the 4 conditions $(p<0.001)$. This suggests that PAs are maintaining their cost-effectiveness by asking the patient to return at the same rate as physicians - at least for these four conditions.

The return visit observation is an interesting one and reasons were sought as to why this was occurring for some diagnoses and not others. In a post-analysis series of discussions with IM, FP, and pediatric clinicians about these diagnoses, it was verified that $\mathrm{OM}$ is often associated with a higher rate of return visit - often initiated by the clinician. Various reasons were given but no consistency could be determined. These differences are viewed as styles of practice and vary widely among providers both in this observation and in the literature \{Roark 1995\}. In the post-analysis of the other three diagnoses, return visits were rarely initiated by providers except to document in the medical record that patients should return soon if they are not improving. These observations were also verified by a random chart audit. The results were that no pattern in return visits could be found.

Gender is an important variable in most clinical studies. Females are seen in the majority of all conditions, but this varies considerably from $51 \%$ for OM to $94 \%$ for UTIs. This is consistent with other observations that UTIs are gender specific for the most part, but bronchitis, OM, and tendinitis affect both sexes equally \{National Ambulatory Medical Survey 1997\}.

To examine if there were sorting out of patients by some other variable, each cohort was examined separately by diagnosis, by who cared for them, and by attribute. The age, gender, and CDS were selected and examined by type of provider within a 
department. Table 18, 19, 20 and 21 display this analysis in detail by each of the four conditions of interest. The results of this scrutiny demonstrated that there was no statistically significant difference by age, CDS, or gender of patient. In each of the four tables below there is remarkable similarity in the types of patients seen by PAs and physicians. Again, this observation supports the belief that patients do not sort themselves by type of provider by, health status, or when they have an acute illness at least for these four diagnoses.

Finally, a note of caution about the value of the health status index or CDS. This identifier is an economical tool for to obtain a proxy on the health of adults who have been in this health system for a few years. It relies on one years worth of data. It has been validated for adults, but remains uncertain for use in children. Most of the scores for children were low, which is consistent with the fact few children have chronic diseases, but still remains to be tested. 
TABLE 18

URINARY TRACT INFECTION PATIENT ATTRIBUTES BY TYPE OF PROVIDER IN THREE DEPARTMENTS (N=2452)

\begin{tabular}{|l|c|c|c||}
\hline \multicolumn{1}{|c|}{ PROVIDER } & $\begin{array}{c}\text { \% } \\
\text { FEMALE }\end{array}$ & $\begin{array}{c}\text { AGE } \\
\text { (MEAN) }\end{array}$ & $\begin{array}{c}\text { CDS } \\
\text { (MEAN) }\end{array}$ \\
\hline IM PHYSICIAN & $89.6 \%$ & 43.4 & 1.6 \\
\hline IM PHYSICIAN ASSISTANT & $90.8 \%$ & 40.6 & 1.2 \\
\hline \hline FP PHYSICIAN & $89.4 \%$ & 38.8 & 1.3 \\
\hline FP PHYSICIAN ASSISTANT & $95.3 \%$ & 36.0 & 1.2 \\
\hline PED PHYSICIAN & $91.8 \%$ & 8.5 & 0.4 \\
\hline PED PHYSICIAN ASSISTANT & $93.9 \%$ & 8.2 & 0.6 \\
\hline
\end{tabular}

Note: There was no statistical difference between cohorts by any attribute.

Additional values for the multivariate regression analysis are located in Appendix B.

TABLE 19

SHOULDER TENDINITIS PATIENT ATTRIBUTES BY TYPE OF PROVIDER IN TWO DEPARTMENTS (N=354)

\begin{tabular}{|l|c|c|c|}
\hline \multicolumn{1}{|c|}{ PROVIDER } & $\begin{array}{c}\text { \% } \\
\text { FEMALE }\end{array}$ & $\begin{array}{c}\text { AGE } \\
\text { (MEAN) }\end{array}$ & $\begin{array}{c}\text { CDS } \\
\text { (MEAN) }\end{array}$ \\
\hline IM PHYSICIAN & $62.5 \%$ & 49.9 & 1.6 \\
\hline IM PHYSICIAN ASSISTANT & $60.0 \%$ & 49.0 & 0.9 \\
\hline FP PHYSICIAN & $48.2 \%$ & 42.5 & 0.9 \\
\hline FP PHYSICIAN ASSISTANT & $53.9 \%$ & 42.7 & 0.9 \\
\hline
\end{tabular}

Note: There was no statistical difference between cohorts by any attribute.

Additional values for the multivariate regression analysis are located in Appendix B. 
TABLE 20

ACUTE OTITIS MEDIA PATIENT ATTRIBUTES BY TYPE OF PROVIDER IN THREE DEPARTMENTS $(\mathbf{N}=\mathbf{8 2 3 2})$

\begin{tabular}{|l|c|c|c|}
\hline \multicolumn{1}{|c|}{ PROVIDER } & $\begin{array}{c}\% \\
\text { FEMALE }\end{array}$ & $\begin{array}{c}\text { AGE } \\
\text { (MEAN) }\end{array}$ & $\begin{array}{c}\text { CDS } \\
\text { (MEAN) }\end{array}$ \\
\hline IM PHYSICIAN & $61.1 \%$ & 39.9 & 1.2 \\
\hline IM PHYSICIAN ASSISTANT & $62.0 \%$ & 38.2 & 1.1 \\
\hline FP PHYSICIAN & $52.3 \%$ & 17.4 & 0.7 \\
\hline FP PHYSICIAN ASSISTANT & $50.2 \%$ & 17.4 & 0.6 \\
\hline PED PHYSICIAN & $50.2 \%$ & 5.2 & 0.6 \\
\hline PED PHYSICLAN ASSISTANT & $49.7 \%$ & 4.9 & 0.7 \\
\hline
\end{tabular}

Note: There was no statistical difference between cohorts by any attribute.

Additional values for the multivariate regression analysis are located in Appendix B.

TABLE 21

ACUTE BRONCHITIS PATIENT ATTRIBUTES BY TYPE OF PROVIDER IN THREE DEPARTMENTS $(n=1744)$

\begin{tabular}{|l|c|c|c|}
\hline \multicolumn{1}{|c|}{ PROVIDER } & $\begin{array}{c}\% \\
\text { FEMALE }\end{array}$ & $\begin{array}{c}\text { AGE } \\
\text { (MEAN) }\end{array}$ & $\begin{array}{c}\text { CDS } \\
\text { (MEAN) }\end{array}$ \\
\hline IM PHYSICIAN & $56.7 \%$ & 44.2 & 2.1 \\
\hline IM PHYSICIAN ASSISTANT & $56.7 \%$ & 41.9 & 1.7 \\
\hline FP PHYSICIAN & $56.1 \%$ & 38.8 & 1.8 \\
\hline FP PHYSICIAN ASSISTANT & $59.2 \%$ & 34.8 & 1.4 \\
\hline \hline PED PHYSICIAN & $51.4 \%$ & 7.0 & 1.2 \\
\hline PED PHYSICIAN ASSISTANT & $42.9 \%$ & 6.1 & 2.0 \\
\hline
\end{tabular}

Note: There was no statistical difference between cohorts by any attribute.

Additional values for the multivariate regression analysis are located in Appendix B. 
The next step was to examine the number and percentage of orders for a visit by type of provider for each condition. The data for this analysis is contained in the EpicCare End Users Database and displayed in Table 22.. This results in 31,461 separate orders. The orders that were found occurring in any significant amount are medication, laboratory, and x-rays and account for 97 percent of all orders for this study. Within each of these orders, there is a wide range of choices such as various medications and different types of laboratory tests and imaging studies. Each of these medical resources, ordered for either diagnostic or treatment purposes, has an assigned internal or allocation cost. Medications are the most frequent orders for all conditions, followed by laboratory orders and then imaging orders. Pharmaceutical orders account for 41-90 percent of the orders depending on the diagnosis. The three percent of orders not part of the study are orders that occur at very low frequencies, and were not found to be significantly different statistically by type of provider. This decision was reinforced when the random medical record review validated that many of the extraneous orders in this three percent exclusion were for services unrelated to the visit. These include unrelated items such as a wrist splint, a referral for genetic counseling, mental health referral, color vision screening, and taping an injured ankle. This mode of practice is common in pediatrics - taking advantage of a medical office visit to immunize the child or perform some other wellness check while treating for an illness. Statistically, this did not occur often in this study and was not viewed as a compounding effect on the data.

There are a few other resources that are occasionally used for managing one of these medical conditions. These are internal referrals to physical therapy and office 
procedures such as an injection of cortisone for shoulder tendinitis. The most frequently performed office procedure was a corticosteroid injection for shoulder tendinitis. This occurred at $9.8 \%$ of all acute shoulder tendinitis visits in this study and the rate was approximately the same for physicians and PAs in Internal Medicine and Family Practice. In this setting, procedures are considered part of the office visit charge, factored into the aggregated office visit cost, and are not included as a separate cost under the current billing practice. The allocation costs and not the procedure are the focus of this study, so office procedures are ignored from a cost standpoint.

An internal referral to the Department of Physical Therapy occurred in $23.1 \%$ of the tendinitis visits. Referrals to the Department of Ear, Nose and Throat for recurrent OM (primarily for myringotomy, eardrum tube placement, or tonsillectomy) occurred in $10.4 \%$ of the OM visits. There was no significant difference between the percentage of referrals to physical therapy (PT) by PAs or physicians within any department. The percentage of referrals to ENT by PAs and physicians was similar as well. Again, this supports the notion that patients seen by a PA or a physician within a department do not differ by any of the usual attributes. Nor are the patients with a typical acute primary care condition being referred at a disproportional rate to one type of provider over the other.

The subject of referrals is difficult to assess from a cost-benefit standpoint especially in an HMO where there are no disincentives to refer \{Sloan 1996\}. The value of a referral can be assigned a value from a cost standpoint, but does the referral have some cost-benefit by itself to the organization? A referral to PT for shoulder 
tendinitis may be because the provider does not know how to manage the patient or because the PT referral adds some value to the encounter. However, the referral may be for other reasons such as the patient demanding a referral, or it may be for preventive services which have some downstream effect by reducing return visits for the same condition. The value of a PT visit has not been assessed from a cost-benefit standpoint and therefore makes assigning a value problematic. An ENT referral is another example of difficulty in assigning a cost to an episode where all costs are borne by the same organization. To have ear tubes placed or to shift a difficult case to a specialist makes assigning the cost of a referral challenging. Once $\mathrm{OM}$ or shoulder tendinitis is outside the care of the primary care provider, it is not a primary care episode and the resources used are assigned to the ENT or PT department. With the exception of some mental health studies on referred patients and the cost of a mental health episode of care, there is very little literature available on cost-benefits of referrals in general and none in the managed care literature going back to 1985. Because there was no method to reconcile a referral cost from the episode analysis all visits that ended with a referral were deleted from the study. 
TABLE 22

ORDERS CREATED AT MEDICAL OFFICE VISITS

\begin{tabular}{|c|c|c|c|c|c|c|c|c|}
\hline \multirow[t]{2}{*}{ ORDERS } & \multicolumn{2}{|c|}{ BRONCHITIS } & \multicolumn{2}{|c|}{ TENDINITIS } & \multicolumn{2}{|c|}{$\begin{array}{l}\text { OTITIS } \\
\text { MEDIA }\end{array}$} & \multicolumn{2}{|c|}{ UTI } \\
\hline & $\#$ & $\%$ & $\#$ & $\%$ & $\#$ & $\%$ & $\#$ & $\%$ \\
\hline Clinical laboratory & 471 & 7.9 & 129 & 12.4 & 556 & 3.7 & 7394 & 54.5 \\
\hline $\begin{array}{l}\text { Computerized } \\
\text { tomography }\end{array}$ & N/A & 0 & N/A & 0 & N/A & 0 & 2 & 0 \\
\hline Cytology & 3 & 0.1 & N/A & 0 & N/A & 0 & 27 & 0.2 \\
\hline Electrocardiogram & 19 & 0.3 & 3 & 0.3 & 3 & 0 & 11 & 0.1 \\
\hline Education & 2 & 0 & $N / A$ & 0 & N/A & 0 & N/A & 0 \\
\hline Exam procedures & 75 & 1.3 & 102 & 9.8 & 113 & 0.8 & 56 & 0.4 \\
\hline Fluoroscopy & N/A & 0 & N/A & 0 & 1 & 0 & 75 & 0.6 \\
\hline General radiology & 194 & 3.2 & 90 & 8.7 & 51 & 0.3 & 43 & 0.3 \\
\hline Immunizations & 38 & 0.6 & 5 & 0.5 & 517 & 3.4 & 49 & 0.4 \\
\hline Injections & 31 & 0.5 & 10 & 1.0 & 35 & 0.2 & 73 & 0.5 \\
\hline Internal referrals & 34 & 0.6 & 140 & 23.1 & 210 & 10.4 & 114 & 0.8 \\
\hline Mammography & 8 & 0.1 & 7 & 0.7 & 6 & 0 & 11 & 0.1 \\
\hline Medications & 5113 & 85.3 & 437 & 42.1 & 13503 & 90.1 & 5560 & 41.0 \\
\hline MRI & $N / A$ & 0 & 3 & 0.3 & N/A & 0 & N/A & 0 \\
\hline Nuclear medicine & 1 & 0 & N/A & 0 & N/A & 0 & 1 & 0.0 \\
\hline $\begin{array}{l}\text { Supplies \& } \\
\text { equipment }\end{array}$ & $\mathrm{N} / \mathrm{A}$ & 0 & 14 & 1.3 & N/A & 0 & 8 & 0.1 \\
\hline Ultrasound & N/A & 0 & N/A & 0 & N/A & 0 & 113 & 1.0 \\
\hline Total & 5,989 & $100 \%$ & 940 & $100 \%$ & 14,995 & $100 \%$ & 13,537 & $100 \%$ \\
\hline
\end{tabular}

Source: EpicCare End-user Database, 1997.

Note: $\mathrm{N} / \mathrm{A}=$ not applicable or none assigned; $\mathrm{MRI}=$ magnetic resonance imaging 
The next step was to take the various orders created at the medical visit by provider within a diagnostic group, assign costs to the orders, medications, and the provider, and compute a total cost for a visit. These are the dependent variables for the study. A general linear model procedure was constructed to examine where the costs of an episode were by each of the dependent variables: provider or visit cost, medication, laboratory procedures, and imaging studies. Total costs were computed to show the cost of an episode of a diagnosis before differentiating provider costs. These computed costs are displayed in Table 23. Assigned as allocation costs, these average health plan costs are the allocation costs for each of the different diagnoses by the five different costs of an episode of an illness (visit cost, medication cost, laboratory cost, imaging cost, and total cost). A single episode of UTI is the most expensive illness cost (\$244.10), followed by bronchitis (\$232.24). OM and shoulder tendinitis are the least expensive -- $\$ 175.79$ and 174.62 respectively.

Determining the cost of an episode when assigned to either a PA or physician required taking the data from Table 23 and parsing it to reveal both the diagnosis and the department, and then within the department, by the type of provider. Backing out the provider costs -- displayed as the visit cost -- from the total cost drives the study to examine what the differences are by type of provider. This strategy revealed a number of differences in costs per order by type of provider (sorted by department) across all conditions. These are displayed in Tables $24,25,26$ and 27. A discussion of the results follows the tables. 
TABLE 23

MEAN COSTS FOR AN EPISODE OF CARE BY SPECIFIC ORDERS

\begin{tabular}{|l|c|c|c|c|}
\hline ATTRIBUTES & BRONCHITIS & $\begin{array}{c}\text { SHOULDER } \\
\text { TENDINITS }\end{array}$ & $\begin{array}{c}\text { OTITIS } \\
\text { MEDIA }\end{array}$ & UTI \\
\hline $\begin{array}{l}\text { Number of visits per } \\
\text { episode }\end{array}$ & 1.03 & 1.09 & 1.22 & 1.13 \\
\hline $\begin{array}{l}\text { Number of orders per } \\
\text { episode }\end{array}$ & 3.53 & 3.20 & 2.22 & 6.25 \\
\hline Provider/visit costs & $\$ 123.90$ & $\$ 133.00$ & $\$ 126.26$ & $\$ 126.99$ \\
\hline Lab costs & $\$ 1.40$ & $\$ 0.90$ & $\$ 0.48$ & $\$ 17.03$ \\
\hline Imaging costs & $\$ 3.63$ & $\$ 7.99$ & N/A & $\$ 13.52$ \\
\hline Medication costs & $\$ 103.32$ & $\$ 32.72$ & $\$ 49.04$ & $\$ 86.56$ \\
\hline Total episode costs & $\$ 232.24$ & $\$ 174.62$ & $\$ 175.79$ & $\$ 244.10$ \\
\hline
\end{tabular}

Note: N/A = not applicable or none assigned. 
TABLE 24

MEAN EPISODE COSTS BY TYPE OF PROVIDER FOR BRONCHITIS $\mathrm{N}=\mathbf{1 7 4 7}$

\begin{tabular}{|l|c|l|l|l|l|c|}
\hline $\begin{array}{l}\text { PROVIDER } \\
\text { TYPE }\end{array}$ & $\mathbf{N}$ & $\begin{array}{l}\text { TOTAL } \\
\text { COSTS }\end{array}$ & $\begin{array}{l}\text { PROV } \\
\text { COSTS }\end{array}$ & $\begin{array}{l}\text { MED } \\
\text { COSTS }\end{array}$ & $\begin{array}{l}\text { MAGE } \\
\text { COSTS }\end{array}$ & $\begin{array}{l}\text { LAB } \\
\text { COSTS }\end{array}$ \\
\hline IM PHYSICIAN & 568 & $\$ 256.32$ & $\$ 145.48$ & $\$ 104.45$ & $\$ 4.65$ & $\$ 1.75$ \\
\hline $\begin{array}{l}\text { IM PHYSICIAN } \\
\text { ASSISTANT }\end{array}$ & 142 & $\$ 254.94$ & $\$ 110.32$ & $\$ 136.11$ & $\$ 6.97$ & $\$ 1.54$ \\
\hline FP PHYSICIAN & 731 & $\$ 217.57$ & $\$ 125.67$ & $\$ 88.58$ & $\$ 2.17$ & $\$ 1.14$ \\
\hline $\begin{array}{l}\text { FP PHYSICIAN } \\
\text { ASSISTANT }\end{array}$ & 262 & $\$ 200.18$ & $\$ 83.41$ & $\$ 111.73$ & $\$ 3.53$ & $\$ 1.51$ \\
\hline $\begin{array}{l}\text { PED PHYSICIAN } \\
\text { PED PHYSICIAN } \\
\text { ASSISTANT }\end{array}$ & 7 & $\$ 495.61$ & $\$ 55.69$ & $\$ 439.92$ & $\$ 0.0$ & $\$ 0.0$ \\
\hline $\begin{array}{l}\text { TOTAL OR AVG. } \\
\text { OBSERVATIONS }\end{array}$ & 1,747 & $\$ 232.24$ & $\$ 123.90$ & $\$ 103.32$ & $\$ 3.63$ & $\$ 1.40$ \\
\hline
\end{tabular}

Note: $\mathrm{N}$ =total number of episodes observed; $\mathbb{I M}=$ Internal Medicine; FP=Family Physician; Ped=Pediatrics. Each cell represents an average cost. 
TABLE 25

MEAN EPISODE COSTS BY TYPE OF PROVIDER FOR OTITIS MEDIA $\mathrm{N}=\mathbf{8 2 5 4}$

\begin{tabular}{|l|c|c|c|c|c|c|}
\hline $\begin{array}{l}\text { PROVIDER } \\
\text { TYPE }\end{array}$ & $\mathbf{N}$ & $\begin{array}{l}\text { TOTAL } \\
\text { COSTS }\end{array}$ & $\begin{array}{l}\text { PROV } \\
\text { COSTS }\end{array}$ & $\begin{array}{l}\text { MED } \\
\text { COSTS }\end{array}$ & $\begin{array}{l}\text { IMAGE } \\
\text { COSTS }\end{array}$ & $\begin{array}{l}\text { LAB } \\
\text { COSTS }\end{array}$ \\
\hline IM PHYSICIAN & 469 & $\$ 250.30$ & $\$ 145.47$ & $\$ 103.36$ & N/A & $\$ 1.47$ \\
\hline $\begin{array}{l}\text { IM PHYSICIAN } \\
\text { ASSISTANT }\end{array}$ & 210 & $\$ 225.66$ & $\$ 112.93$ & $\$ 112.05$ & N/A & $\$ 0.67$ \\
\hline FP PHYSICIAN & 1029 & $\$ 202.09$ & $\$ 142.06$ & $\$ 59.52$ & N/A & $\$ 0.51$ \\
\hline $\begin{array}{l}\text { FP PHYSICIAN } \\
\text { ASSISTANT }\end{array}$ & 733 & $\$ 152.09$ & $\$ 93.33$ & $\$ 58.52$ & N/A & $\$ 0.24$ \\
\hline PED PHYSICIAN & 4748 & $\$ 179.31$ & $\$ 139.11$ & $\$ 39.74$ & N/A & $\$ 0.46$ \\
\hline $\begin{array}{l}\text { PED PHYSICIAN } \\
\text { ASSISTANT }\end{array}$ & 1065 & $\$ 108.38$ & $\$ 70.54$ & $\$ 37.54$ & N/A & $\$ 0.30$ \\
\hline $\begin{array}{l}\text { TOTAL OR AVG. } \\
\text { OBSERVATIONS }\end{array}$ & 8254 & $\$ 175.79$ & $\$ 126.26$ & $\$ 49.04$ & N/A & $\$ 0.48$ \\
\hline
\end{tabular}

Note: $N=$ total number of episodes observed; $\mathbb{M}=$ Internal Medicine; FP=Family Physician;

Ped $=$ Pediatrics. Each cell represents an average cost. 
TABLE 26

MEAN EPISODE COSTS BY TYPE OF PROVIDER FOR URINARY TRACT INFECTION

$\mathbf{N}=\mathbf{2 5 1 1}$

\begin{tabular}{|l|c|c|c|c|c|c|}
\hline $\begin{array}{l}\text { PROVIDER } \\
\text { TYPE }\end{array}$ & $\mathbf{N}$ & $\begin{array}{l}\text { TOTAL } \\
\text { COSTS }\end{array}$ & $\begin{array}{l}\text { PROV } \\
\text { COSTS }\end{array}$ & $\begin{array}{l}\text { MED } \\
\text { COSTS }\end{array}$ & $\begin{array}{l}\text { IMAGE } \\
\text { COSTS }\end{array}$ & $\begin{array}{l}\text { LAB } \\
\text { COSTS }\end{array}$ \\
\hline IM PHYSICIAN & 572 & $\$ 285.16$ & $\$ 157.55$ & $\$ 100.66$ & $\$ 8.73$ & $\$ 18.22$ \\
\hline $\begin{array}{l}\text { IM PHYSICIAN } \\
\text { ASSISTANT }\end{array}$ & 269 & $\$ 224.25$ & $\$ 118.49$ & $\$ 82.16$ & $\$ 4.20$ & $\$ 19.40$ \\
\hline \hline FP PHYSICIAN & 615 & $\$ 255.03$ & $\$ 140.43$ & $\$ 91.10$ & $\$ 8.85$ & $\$ 14.65$ \\
\hline $\begin{array}{l}\text { FP PHYSICIAN } \\
\text { ASSISTANT }\end{array}$ & 542 & $\$ 204.24$ & $\$ 92.07$ & $\$ 95.88$ & $\$ 3.56$ & $\$ 12.74$ \\
\hline \hline PED PHYSICIAN & 446 & $\$ 242.56$ & $\$ 126.91$ & $\$ 52.52$ & $\$ 41.31$ & $\$ 21.83$ \\
\hline $\begin{array}{l}\text { PED PHYSICIAN } \\
\text { ASSISTANT }\end{array}$ & 67 & $\$ 205.94$ & $\$ 59.84$ & $\$ 93.62$ & $\$ 30.49$ & $\$ 21.98$ \\
\hline $\begin{array}{l}\text { TOTAL OR AVG. } \\
\text { OBSERVATIONS }\end{array}$ & 2511 & $\$ 244.10$ & $\$ 126.99$ & $\$ 86.56$ & $\$ 13.52$ & $\$ 17.03$ \\
\hline
\end{tabular}

Note: $\mathrm{N}=$ total number of episodes observed; $\mathrm{IM}=$ Internal Medicine; $\mathrm{FP}=$ Family Physician;

Ped=Pediatrics. Each cell represents an average cost. 


\section{TABLE 27}

\section{MEAN EPISODE COSTS BY TYPE OF PROVIDER FOR SHOULDER}

\section{TENDINITIS}

N=354
\begin{tabular}{|l|c|c|c|c|c|c||}
\hline PROVIDER & $\mathbf{N}$ & TOTAL & PROV & MED & IMAGE & LAB \\
TYPE & 129 & $\$ 191.37$ & $\$ 158.77$ & $\$ 23.88$ & $\$ 7.16$ & $\$ 1.56$ \\
\hline IM PHYSICIAN & 25 & $\$ 188.37$ & $\$ 130.55$ & $\$ 37.02$ & $\$ 18.48$ & $\$ 2.33$ \\
\hline $\begin{array}{l}\text { IM PHYSICIAN } \\
\text { ASSISTANT }\end{array}$ & 135 & $\$ 175.66$ & $\$ 131.39$ & $\$ 36.12$ & $\$ 7.82$ & $\$ 0.33$ \\
\hline FP PHYSICIAN & 65 & $\$ 134.96$ & $\$ 86.56$ & $\$ 42.05$ & $\$ 6.09$ & $\$ 0.27$ \\
\hline $\begin{array}{l}\text { FP PHYSICIAN } \\
\text { ASSISTANT }\end{array}$ & 354 & $\$ 175.79$ & $\$ 133.00$ & $\$ 32.72$ & $\$ 7.99$ & $\$ 0.90$ \\
\hline $\begin{array}{l}\text { TOTAL OR AVG. } \\
\text { OBSERVATIONS }\end{array}$ & & & & & & \\
\hline
\end{tabular}

Note: $\mathrm{N}=$ total number of episodes observed; $\mathrm{IM}=$ Internal Medicine; FP=Family Physician; Ped=Pediarrics. Each cell represents an average cost. 
The bivariate model for Tables $24-27$ sorts by each diagnostic group and compares the cost of all resources for a MOV between types of providers. Each row combines the cost of the initial visit and all return visits and adds medication costs, imaging costs, and lab costs to obtain a total cost. The number of episodes in a column is assigned as N. All costs are average costs.

The value of this analysis is to establish the differences in resource use by type of provider. What emerges is inconsistency in the differences. For example, physicians tend to prescribe less costly medication for an episode of bronchitis than PAs across all three departments. While this medication observation is interesting, it was not consistent with the other three diagnoses where PAs prescribed less costly medication. There were no imaging costs rendered for $\mathrm{OM}$, so this was not a factor in the cost of an OM episode. Other observations include a remarkable similarity in laboratory costs for each diagnosis by type of provider and within a department. The total cost of a visit when assigned to a PA is always less than the cost of a visit to a physician within the same department regardless of the diagnosis.

\section{Multivariate Analysis}

The null hypothesis tested is that PAs negate their cost-effectiveness by practicing differently from physicians. In the first part of the analysis, a simple $3 \times 2$ table of departments (internal medicine, family practice, and pediatrics) is crossed with the type of provider and then a Chi-square test is conducted. 
The second part of the analysis model calls for the control variables to be added by entering them into a general linear model. The dependent variable is the total cost for an episode of an illness. The general linear model has four variables (visit or provider cost, medication cost, imaging cost, and laboratory cost). The results of these analyses produces a set of statistics such as the mean total cost for an episode of a diagnosis, the Pearson coefficient (R-square value), Fishers Exact Test (F values) and the statistical significance for each variable in the model. This analysis is done for each of the providers in each of the three primary care departments.

Finally, the outcome variable (total costs) is examined to see which covariant (type of provider, age of patient, gender of patient, or health status) has the greatest influence on the model. This was conducted using an ANOVA test for each diagnosis. The results are discussed below. The statistics generated from the general linear model and ANOVA are in located Appendix B and reproduced in greater detail.

\section{Urinary Tract Infection}

An episode of UTI costs the health plan, on average, $\$ 244.10$. When this episode is managed by a physician, the total visit cost is $\$ 262.17$. When managed by a PA, the total visit cost is $\$ 210.50$. The difference in total cost of the visit $(\$ 51.67)$ is statistically significant at $\mathrm{p}<0.001$ and is found mainly in the provider cost where the physician part of the visit is $\$ 142.73$ versus the PA part of the visit is $\$ 97.70$ (also statistically significant at $\mathrm{p}<0.001$ ). There is no significant statistical difference in medication cost between the two providers in the aggregate. However, there is a difference in the imaging costs and laboratory costs between the two providers. 
Physicians order more costly imaging services than PAs for an episode of UTI (\$17.67 versus $\$ 5.80$, respectively, an $\$ 11.87$ difference, which is statistically significant at $p<0.01)$. The number of visits in an episode of UTI is the same for physicians and PAs.

The ANOVA results identify wide variations in resource use and practice styles by providers in the management of UTIs $\left(F\right.$ value $\left.=14.76 ; R^{2}=0.023\right)$. This is also seen in the general linear model where the standard deviation costs of all resources are large. For example, the standard deviation of medication costs ranged as much as 5 times the mean costs of an episode in some cases. When the two providers are examined by department, we find wide variations in all medical resources without any trend in efficiency in one type of provider over the other.

Covariants are also examined to see what effect they may have. The rank order of significant covariants is:

- Type of Provider (PA versus physician) $\quad \mathrm{p}=0.0001$

- Health Status (CDS) $\quad \mathrm{p}=0.0008$

- Age of Patient $\quad \mathrm{p}=0.0034$

- Gender of Patient $\quad \mathrm{p}=0.8198$

The inclusion of control variables has little effect on the results and only accounts for 2.3 percent of the analysis model. From this analysis, the conclusion is that the outcome of an episode of UTI is less expensive when a PA manages the patient than when a physician manages the patient. This seems to be the case regardless of the medical resources used and the type of patients seen. 


\section{Bronchitis}

An episode of acute bronchitis costs the health plan, on average, \$234.24. When this episode is managed by a physician, the total cost is $\$ 234.74$. When managed by a PA the cost is $\$ 224.13$. The difference in the total cost of a visit comparing the two providers $(\$ 10.61)$ is not statistically significant. What difference that exists is found mainly in the provider cost where the cost of a visit to a physician is $\$ 133.63$ and the cost of a visit to a PA is $\$ 92.23$ (statistically significant at $\mathrm{p}<0.001$ ). One difference that is evident is at the medication cost level where a PA prescribes more costly medications per episode of acute bronchitis than a physician ( $\$ 125.74$ versus $\$ 92.42$ respectively $[\mathrm{p}<0.001])$. When the other resources are examined there is no difference statistically between PAs and physicians for imaging costs or laboratory costs. The number of visits in an episode of acute bronchitis is the same for physicians and PAs and rarely exceeds more than one.

The ANOVA results identify wide variations in resource use and practice styles by providers in the management of acute bronchitis $\left(F\right.$ value $=19.20 ; R^{2}=$ 0.042). This is also seen in the general linear model where the standard deviation costs of some resource uses are wider than others. For example, in some cases, the standard deviation of medication costs ranged as much as two-fold, and laboratory costs as much as seven-fold in the mean total costs of an episode. When the two providers are examined by departments we find wide variations in all medical resource use. The most striking difference is in the pediatric department where seven episodes of bronchitis were managed by pediatric PAs and 37 episodes were managed by physicians. In this case the mean difference in medication costs were $\$ 439.92$ and 
$\$ 128.06$, respectively. These seven cases drove up the cost of an episode of acute bronchitis managed by PAs over $\$ 250.00$. Why this occurred cannot be explained by the data. The number of episodes are too small to reach any conclusion.

Covariants are also examined to see what effect they may have. The rank order of significant covariants is:

- Health Status (CDS)

$$
\begin{aligned}
& p=0.0001 \\
& p=0.0167 \\
& p=0.1489 \\
& p=0.6412
\end{aligned}
$$

- Gender of Patient

- Type of Provider (PA versus physician)

The inclusion of control variables has very little effect on the results and only accounts for 4.2 percent of the analysis model. From this analysis, the conclusion is that the outcome of an episode of adult-onset acute bronchitis is less expensive when a PA manages the patient than when a physician manages the patient. However, this is not the case for children. PA managed cases of acute bronchitis have higher total costs based on the medication used for the episode. Because seven cases of acute bronchitis spread over five pediatric PAs has limited statistical power these cases must be viewed as anomalies and little conclusion reached from this part of the analysis.

\section{Otitis Media}

An episode of acute otitis media costs the health plan, on average, \$175.79. When this episode is managed by a physician, the total cost is $\$ 189.39$. When managed by a PA, the cost is $\$ 136.60$. This difference in cost (\$51.79) is statistically 
significant at $\mathrm{p}<0.001$ and is found mainly in the provider cost where the physician portion of the visit cost is $\$ 140.07$ and the PA portion of the visit cost is $\$ 83.29$ (statistically significant at $\mathrm{p}<0.001$ ). There is no significant statistical difference in medication or laboratory cost between the two providers in the aggregate. No imaging costs were recorded for either provider in this study. The number of visits in an episode of OM varied widely between physicians and PAs and were 50 percent higher for pediatric patients than adult patients.

The ANOVA results identify some variations in resource use and practice styles by providers in the management of UTIs $\left(F\right.$ value $\left.=129.92 ; R^{2}=0.059\right)$. This is also seen in the general linear model where the standard deviation costs of all resources are large. When the two providers are examined by department we find a fair amount of variation in all medical resources without any trend in efficiency in one type of provider over the other.

Covariants are also examined to see what effect they may have. The rank order of significant covariants is:

- Type of Provider (PA versus physician)

$$
\begin{aligned}
& p=0.0001 \\
& p=0.0001 \\
& p=0.0001 \\
& p=0.8643
\end{aligned}
$$

- Health Status (CDS)

- Age of Patient

- Gender of Patient

In spite of the highly significant statistical values, the inclusion of control variables has very little effect on the results and only accounts for 5.9 percent of the analysis model. From this analysis, the conclusion is that the total outcome cost of an episode 
of OM is less expensive when a PA manages the patient than when a physician manages the patient. This seems to be the case regardless of the medical resources used and the type of patients seen.

\section{Shoulder Tendinitis}

An episode of shoulder tendinitis costs the health plan, on average, $\$ 174.62$. When an episode is managed by a physician, the total cost is $\$ 183.33$; when managed by a PA, the cost is $\$ 149.80$. This difference in cost $(\$ 33.53)$ is statistically significant at $\mathrm{p}<0.001$ and is found mainly in the provider cost where the cost of a visit to a physician is $\$ 144.77$ and the cost of a visit to a PA is $\$ 98.77$ (statistically significant at $\mathrm{p}<0.001$ ). There is no significant statistical difference in medication, imaging, or laboratory cost between the two providers in the aggregate. No pediatric episodes of shoulder tendinitis were recorded. The number of visits in an episode is the same for physicians and PAs, and about 10 percent of patients returned for a second visit.

The ANOVA results identify wide variations in resource use by provider in the management of shoulder tendinitis $\left(F\right.$ value $\left.=4.17 ; \mathrm{R}^{2}=0.045\right)$. This is also seen in the general linear model where the standard deviation cost of some resources are large. For example, the standard deviation of medication cost ranged as much as 2.5 times the mean costs of an episode in some cases. When the two providers are examined by department we find wide variations in all medical resources without any trend in efficiency in one type of provider over the other.

Covariants are also examined to see what effect they may have. The rank order of significant covariants is: 
- Type of Provider (PA versus physician)

- Age of Patient

- Gender of Patient

- Health Status (CDS)

$$
\begin{aligned}
& p=0.0008 \\
& p=0.1106 \\
& p=0.4489 \\
& p=0.6797
\end{aligned}
$$

The inclusion of control variables and covariants has very little effect on the results and only accounts for 4.5 percent of the analysis model. From this analysis, the conclusion is that the outcome of an episode of shoulder tendinitis is less expensive when a PA manages the patient than when a physician manages the patient. This seems to be the case regardless of the medical resources used and the type of patient seen.

The multivariate analysis centers on the simultaneous analysis of several independent variables rather than a dependent variable. A number of generalizations emerge from this analysis technique. The provider cost and total cost of a visit (resource cost plus provider or visit cost) to a PA is always less than a similar visit to a physician. While this was an episode-based approach to examine differences, no 
TABLE 28

MULTIVARIATE REGRESSION COST MODEL HOLDING DIFFERENT VARIABLES CONSTANT WHILE EXAMINING FOR DIFFERENCES BETWEEN TYPES OF PROVIDERS

\begin{tabular}{|c|c|c|c|c|c|c|}
\hline PROVWER & $\mathbf{N}$ & $\begin{array}{c}\text { TOTAL } \\
\text { COST }\end{array}$ & $\begin{array}{l}\text { PROV } \\
\text { COST }\end{array}$ & $\begin{array}{l}\text { MED } \\
\text { COST }\end{array}$ & $\begin{array}{c}\text { MMAGE } \\
\text { COST }\end{array}$ & $\begin{array}{l}\text { LAB } \\
\text { COST }\end{array}$ \\
\hline \multicolumn{7}{|c|}{ BRONCEITIS EPISODE COSTS } \\
\hline PHYSICIAN & 1336 & $\$ 234.74$ & $\$ 133.63^{*}$ & $\$ 96.42 * *$ & $\$ 3.31$ & $\$ 1.37$ \\
\hline $\begin{array}{l}\text { PHYSICIAN } \\
\text { ASSISTANT }\end{array}$ & 411 & $\$ 224.13$ & $\$ 92.23^{*}$ & $\$ 125.74^{* *}$ & $\$ 4.65$ & $\$ 1.50$ \\
\hline \multicolumn{7}{|c|}{ TENDINITIS EPISODE COSTS } \\
\hline PHYSICIAN & 264 & $\$ 183.33^{* *}$ & $\$ 144.77^{*}$ & $\$ 30.14$ & $\$ 7.50$ & $\$ 0.93$ \\
\hline $\begin{array}{l}\text { PHYSICLAN } \\
\text { ASSISTANT }\end{array}$ & 90 & $\$ 149.80^{* *}$ & $\$ 98.77^{*}$ & $\$ 40.65$ & $\$ 9.53$ & $\$ 0.84$ \\
\hline \multicolumn{7}{|c|}{ OTITIS MEDIA EPISODE COSTS } \\
\hline PHYSICIAN & 6246 & $\$ 188.39^{*}$ & $\$ 140.07^{*}$ & $\$ 47.77$ & $\$ 0.0$ & $\$ 0.54$ \\
\hline $\begin{array}{l}\text { PHYSICIAN } \\
\text { ASSISTANT }\end{array}$ & 2008 & $\$ 136.60^{*}$ & $\$ 83.29^{*}$ & $\$ 52.99$ & $\$ 0.0$ & $\$ 0.32$ \\
\hline \multicolumn{7}{|c|}{ UTI EPISODE COSTS } \\
\hline PHYSICIAN & 1633 & $\$ 262.17^{*}$ & $\$ 142.73^{*}$ & $\$ 83.91$ & $\$ 17.67^{*}$ & $\begin{array}{l}\$ 17.86 \\
* *\end{array}$ \\
\hline $\begin{array}{l}\text { PHYSICIAN } \\
\text { ASSISTANT }\end{array}$ & 878 & $\$ 210.50^{*}$ & $\$ 97.70^{*}$ & $\$ 91.50$ & $\$ 5.80^{*}$ & $\begin{array}{l}\$ 15.48 \\
* *\end{array}$ \\
\hline TOTAL & 12,866 & & & & & \\
\hline
\end{tabular}

Note: * Significant at $p<0.001 ; * *$ Significant at $p<0.01$ 
differences emerged in number of visits in an episode by provider for each diagnosis to make one provider less efficient than the other. When provider differences by diagnosis are examined bronchitis, OM, and tendinitis resource use (imaging, medication, and laboratory) are more similar than different. In the UTI, OM, and tendinitis analyses PA costs are significantly less than physician costs. The large number of visits per type of provider (within a department and by diagnosis) and the statistical powers of differences lends credibility to the observations and conclusion that PAs do not differ from physicians to a great extent in the aggregate in how they manage similar patients. Nor do the attributes of patients seem to make much difference in the analysis of variance between patients seen by PAs and patients seen by physicians when diagnoses are held constant.

\section{SUMMARY OF RESULTS}

In summary, over 12 separate steps were undertaken to identify a research population and to adjust for any differences between types of patients managed by PAs and physicians. This was followed by assigning costs to all parts of the visit including medication, laboratory, and imaging orders. The results were analyzed by one-way analysis of variance and Chi-square tests. A logistic regression analysis for the association of different variables having an influence on patient differences was 
performed. From this analysis a number of findings emerged. Wide variations in costs for an episode of an illness exist and these variations are found regardless of the type of provider, the medical department, the medical resources used, or the type of patients seen. Providers (PAs and physicians) tend to have cases of OM return to the medical office about one-fifth of the time, either by design or by the nature of the condition. The other conditions (shoulder tendinitis, bronchitis, and UTIs) tend to be treatable with a single visit; return visits occur with less regularity and frequency.

Patients with the diagnosis of OM, UTI, tendinitis, or bronchitis are likely to have a number of diagnostic and therapeutic orders generated by their providers. All orders represent an expense and contribute to the cost of an episode of a visit. These costs are revealed in this study as sometimes significantly different depending what type of provider is managing the patient. However, at no time is the total cost of a visit, the sum of all the resources for an episode, to a PA more than the cost of a visit to a physician when examined separately by department. Multivariate analysis results find that PAs remain less costly for all total visit costs even after controlling for variables that impact the cost of an episode of an encounter. In some instances PAs use less resources than physicians, improving their cost-benefit profile. The significance of these results is discussed in the next chapter. 
CHAPTER V

DISCUSSION 


\section{CHAPTER V}

\section{DISCUSSION}

In this chapter the results of the analysis (Chapter IV) are discussed as are the implications of the findings. First, the significant results are interpreted from the standpoint of health services research and management implications. Next, the policy implications of the results are discussed.

The research question asks: Are PAs cost-beneficial to their employers? There are many types of PA employers - the federal and state governments, for-profit physician or hospital groups, non-profit HMOs, and others. This study focused on one type of employer - a non-profit HMO that employs many PAs and uses many innovative labor and technical strategies to deliver quality care without compromising the safety or the satisfaction of the patient.

The hypothesis is that $P$ As are cost-beneficial to employers for delivering primary care medical services for common acute conditions. From the research conducted over the last two decades we know that PAs are cost-effective in many settings. The salary of a PA is approximately half of a physician's salary in a primary care department. When employee benefits such as vacation, health insurance, medical education reimbursement, and other perquisites are considered, the physician's compensation differences are even larger, placing the PA at approximately 45 percent of the total compensation of a physician. 
PAs are adaptable to almost any work environment. They are utilized in many medical settings and there is virtually no unemployment of PAs. Sufĩce it to say that PAs would not be employed today if they were not cost-effective. As of 1998 there are over 34,000 PAs employed and there seems to be continuing a strong market for their employment, at least in the near future \{AAPA 1998; Hooker 1997\}.

There are other indicators of PA cost-effectiveness within KPNW. In the health plan, the patient satisfaction after seeing a PA is the same as a visit with a physician \{Hooker 1997\}. This suggests that PAs are being valued the same way as physicians from the patient's perspective. If patients were less satisfied with the care delivered by a PA, their value to the health plan would be less. When productivity is examined, KPNW PAs have the same or higher productivity in seeing nonhospitalized patients on an annual and hourly basis than physicians \{Hooker 1989\}. PAs have approximately a 5 percent annual tumover making them reliable employees (personal communication Judy Parmenter, KPNW Provider Recruitment). When types of patients are viewed from a diagnosis standpoint, there is no appreciable difference between types of patients managed by PAs and physicians. The overlap by diagnosis between PAs and physicians in the Departments of Family Practice and Internal Medicine is approximately 90 percent \{Hooker 1989\}.

There have been discussions as to whether PAs negate some of their costeffectiveness by ordering resources differently in the management of patients as compared to physicians \{Moore 1994\}. One critique, Moore, is an academic physician who has made a number of contributions in the health services literature. 
While his beliefs are highly respected his opinion in this regard is not necessarily grounded in the literature. Other instances of concern about PA practice have been addressed by lawmakers. In Maryland, legislation granting PAs prescribing authority has been stalled since 1990 because a few physicians in the state congress believe that PAs may not be cost-beneficial to Maryland citizens in the long run \{Cohen 1995\}.

\section{INTERPRETATION OF RESULTS}

In this study, the analysis supports the hypothesis that "PAs are cost-beneficial to employers for delivering primary care medical services for common acute conditions." Results presented in the previous chapter of this study indicate that the total cost for an acute primary care episode is less costly when managed by a PA than by a physician within the same department. In examining four different diagnoses that are seen at high frequencies within the KPNW health plan, at no time did PAs incur a higher "total visit cost" for an episode of a condition than physicians. In some instances the cost savings were not only in the visit cost, which is lower because of PA salaries, but the cost of resources was either the same or less than incurred by physicians. This has significant implications for employers and potential employers of PAs.

In addition to the primary finding - that PAs are cost-beneficial to their employer - some of the variables suggest some interesting conclusions. 


\section{Bivariate Results}

In a single bivariate comparison between physicians and PAs examining four commonly seen primary care diagnoses, a large number of encounters were studied (greater than 260,000 encounters in 1997). These encounters represent almost 10 percent of the 2.6 million encounters for KPNW health plan members in 1997 . When rigorous selection criteria were applied the numbers were reduced. The reduction by selection criteria occurred more or less equally across both types of providers.

Overall, these diagnoses seem appropriate to study because there is little inherently different in the patients with these diagnoses who are seen by physicians and PAs. While physicians are trained differently in the postgraduate phase of medical education leading to a career in pediatrics, internal medicine, or family practice, the way they manage the patients with these four diagnoses is more or less similar, within and across those departments. While this observation is interesting in and of itself, it is also interesting to note that PAs in these departments seem to be practicing in a manner similar to physicians as well. Clearly there are style differences and variations in practice which may represent inefficiencies in practice. However, these style differences and variations seem to be dispersed among providers, are not systematic, and are not confined to one type of provider or another.

Prior to examining for patient differences between types of providers, the use of resources within a diagnosis was examined. The use of resources is an important aspect of health care delivery if costs are to be contained. All diagnoses examined in this study consume many types of medical resources: office visits, provider's time, 
diagnostic services such as laboratory and imaging services, medication and procedures; and other support services. This may be the first study that systematically examined all of these resources from both institution and episode standpoints. The approach to this study helps us to understand the aggregate cost of a visit for an episode of an illness. This, in turn, helps us to understand that the PA's salary makes less difference in the cost of an episode than was previously theorized.

\section{Multivariate Results}

There are significant differences in the total cost of an episode when PAs and physicians are compared for treatment of shoulder tendinitis, OM, and UTI - PA episodes (and visits) are less costly. The difference in the total cost of bronchitis managed by PAs or physicians is not very large and does not reach a statistical level. When the differences in the resource cost of various diagnoses are examined, the differences are not consistent throughout all diagnoses. In an effort to identify other causes of these differences covariates were included for greater explanatory power. After controlling for various differences via multivariate logistic regression, some differences in the cost of an episode of an illness did emerge prior to inserting the salaries that determine the visit cost. Adult practice PAs (IM and FP departments) tended to use slightly more expensive medications in the aggregate than their physician departmental colleagues for acute bronchitis, acute OM, and tendinitis episodes of care. If physicians are held as the standard of care, then these differences range from approximately $\$ 18$ to $\$ 23$ for PA-generated prescriptions. However, only 
at the bronchitis encounter was this difference statistically significant. The mean cost of a physician medication treatment was $\$ 96.42$, and the PA cost was $\$ 125.74$. Interestingly, this difference still becomes absorbed at the visit cost difference level (Physician $=\$ 133.63 ; \mathrm{PA}=\$ 92.23, \mathrm{p}<0.01$ ), making it negligible at the total cost tabulation. The physician's total cost was $\$ 10$ higher than the PA's, which was not statistically significant.

In the UTI analysis, all of the physician costs are higher than the PA costs across the board including the total cost, visit cost, medication, imaging, and laboratory costs. The imaging costs for PAs are one-third what they are for physicians, and the lab costs for PAs are less than for physicians by more than $\$ 2$. All of these observations are statistically significant making PAs more cost-effective than physicians for this condition.

Converting all benefits into dollar amounts is a requirement of cost-benefit analysis. The benefit to the organization is the cost savings due to employing PAs. In the four diagnoses examined, the dollar amounts of cost savings range from $\$ 10.61$ to $\$ 51.79$ when a PA manages an episode of an acute illness (Table 28). If PAs were not present in this organization, the added cost of a physician managing the care would be substantial and the cost would be shifted to the patient in terms of higher premiums or a reduction in insurance benefits.

One of the unique features and strengths of this study is the adjustment for an uncertainty that studies on comparisons among types of physicians have had to overlook. This is the adjustment for different comorbidities among patients. Studies 
have examined the differences in physician practices in many different ways: urban versus rural physicians, older versus younger, female versus male, group versus solo practitioners, and internists versus family practitioners \{Rieder 1990; Bertakis 1993\}. Even when the patient demographics are controlled and studies are rigorously conducted, the same uncertainty emerges - the patients may be different because of individual sets of complex medical problems \{Bertakis 1993\}. This has also been a dilemma in studies about patients of PAs. It has been suggested that PAs may be "skimming" off the easier-to-treat patients leaving the more complex patients to physicians \{Hooker 1986; Moore 1994\}. Critics believe the results of these comparative studies between types of providers remain inconclusive until health status can be accounted for Peterson 1997; Poses 1995; Grumbach 1996\}. The use of the CDS is a convenient tool that attempts to overcome some of this uncertainty.

The use of the CDS as the index for health status strengthens the observation that, within the acute primary care setting, PAs are seeing patients that are little different from patients seen by physicians - at least in the KPNW system where no financial or other barriers to access exist. The CDS for patients in this sample of the membership was low in the aggregate though scores ranged from zero to 17 . The mean health status scores of the patients seen by PAs and physicians were almost identical. Even if the average differences had been one or two points, it is not clear whether this would reflect significant differences in patient types. The fact that the average health status scores for both types of providers were almost the same reflects that patients seen in an acute care setting are relatively healthy, and most probably have single diagnosis encounters or episodes. It also points out that patients are not 
sorting themselves out to be seen by one type of provider over the other based on their health status. One interpretation is that primary care provider practices tend to be similar within an organization where providers work together closely, and share offices, support staff, and medical records. Some patients may choose to see view their doctor as Kaiser instead of the individual physician and thus are largely indifferent to whom they see at a visit.

While patient attributes are the same or similar between PAs and physicians there are wide differences in how patients are managed that transcends provider type. The use of laboratory or x-ray diagnostic studies vary widely. The types of medications dispensed or return visits for a diagnosis seems to fit no obvious patterns. Discussion with different providers failed to identify reasons for these variations in practice style as well. These observations are important to mention but may have to wait for more systematic studies to determine why they occur.

The beneficial effect of employing PAs in a large HMO has not been an isolated observation. Hummel and Pirzada (1994) attributed the economic effect of a reduction of the per member per month cost solely to employing PAs in primary care at Group Health Cooperative of Puget Sound. They estimated that PA-physician teams could see more patients in the aggregate and result in savings of $\$ 1.38$ per member per month. This was projected to approximately $\$ 1.65$ million 1993 dollars per 100,000 enrollees per year.

Overall this study brings together a number of observations for organizational effectiveness and health care benefits for the KPNW membership. Under the current 
organizational arrangement, approximately 10 percent of all primary care within KPNW is delivered by PAs. If we simply multiply the allocation cost for each of the four diagnoses by the number of times each diagnostic event was seen in 1997, we arrive at a figure of over $\$ 54,000,000$ (262,490 office visits sorted by the number of visits for each diagnosis and multiplied by the average total cost for each diagnosis). If the organization chose to shift an additional 10 percent of these encounters to PAs, and if PAs could maintain their cost-benefit to the organization for each of the four diagnoses, the savings would exceed \$6 million annually. Using a second scenario, if PAs and physicians within a department developed a strategy that selected the most economical cost savings in the allocation of resources used for each diagnosis (excluding the provider or visit cost), the savings would be over $\$ 5$ million annually. Finally, under a third scenario if purchasing authorities within the organization would partner with the managers of primary care departments to explore other cost saving strategies, the annual cost savings could probably be even greater by examining other commonly seen diagnoses.

Overall this study offers evidence of benefit from employing certain types of providers within a large organization. In the aggregate it appears PAs practice surprisingly similar to their physician counterparts within the same department. The study supports the belief that PAs are good economical substitutes for physicians in select roles and counters the notion that they are somehow not as effective or efficient in an episode of care. However imperfect these methods may be, they are superior to the alternative, which is global subjective human judgment unaided by formal analysis. Additional studies are needed to support these findings. 


\section{POLICY IMPLICATIONS}

In this study the hypothesis that $P A s$ are cost-beneficial to employers for delivering primary care medical services for common acute conditions has been supported by the analysis. More specifically, PAs do not erode their costeffectiveness by ordering resources differently than the physicians they are associated with, at least in acute primary care conditions seen frequently by both types of providers. At times they are more efficient in their use of resources for an episode of an illness by ordering less resources. At other times, they are less efficient than physicians in their resource use. However, in the aggregate, they refer patients, order laboratory, imaging studies, and medications similar to physicians for the same diagnoses when numerous variables are held constant. These findings have strong policy implications, for they validate the inherent belief of many PAs -- that they make unique contributions to society that are not fully realized \{Carter 1997\}. From a social perspective, PAs cost approximately one-fifth to one-fourth as much to educate as physicians, begin producing medical care delivery after two years versus eight years for a physician, and the employment efficiency may be one of the highest of all providers in primary care \{MGMA 1997; Hooker 1997\}. It appears the federal government has received a significant return from the investment in PA education in that PAs provide unique and substantial cost differences in how they manage patients compared to physicians. This is true in this study of four diagnoses, and is true for other studies cited earlier. 
From an institutional perspective it appears that PAs practice acute primary care more cost-effectively and more cost-beneficially than physicians. Whether this fact is the result of organizational influences or some other inherent factor remains to be determined. Wide variations in practice style and resource use exist within the organization, but once the patient experiences an encounter with a PA, the outcome will be much the same as with a physician. The patient will experience the same satisfaction from the visit as if she or he were seeing a physician, and the allocation cost to the employing institution will be less overall.

How applicable these findings are to other organizational settings remains to be seen since the regulator and social planner often make different valuations of costs. For example, the hospital perspective requires careful consideration of different cost centers such as the pharmacy department which acquires and administers a drug than an outpatient-based HMO. Handling the drug by pharmacists, ward personnel, and nurses add to the cost. A for-profit insurer may view the incremental costs from the cost of the drug alone (even if the drugs are perfect substitutes) since the insurer only sees the cost from a single visit perspective sometimes and may reimburse the patient for indirect expenses other times making comparisons difficult. In another example the federal government may view the episode of care with little consideration of the indirect expenses to the patient, such as in Medicaid and Medicare reimbursement rates. The for-profit solo practitioner who owns a laboratory may view the employment of the PA differently if the practice depends upon return visits and laboratory-generated fees. Finally, the capitated managed care organization may view the referral rate differently than in this study and charge the practice with the cost of a 148 
referral as a deduction of the reimbursement or capitated rate. While each of these organizational settings will account for costs of resources differently all organizations share the goal of maximizing total medical costs, which is often espoused in the costbenefit literature \{Hollenberg 1988; Podrid 1991; Weiner 1996\}. The added value of this study is that it offers a consistent model for studying cost centers the same way regardless of the organizational setting.

The findings from this study suggest that PAs may be underused in this medical care system. This study also underscores numerous other cost-effectiveness studies that find the employment of PAs an economical strategy for organizations of all types. Since the findings of this study favor PA employment from an economic standpoint, there may be room for greater substitution of physician services - at least in this setting,. Other areas of cost savings in PA employment may exist in KPNW since PAs are not used in all departments. Staffing changes seems to occur more slowly in some areas of physician management than others. Historically it is the physician organization that controls the number and type of personnel providing physician-type services not the business managers.

Based on these findings and the associated literature, policy mechanisms for increasing the employment of PAs should be encouraged. Most health care encounters are time-and labor-intensive in American society and reimbursement is maximized through volume, which requires time minimization. Policymakers at the federal and state level could create financial incentives that would equally distribute medical training costs so PA programs could reduce education costs and improve training in 
medically underserved areas. The details of such incentives are beyond the scope of this study, but it is fair to speculate that if five percent of all federal Medicare dollars currently devoted to graduate medical education were diverted to PA education more PAs could be trained with financial obligations to work in rural and underserved area. This has enormous policy implications for American citizens since more underserved citizens would have greater health care access.

Finally, health organizations such as Kaiser Permanente stand to gain much from the increased employment of PAs (and other economical providers such as advanced practice nurses). These findings indicate substantial economical differences when PAs are used in primary care. For example over 78,000 visits are made annually to $\mathrm{KPNW}$ for management of $\mathrm{OM}$ alone. There is good reason to believe that almost all of these visits could be managed solely by PAs, safely, unsupervised, and with significant patient satisfaction. The annual cost savings would be over $\$ 160,000$ just for this strategy alone.

In conclusion, PAs are not only cost-efficient but also cost-beneficial to those who employ them and probably to society as well. Medical education, institutional policy and health care reimbursement policy should be reexamined and reformulated to improve PA utilization. 


\section{CHAPTER VI}

\section{CONCLUDING REMARKS}


This study verifies that, in certain institutions, PAs are used in large numbers because they provide some value to the system \{Ballweg 1998\}. Most of the rationale for their employment has been either a significant cost difference in salary or because they are easier to employ and deploy than physicians. Within this organization, they are employed in primary care and see a proportion of primary care disorders similar to physicians \{Hooker 1986\}. That they do this with little differentiation of patients suggests that delegation of this role appears to be an effective strategy to deliver economical care. It also appears to be beneficial to the health plan as a labor saving device that does not compromise safety. The benefits to the membership are in the cost savings, thus allowing resources to be used elsewhere which holds down membership premiums. The observation of acute conditions linked to primary care PAs and physicians does not seem to be any different for the two providers. This reinforces the results of other studies that show that PAs are substituting for physician services in many instances. This observation has strong implications that PAs are substituting for physician services (not complementing physicians) because they are practicing the same way and with the wide range of style differences and practice variations as seen in physicians.

\section{Study Limitations:}

While this research effort examines an area of health workforce economics not previously studied - cost benefit analysis of PA employment - all research has its 
limitations. First, the areas of provider style and variations in practice are not fully explored in this study. A great deal is known about the practicing behavior of physicians and how they differ in the use of resources. Age, gender, length of service, and type of training are known to make large differences in how and what physicians order and what conditions they treat. A study that addresses these attributes may find more interprovider differences in style and substance of practice than was revealed in this study. Issues such as utilization bias, provider variations in test ordering patterns, and secular trends in prescribing patterns need to be explored. While this is a perceived limitation, other studies have shown that physicians within a group tend to provide care more or less the same over time when certain variables are held constant. We may find the same holds true for PAs. This is clearly an area for further study.

The multi-stage population selection used in this study produces a research population that may differ from the KPNW population slightly. To be in this study, patients had to be younger than 65 and have only one diagnosis for an episode of care. The patient had to be enrolled in the health plan for one year on either side of the episode. This probably produces a representative Kaiser Permanente member, but this member is not representative of an older or more transient population.

In this study, a patient was selected by having one diagnosis per visit. This was to determine the use of resources for that episode. The reduction of cases to only those with a single diagnosis may have altered the population toward one type of provider over another. This theoretical consideration was explored in this study to some extent. A random selection of medical records that fell out of the study criteria 
were compared to those within the criteria defined population. There were no differences in the exclusion versus the inclusion in terms of age, gender, CDS, and referral. Most of the diagnoses that were used for the criteria had little if anything to do with the diagnosis of interest. Examples include smoking, Tinea pedis, hysterectomy, or some issue that may have come up to discuss in the visit but did not impact the resources assigned to the diagnosis. While future studies could try to control for this strict criteria selection by determining if PAs diagnose the same number of conditions as physicians per visit, there is little to suggest that a larger study population would be any more representative of the population at large.

A possible limitation is that some untoward bias may have been inadvertently introduced when undertaking and analyzing this work due to the fact that the author is a PA. All means to guard against the possibility of bias were employed. The use of aggregated data that fulfills certain predetermined criteria and the use of population statistics are usually considered safeguards against this effect. The author also had the benefit of the dissertation committee acting as a monitor to avoid introducing any halo effect in the interpretation of the results.

This study could be modified to fit other nonprimary care settings in subspecialty medicine or surgery. PAs in neurology, rheumatology, geriatrics, orthopedic surgery, and emergency medicine could be examined with the same rigors of methodology established in this model.

Replicating this study would help determine if the findings remain valid. Expanding the study to include nurse practitioners (NPs) and certified nurse midwives, 
as well as physicians and PAs, as providers of interest would identify other cost efficiencies. All of these different types of providers are used extensively within this organization, as well as across the United States in similar settings, making this study feasible for other organizations. This research did not include advance practice nurses because of the complexity of the study in comparing just two types of providers. The benefits of excluding other types of providers was that it afforded the opportunity to examine PAs in greater depth, introduce the health status variable in the model, and to develop a model for future studies. The author believes that all providers within an organization tend to practice similarly over time, and that patients tend to care little, if any, who the provider is as long as their needs are being met \{Hooker 1997\}.

One last limitation to this research should be noted. Since this study used a number of clinical and administrative data sources, some of the coding and grouping of data were predetermined. As in all social science research on human subjects that is derived from large databases, details on individual behavior tend to become aggregated and averaged. While it is felt that the results of this study are methodologically sound, the reader should keep these limitations in mind when critically analyzing the results of this research.

\section{Suggestions for Further Study:}

This study succeeded in answering the research question posed: PAs are costbeneficial to those who employ them. However, some of the study limitations are 
potentially important and deserve attention. Not surprisingly, this study raises other questions that are worth addressing.

Two of the limitations should be examined in future studies. First, a study should examine a wider range of conditions managed by physicians and PAs to see if the range of diagnoses and frequency of diagnoses as similar. We should understand the full extent of the value that physicians bring to a practice. Clearly, they are assuming the care for the more complex cases and doing this with some regularity. Presumably, this work is over and above what PAs are doing. Generating and comparing a list of diagnoses along with the frequencies of these diagnoses for both physicians and PAs would show where the overlap lies in the services they are providing and where the differences are. This would come closer to understanding the extent of physician substitution by PAs.

Another study should examine to what extent PAs manage chronic conditions independently from physicians to determine the extent of that area of substitution versus team effort. This study examined acute primary care conditions. Understanding the role of the PA in long-term outpatient-based care may find areas of greater efficiencies and divisions of labor not fully understood.

Finally, a study should examine if the use of PAs in the management of chronic conditions improves the outcome or cost of care in any way. This would entail assigning some value for each visit to a separate provider in the long-term use of both types of providers managing a chronic episode of illness such as hypertension, congestive heart failure, osteoarthritis of the knees or some other condition. These 
studies would help satisfy questions about whether team approaches to management of care improves patient well-being.

Similar studies need to be undertaken with nurse practitioners and certified nurse midwives. Aside from PAs, these two types of providers are in roles that substitute for traditional physician services. Some differences may emerge when these types of providers are included in the equation. Understanding more subtle styles and variations with a richer mix of providers in the equation of an episode of care may yield different approaches to the patient that are more cost-effective.

Since the early 1990 s there has been a growing realization that new approaches must be found in the allocation of resources devoted to personal health care services. How does a particular encounter enrich the quality of life for a patient and what value do we place on that? On the whole, having an index of quality of life is important but difficult to document when examining health care costs. One method that has found some usefulness to this complex type of question is cost utility analysis. Cost utility analysis is an economic tool that goes beyond cost-benefit analysis and examines the components of health care cost using quality assessment of life years (QALY). To evaluate health-related quality of life, one must consider all of the different ways that illness and treatment affect outcome. The provider visit, medical resources, and indirect costs, patient's support, other variables go in the equation. The QALY documents how much has been gained by the patient in the encounter. It would be useful to quantify if PAs differ from physicians in the way they impact patient QALY. If we could quantitatively assign some value that a PA brings to patients overall health 
through the care they receive, we could then better appreciate their utility. Unfortunately, there is currently a lack of consensus about which QALY measures to use. Further work on the QALY measures, preferably by interdisciplinary teams sensitive to the alternative disciplinary perspectives, is likely to be fruitful and will produce better measure. Since it appears that no one disciplinary perspective is as yet able to provide all the answers, policymakers need to be included in those teams. The dual problem of rising health care expenditures and pressures on public budgets is not unique to any country, so these studies need to transcend other societies as well if they are to have widespread utility.

\section{EXECUTIVE SUMMARY}

\section{Background:}

The purpose of this study is to determine if physician assistants (PAs) are costbeneficial to those who employ them. In an era of cost accountability, some have raised questions about whether a visit to a PA for an episode of care differs from a visit to a physician, and if PAs negate their cost-effectiveness in any way by the manner in which they manage patients.

\section{Method:}


An episode approach was undertaken to identify four common acute medical conditions seen by PAs and physicians within a large health maintenance organization. All orders and medications were identified for each diagnosis, assigned to each type of provider, and separated by departments of family practice, internal medicine, and pediatrics. Patient variables considered most important for comparison of practices were age, gender, and health status. A multivariate analysis was undertaken using a large list of variables in a medical office visit to see where there may be significant cost differences among cohorts of patients. 
Results:

In every condition managed by PAs, the total cost of the episode was less than that of a physician in the same department. This was statistically significant for episodes of shoulder tendinitis, otitis media, and urinary tract infections. In no instance were PAs statistically different from physicians in greater use of laboratory and imaging costs and, in some instances, PAs ordered fewer laboratory tests than physicians. Only in bronchitis was more expensive medication prescribed by PAs than physicians did. In every instance, the PA's total cost of an episode of an acute primary care illness managed by a PA was less than a physician. There were no differences between physicians and PAs in the rate of return visits for a diagnosis. Patient differences were held constant for age, gender, and health status.

\section{Conclusions:}

This study confirms that PAs are not only cost-effective from a number of standpoints but are also cost-beneficial to those who employ them, when compared to physician cohorts in primary care seeing patients with select acute medical conditions. PAs tend to diagnose and treat patients for an episode of care in a manner similar to physicians. However, the total cost of an episode of care is more economical overall when the PA delivers the care. This study validates the federal policy of support for PA primary care education and suggests that PA employment should be expanded in many sectors of the health care system. These findings and the results of its application to a risk-adjustment model to predict health care costs are evidence of its predictive validity. 
BIBLIOGRAPHY

161 


\section{BIBLIOGRAPHY}

American Academy of Physician Assistants. The Development of Standards to Ensure the Competency of Physician Assistants. American Academy of Physician Assistants, Arlington, VA, 1979.

American Academy of Physician Assistants. Information on The Physician Assistant Profession. Physician Assistant Educational Programs. Alexandria, VA: September, 1998a.

American Academy of Physician Assistants. 1997 AAPA Physician Assistant Census Report. Alexandria, VA 1998b.

American Academy of Physician Assistants. General Census Data on Physician Assistants: 1995. Alexandria, VA 1996a.

American Academy of Physician Assistants. 1991-1995AAPA Mermbership Census Report. Alexandria, VA $1996 \mathrm{~b}$.

Alexander BJ, Lipscomb J. Nonphysician practitioners panel report. Page 421- 465. In Joseph Lipscomb \& Bobbie J Alexander (Eds). Physician Staffing for the VA: Volume II, Supplementary Papers. Institute of Medicine, National Academy Press. Washington, DC, 1992.

Ballweg R, Cawley J, Crane S, Davis A, Estes EH, Hooker R, Hummel J, Lindblad P, O'Neil E, Ruzek J. The Physician Assistant Task Force on the Impact of Managed Care. Charting a Course for the $21^{\text {st }}$ Century: Physician Assistants and Managed Care. A Joint Report of the Pew Health Professions Commission and the Center for the Health Professions, University of Califomia, San Francisco, CA. 1998. 
Barry HC, Ebell MH, Hickner J. Evaluation of suspected urinary tract infection in ambulatory women: a cost-utility analysis of office-based strategies. J Fam Practice. 1997; 44(1): 49-60.

Baumol WJ, Binder AS. Microeconomics, Principles and Policy. Fifth Edition. 1991, Harcourt Brace Javonovic, Inc. Fort Worth, TX.

Bertakis KD, Callahan EJ, Helms LJ, Azari R, Robbins JA. The effect of patient health status on physician practice style. Family Medicine. 1993; 25(8): 530535.

Breslau N, Novack AH, Wolf G. Work settings and job satisfaction: A study of primary care physicians and paramedical personnel. Medical Care. 1978; 16(10): 850-862.

Carter RD, Cawley JF, Fowkes V, Hooker RS, Rackover MA, Zellmer M. Blue Ribbon Panel report on physician assistant program expansion. Perspectives on Physician Assistant Education. 1998; 9(1): 21-30.

Cawley JF. The Cost Effectiveness of Physician Assistants. Alexandria, VA: American Academy of Physician Assistants, 1986

Cawley JF. The evolution of new health professions: a history of physician assistants. in Osterweis M, McLaughlin CJ, Manasse HR, Hopper CL (Eds.). The U.S. Health Workforce: Power, Politics, and Policy. Academic Health Centers. 1996, Washington, DC.

Chin HL, Krall MA. Implementation of a comprehensive computer-based patient record system in Kaiser Permanente's Northwest Region. MD Computing. 1997; 14(1): $41-45$.

Christakis DA, Rivara FP. Pediatricians' awareness of and attitudes about four clinical practice guidelines. Pediatrics. 1998; 101(5): 825-830. 
Cohen H. Physician Assistant Pursuit of Prescriptive Authority: A Five State Analysis. Masters of Arts thesis. The Johns Hopkins School of Public Health. Baltimore, MD, 1996.

Consumer Price Index and average annual percent change for all items and selected items: United States, selected years 1960-1997. Health, United States. Bureau of Labor Statistics. http://www.ssa.gov/OAC/COLA/FR.sum.html 1998.

Cooper RA. Perspectives on the physician workforce to the year 2020. J Am Med Assoc. 1995; 274(19): 1534-1543).

Crandall LA, Santulli WP, Radelet ML, Kilpatrick KE, Lewis DE. Physician assistants in primary care. Medical Care. 1984; 22(3): 268-282.

Cromwell J. in Osterweis M, McLaughlin CJ, Manasse HR, Hopper CL (Eds.). The U.S. Health Workforce: Power, Politics, and Policy. Academic Health Centers. 1996, Washington, DC.

Cyr KA. Physician-PA practice in a military clinic: A statistical comparison of productivity/availability. Physician Assistant. 1985; 10(4): 112-113, 119, 123-124.

DeBarth K. Outer Banks PA: Medicine at the edge. Clinician Reviews. 1996; 6(7): 148-158.

Donaldson C. The state of the art of costing health care for economic evaluation. Community Health Studies. 1990; 14(4): 341-356.

Donaldson MS, Yordy KD, Lohr KN, Vanselow NA. Primary Care: America's Health in a New Era. National Academy Press. Washington, DC. 1996.

Eisenberg JM. If trickle-down physician workforce policy failed, is the choice now between the market and government regulation? Inquiry. 1994; 31(3): 241249. 
Ekwo E, Daniels M, Oliver D, Fethke C. The physician assistant in rural primary care practices: Physician assistant activities and physician supervision at satellite and non-satellite practice sites. Medical Care 1979; 17(8): 787-795.

Fargason CA, Bronstein JM, Johnson VA. Patterns of care received by Medicaid recipients with urinary tract infections. Pediatrics. 1995; 96(4 Pt 1): 638-642.

Feldstein PJ. Health Care Economics, Third Edition. 1988. Delmar Publishers, Inc. Albany, NY.

Feldstein PJ. Health associations and the legislative process. In Litman TJ, Robins LS (eds.) Health Politics and Policy; 2nd edition. Delmar Publishers, Inc., Albany, New York. 1991

Franks P, Nutting PA, Clancy CM. Health care reform, primary care, and the need for research. J Am Med Assoc. 1993; 270(12): 1449-1453.

Freeborn DK, Pope CR. Promise and Performance in Managed Care: The Prepaid Group Model. 1994. The Johns Hopkins University Press. Baltimore, MD

Frick, JE. Physician assistants as house officers: our experience. Physician Assistant. $1983 ; 7: 13-16$.

Gara N, Coombs B. The national practitioner data bank:a registry for reporting disciplinary action. J American Academy of Physician Assistant. 1990; 3(8): $641-645$.

General Accounting Office. Comptroller General of the United States: Report to the Congress: Progress and Problems in Training and Use of Assistants to Primary Care Physicians. DHEW Publication No MWD 75-35. Washington, DC, General Accounting Office, 1975.

Gilliam JW. A contemporary analysis of medicolegal concerns for physician assistants and nurse practitioners. p.p. 133-180. 
Golladay Fl, Miller M, Smith KR. Allied health manpower strategies: Estimates of the potential gains from efficient task delegation. Medical Care. 1973; 11: 457-469.

Golladay FL, Smith K, Davenport E, et al. Policy planning for mid-level health workers: Economic potentials and barriers to change. Inquiry. 1976;13:8089.

Goodman DC, Fisher ES, Bubolz TA, Mohr JE, Poage JF, Wennberg JE. Benchmarking the US physician workforce: an alternative to needs-based or demand-based planning. J Am Med Assoc. 1996; 276 (22): 1181-1817.

Gonzalez R, Sande M. What will it take to stop physicians from prescribing antibiotics in acute bronchitis. Lancet. 1995; 18(345: 665-666.

Goupille P, Sibilia J. Local corticosteroid injections in the treatment of rotator cuff tendinitis (except for frozen shoulder and calcific tendinitis). Clinical and Experimental Rheumatology. 1996; 14(5): 561-566.

Greenfield S., Komaroff ȦL, Pass TM, et. al. Efficiency and cost of primary care by nurses and physician assistants. New Eng J Med. 1978; 298(6): 305-309.

Greenlick MR, Freeborn DK, Pope CR (eds.). Health Care Research in an HMO: Two Decades of Discovery. Johns Hopkins Press, 1988. Baltimore, MD.

Grumbach K. Quality of primary care practice at a large HMO: comparison by physician specialty and sex. Association for Health Services Research and the Foundation for Health Services Research Annual Meeting Abstract Book. $1993 ; 13: 43-44$.

Hale JA, Hunter MM. 1988. From HMO Movement to Managed Care Industry: The Future of HMOs in a Volatile Health Care Market. Excelsior, MN. InterStudy. 
Hansen JP, Stinson JA, Herpok FJ. Cost effectiveness of physician extenders as compared to family physicians in a university health clinic. J Am Coll Health Assn. 1980; 28: 211-214.

Harbert K, Shipman RA, Conrad W. The utilization of physician extenders: Mid-level providers in a large group practice within tertiary health care setting. $M G M$ Journal. 1994, 26, 28, 49, 50, 52, 54.

Hart LG, Wagner E, Pirzada S, Nelson AF, Rosenblatt RA. Physician staffing ratios in staff-model HMOs: a cautionary tale. Health Affairs. 1997; 16(1): 55-70.

Henderson T, Chovan T. Removing Practice Barriers of Nonphysician Providers: Efforts by States to Improve Access to Primary Care. Intergovernmental Health Policy Project. The George Washington University, Washington, DC. 1994.

Heinman RA, Bluhm WT, Peterson SA, Kearny EN. The World of the Policy Analyst: Rationality, Values, and Politics. 1990; Chatham House Publishers, Inc. Chatham, NJ.

Henry RA. Evaluation of physician's assistants in Golchrist County, Florida. Public Health Reports. 1974; 89: 429-432.

Hollenberg JP, Lubak LL, Ferry JJ, Bussel JB. Cost-effectiveness of splenectomy versus intravenous gamma globulin in treatment of chronic immune thrombocytopenic purpura in childhood. Journal of Pediatrics. 1988; 112(4): 530-539.

Hooker RS. Medical care utilization: MD-PA/NP comparisons in an HMO. In: Physician Assistants: Their Present and Future Models of Utilization. Zarbock S. Harbert K. (Eds). New York: Praeger Publishers, 1986. 
Hooker RS, Freeborn DK. Use of physician assistants in a managed health care system. Public Health Reports. 1991; 106(1): 90-94.

Hooker RS. The roles of physician assistants and nurse practitioners in a managed care organization. In Clawson DK, Osterweis M (eds). The Roles of Physician Assistants and Nurse Practitioners in Primary Care. 1993; Association of Academic Health, Centers, Washington, DC.

Hooker RS. PAs and NPs in HMOs. HMO Practice. 1994; 8(4): 148-150.

Hooker RS, Cawley JF. Physician Assistants in American Medicine. 1997, Churchill Livingstone, New York, NY

Hooton TM, Scholes D, Hughes JP, Winter C, Roberts PL, Stapleton AE, Stergachis A, Stamm WE. A prospective study of risk factors for symptomatic urinary tract infection in young women. N Engl Med. 1996; 335(7): 468-474.

Hummel J, Pirzada S. Estimating the cost of using non-physician providers in primary care teams in an HMO: where would the savings begin? HMO Practice. $1994 ; 8(4): 162-164$.

Johnson RE, Freeborn DK, McCally M. Delegation of office visits in primary care to PAs and NPs: the physicians' view. Physician Assistant 1985; 9(1): 159-160, 165-169.

Johnson RE, Hombrook MC, Nichols GA. Replicating the chronic disease score (CDS) from automated pharmacy data. JClin Epidemiology. 1994; 47(10): 1191-1199.

Johnson TM. Physician's assistants, their physician employers, and the problem of autonomy: consensus or conflict? J Family Practice. 1978; 6(3): 621-625.

Jones PE, Cawley JF. Physician assistants and health system reform. JAm Med Assoc. 1994; 271: 1266-1272. 
Kane RL, Olson DM, Castle CH. Effects of adding a Medex in practice costs and productivity. J Community Health. 1978; 3: 216-226.

Knickman JR, Lipkin M, Finkler SA, Thompson WG, Kiel J. The potential for using nonphysicians to compensate for the reduced availability of residents. Academic Medicine. 1992; 67(7): 429-438.

Kirscher CG, Davis SJ, Duffy C, et. al. Physicians Current Procedural Terminology (CPT 1998). American Medical Association. Chicago, IL 1997.

Kongstvedt PR. Essentials of Managed Health Care. Aspen Publications. Gaithersburg, MD, 1995

Krall MA, Mysinger T, Pearson J, Chin H, McClure P, Collins J. Integrated clinical database in a health maintenance organization. In Proceedings of the Eighth World Congress on Medical Informatics. IMIA 1995; p313-316.

Krall MA, Chin HL, Dworkin L, Gabriel K, Wong R. Improving clinician acceptance and use of computerized documentation of coded diagnosis. American Journal of Managed Care. 1997; 3(4): 597-601.

Laham N. Why the United States Lacks a National Health Insurance Program. 1993; Praeger. Westport, CN.

Lairson P, Record JC, James JC. Physician assistants at Kaiser: distinctive patters of practice. Inquiry. 1974;11:207-219.

Larson PF, Osterweis M (Eds.) The Roles of Physician Assistants and Nurse Practitioners in Primary Care. Washington, DC: Association of Academic Health Centers, 1994.

Lawrence DM. Physician assistants \& nurse practitioners: their impact on health care access, costs, and quality. Health \& Medical Care Services Review. 1978; 1(2): $1-12$. 
Lazarsfeld PF, Jeffrey GR, Pasanella AK. An Introduction to Applied Sociology. New York: Elsevier, 1975.

Luft HS. Health Maintenance Organizations: Dimensions of Performance. 1981; Wiley. New York, NY.

Mahoney DF. An economic analysis of the nurse practitioner role. Nurse Practitioner. 1988; 13(3): 44-52.

McCibbin R. Cost effectiveness of physician assistants: a review of recent evidence. $P A J 1978 ; 8: 110-115$.

Medical Group Management Association. Physician Compensation and Production Survey: 1995Report Based on 1994 Data. Englewood, CO 1995.

Meikle TH. An Expanded Role for the Physician Assistant. Bellwether . Association of Academic Health Centers, Washington, DC, (June) 1992a

Meikle TH. President' Statement. Report of the Josiah Macy, Jr. Foundation: 1992. Josiah Macy, Jr. Foundation, New York, NY. $1992 b$.

Mendenhall RC, Repicky P, Neville R. Assessing the utilization and productivity of nurse practitioners and physician's assistants: methodology and findings on productivity. Medical Care. 1980; 18(6): 609-623.

Miles DL, Rushing WA. A study of physician's assistants in rural setting. Medical Care. $1976 ; 14(2): 987-995$.

Miller RL, Benjamin DK, North DC. The Economics of Public Issues: Ninith Edition. Harper Collins College Publishers, New York, NY. 1993.

Moore GT. Will the power of the marketplace produce the workforce we need? Inquiry. 1994; 31(3): 276-282. 
National Health Service Corps, National Advisory Council. Proposed Strategies for Fulfilling Primary Care Professional Needs: Part II: Nurse Practitioners, Physician Assistants, and Certified Nurse Midwives. DHHS, NHSC, August 1991.

Nelson EC, Jacobs AR, Breer PE, Johnson KG. Impact of physician assistants on patients' visits in ambulatory practices. Ann Intern Med. 1975; 82: 608-612.

Nelson EC, Johnson KG, Jacobs AR. Impact of Medex on physician activities: redistribution of time after incorporating a Medex into the practice. J Family Practice. 1977; 5: 607-612.

Office of Technology Assessment, U.S. Congress. Nurse Practitioners, Physician Assistants, and Certified Nurse Midwives: A Policy Analysis. Case Study \#37, OTA-HCS-37, Washington, DC: Government Printing Office, 1986.

Office of Technology Assessment, U.S. Congress. Health Care in Rural America. (OTA-H-434). Washington, D.C.: Government Printing Office, 1990.

Oeffinger KC, Snell LM, Foster BM, Panico KG, Archer RK. Diagnosis of acute bronchitis in adults: a national survey of family physicians. Journal of Family Practice. 1997; 45(5): 402-409.

Ortiz L. The role of PAs in Alaskan Air Command. Air Force Medical Service Digest. November-December 1979; 6-7.

Osterweis M, McLaughlin CJ, Manasse HR, Hopper CL (Eds.). The U.S. Health Workforce: Power, Politics, and Policy. Academic Health Centers. 1996, Washington, DC.

Ott JE. A Demonstration Project on the Education and Utilization of Child Health Associates and Their Impact on Medical Practice, Executive Summary. 1979. Division of Medicine, CT \#231-75-0006. 
Peterson S, Eriksson M, Tibblin G. Practice variation in Swedish primary care. Scand J Prim Health Care. 1997; 15(2): 68-75.

Page RR. The Military Physician's Assistant 1975. DoD Health Studies Task Force, Office of the Assistant Secretary of Defense (Health and Environment), Study File 7.4.5 DASD (HA).

Physician Payment Review Commission, Annual Report to Congress, 1993. Chapter 16. Medicaid payment policies for nonphysician providers. 1993a; 305-321.

Physician Payment Review Commission, Annual Report to Congress, 1993. Chapter 4. Reforming graduate medical education. 1993b; 55-85.

Physician Payment Review Commission. Nonphysician Practitioners. Report to Congress, 1994.

Podrid PJ, Kowey PR, Frishman WH, Goldberg-Arnold RJ, Kaniecki DJ, Beck JR, Beshansky JR. Comparative cost-effectiveness analysis of quinidine, procainamide and mexiletine. American Journal of Cardiology. 1991; 68(17): 1662-1667.

Pondy LR, Jones JM, Braun JA. Utilization and productivity of the Duke Physician's Associate. Socio-Economic Planning Sciences. 1973; 7: 327-52 (See also PA Journal 1974: 4)

Poses RM, Smith WR, McClish DK, Anthony M. Controlling for confounding by indication for treatment. Are administrative data equivalent to clinical data? Medical Care. 1995; 33(4 Supplement): AS36-46.

Record JC. Cost Effectiveness of Physician Assistants in a Maximum-Substitution Model: Phase II of a Two-Phase Study. DHEW Publication No. HRA 78-1, Contract No. 231-76-0601, 1978. 
Record JC, McCally M, Schweitzer SO, Blomquist RM, Berger BD. New health professionals after a decade and a half: Delegation, productivity, and costs in primary care. J Health Politics, Policy and Law. 1980; 5(3): 470-497.

Record JC. The productivity of new health practitioners. In Record JC. Staffing Primary Care in 1990: Physician Replacement and Cost Savings. New York: Springer Publishing Company; 1981

Reinhardt UE. A production function for physician services. Rev Econ Stat 1972; 54: $55-66$.

Retchin SM. The modification of physician practice patterns. Clinical Performance and Quality Health Care. 1997; 5(4): 202-207.

Rieder MJ, Hammer SJ, Haslam RH. Age- and gender-related differences in clinical productivity among Canadian physicians. Pediatrics. 1990; 85(2): 144-149.

Riess J, Lawrence D. New Practitioners in Remote Practices: Summary of a Study of Training, Utilization, Financing and Provider Satisfaction. Final report for contract No. 1-MB-44168 (Washington, DC: Division of Medicine, Bureau of Health Manpower, Department of Health, Education, and Welfare, 1976).

Riportella-Muller R, Libby D, Kindig D. The substitution of physician assistants and nurse practitioners for physician residents in teaching hospitals. Health Affairs. $1995 ; 14(2)$ : 181-191.

Roark R. Practice variations among pediatricians and family physicians in the management of otitis media. Archives of Pediatrics and Adolescent Medicine. $1995 ; 149(8): 839-844$.

Romm J, Berkowitz A, Cohen MA, et. al. The physician assistant reimbursement experiment. J Amb Care Mgmt 1979; 2: 1-12. 
Rush PJ, Shore A. Physician perceptions of the value of physical modalities in the treatment of musculosketal disease. British Journal of Rheumatology. 1994; 33(6): 566-568.

Russel LB, Gold MR, Siegel JE, Daniels N, Weinstein MC. The role of costeffectiveness analysis in health and medicine. $J$ Am Medical Assoc. 1996; 276(14): 1172-1177.

Safriet B. Health care dollars and regulatory sense: the role of advanced practice nursing. Yale J Regulation. 1992; 419-486.

Scheffler RM. The employment, utilization, and earnings of physician extenders. Soc Science \& Med. 1977; 11: 785-791.

Scheffler RM. The productivity of new health professionals: physician assistants and Medex. Research in Health Economics 1979; 1:37-56.

Scheffler RM, Waitzman NJ, Hillman JM. The productivity of physician assistants and nurse practitioners and health work force policy in the era of managed health care. J Allied Health. 1996; 25(3): 207-217.

Schneider DP, Foley WJ. A systems analysis of the impact of physician extenders on medical cost and manpower requirements. Medical Care. 1977; 15(4): 277 297.

Schroeder SA. How can we tell whether there are too many or too few physicians? The case for benchmarking. J Am Med Assoc. 1996; 276 (22): 1841-1843.

Sekscenski ES, Sansom S, Bazell C, Salmon ME, Mullan F. State practice environments and the supply of physician assistants, nurse practitioners, and certified nurse midwives. NEngl J Med. 1994; 331(19): 1266-71. 
Siegel JE, Weinstein MC, Russel LB, Gold MR; for the Panel on Cost-Effectiveness in Health and Medicine. Recommendations for reporting cost-effectiveness analyses. J Am Med Assoc. 1996; 276(16): 1339-1341.

Silver HK. New allied health professionals: implications of the Colorado Child Health Associate law. New Engl J Med. 1971; 284(6): 304-307.

Simon A, Link M, Miko A. Twelfth Annual Report on Physician Assistant Educational Programs in the United States, 1997. Association of Physician Assistant Programs, Alexandria, VA. 1998.

Simon CJ, Born PH. Physician earnings in a changing managed care environment. Health Affairs. 1996; 15(3): 124-133.

Sloan FA. Valuing Health Care: Costs, Benefits, and Effectiveness of Pharmaceuticals and Other Medical Technologies. 1996. Cambridge University Press. New York, NY.

Smith KR. Health Practitioners: Efficient Utilization and the Cost of Health Care. Madison: Department of Economics, University of Wisconsin, 1973.

Sox HC, Jr. Quality of patient care by nurse practitioners and physician assistants: a ten year perspective. Ann Int Med 1979; 91: 459-472.

Spitzer WO. The nurse practitioner revisited: slow death of a good idea. New Eng $J$ Med. 1984; 310: 1049-1051.

Steinwachs DM, Shaprio S, Yaffe R, Levine DM, Seidel H. The role of new health practitioners in a prepaid group practice. Medical Care. 1976; 14(2): 95-120.

Starr P. The Social Transformation of American Medicine. New York: Basic Books, 1982. 
Stamm WE, Hooton TM. Management of urinary tract infections in adults. $N E n g l J$ Med. 1993; 329(18): 1326-1334.

Tirado NC, Guzman M, Burgos FL. Workload contributions of a physician assistant in a ambulatory care setting. Veterans Administration Medical Center, San Juan, PR. Puerto Rico Health Science Journal. 1990; 9(2): 165-7.

Van der Windt DA, Koes BW, de Jong BA, Bouter LM. Shoulder disorders in general practice: incidence, patient characteristics, and management. Annals of Rheumatic Diseases. 1995; 54(12): 959-964.

Von Korff M, Wagner EH, Saunders K. A chronic disease score from automated pharmacy data. JClin Epidemiology. 1992; 45: 197-203.

Washington Consulting Group. "Survey of Certified Nurse Practitioners and Clinical Nurse Specialists: December 1992 Final Report." Report to the Bureau of Health Professions, Department of Health and Human Services under Contract No. 240-91-0055 (Rockville, MD: 1994).

Weiner JP, Steinwachs DM, Williamson JW. Nurse practitioner and physician assistant practices in three HMOs: implications for future U.S. health manpower needs. Am J Public Health. 1986; 76(5): 507-511.

Weiner JP. Forecasting the effects of health reform on US physician workforce staffing patterns: evidence from HMO staffing patterns. JAMA 1994; 272(3): 222-230.

Weiner JP, McLaughlin CJ, Gamliel S. Extrapolating HMO staffing to the population at large. in Osterweis M, McLaughlin CJ, Manasse HR, Hopper CL (Eds.). The U.S. Health Workforce: Power, Politics, and Policy. Academic Health Centers. 1996, Washington, DC. 
Weinstein MC, Siegel JE, Gold MR, Kamlet MS, Russell LB; for the Panel on CostEffectiveness in Health and Medicine. Recommendations of the panel on costeffectiveness in health and medicine. J Am Med Assoc. 1996; 276(15): 12531258.

Weston JL. Distribution of nurse practitioners and physician assistants: implications of legal constraints and reimbursement. Public Health Reports. 1980; 95: 253256.

Wolman D, Madden JF. Increasing utilization of PAs in the emergency department. Physician Assistant. 1996; 20(11): 108-116.

White House Domestic Policy Council. The President's Health Security Plan. Times Books (Division of Random House). 1993.

Zechauser R, Eliastam M. The productivity potential of the physician assistant. $J$ Human Resour. 1974; 9: 95-116. 
APPENDIX A

DIFFERENTIAL DIAGNOSIS 
DIFFERENTIAL DIAGNOSIS BY SELECT CONDITION AND ICD CODES

\begin{tabular}{|l|c|}
\hline Otitis Media, Suppurative and Acute & $382.00 \& 382$. \\
\hline Pharyngitis & 462 \\
\hline Pharyngitis - Streptococcus & 034.0 \\
\hline Cerumen impaction & 380.4 \\
\hline Otitis externa & 380.10 \\
\hline Otitis media - serous & 381.4 \\
\hline Eustachian tube dysfunction & 381.81 \\
\hline Tonsillitis, acute & 463 \\
\hline Otalgia & 388.70 \\
\hline Otitis externa - acute & 380.22 \\
\hline Labyrinthitis & 386.30 \\
\hline Otitis media serous - chronic & 381.10 \\
\hline Otitis media w/ drum rupture & 382.01 \\
\hline Otitis externa - chronic & 380.23 \\
\hline Eustachian tube disorder & 381.9 \\
\hline Otitis media - suppurative chronic & 382.3 \\
\hline Tympanic membrane perforation & 384.20 \\
\hline Pain - TM joint & 848.1 \\
\hline
\end{tabular}




\begin{tabular}{|l|l|}
\hline BRONCHITIS, ACUTE & $\mathbf{4 6 6 . 0}$ \\
\hline URI & 465.9 \\
\hline Bronchitis & 491.9 \\
\hline Viral syndrome & 079.00 \\
\hline COPD & 496 \\
\hline Pneumonia & 486 \\
\hline Bronchitis - asthmatic/obstruction & 491.20 \\
\hline Bronchiolitis, acute & 466.1 \\
\hline Chest pain - pleuritic & 786.52 \\
\hline Bronchitis - tracheobronchitis & 491.8 \\
\hline Bronchitis NOS* & 490 \\
\hline Pneumonia - mycoplasma & 483.0 \\
\hline Bronchitis - chronic & 491.1 \\
\hline Pleurisy & 511.0 \\
\hline Upper respiratory disease & 478.9 \\
\hline Bronchopneumonia & 485 \\
\hline Sarcoidosis & 135 \\
\hline Pleural effusion & 511.9 \\
\hline Acute up respire infection & 465.8 \\
\hline Simple chronic bronchitis & 491.0 \\
\hline Pneumonia - organism NEC & 483.8 \\
\hline Bronchiectasis & 494 \\
\hline Exercise bronchospasm & 518.82 \\
\hline Pneumonia - bacterial & 482.9 \\
\hline Pneumonia - viral & 480.9 \\
\hline
\end{tabular}




\begin{tabular}{|l|c|}
\hline URINAR Y TRCT INFECTION & $\mathbf{5 9 9 . 0}$ \\
\hline Abdominal pain & 789.0 \\
\hline Irritable bowel syndrome & 564.1 \\
\hline Stomach, functional disorder & 536.8 \\
\hline Vaginitis, monilial & 112.1 \\
\hline Dysuria & 788.1 \\
\hline Female stress incontinence & 625.6 \\
\hline Incontinence - urge \& stress & 788.33 \\
\hline Vaginitis - atrophic & 627.3 \\
\hline Bladder outlet obstruction & 596.0 \\
\hline Enuresis & 788.30 \\
\hline Cystocele/rectocele & 618.0 \\
\hline Cystitis - acute & 595.0 \\
\hline Cervicitis & 616.0 \\
\hline Pyelonephritis - acute & 590.10 \\
\hline Urinary retention & 788.20 \\
\hline Bladder disorder & 596.9 \\
\hline Urethral syndrome & 597.81 \\
\hline \hline
\end{tabular}




\begin{tabular}{|l|c|}
\hline ACUTE SHOULDER TENDINITIS & $\mathbf{7 2 6 . 1 1}$ \\
\hline Tendinitis & 726.90 \\
\hline Pain - shoulder & 719.41 \\
\hline Muscle spasms & 728.85 \\
\hline Sprain/strain - shoulder & 840.9 \\
\hline Strain - supraspinatus & 840.6 \\
\hline Polymyalgia rheumatica & 725 \\
\hline Bursitis & 727.3 \\
\hline Bursitis - shoulder & 726.10 \\
\hline Rotator cuff syndrome & 726.19 \\
\hline Capsulitis of shoulder - adhesive & 726.0 \\
\hline Sprain - rotator cuff & 840.4 \\
\hline Sprain/strain - acromioclavicular joint & 840.0 \\
\hline Rotator cuff tear & 727.61 \\
\hline \hline
\end{tabular}

Note: *NOS - Not otherwise specified 
APPENDIX B

REGRESSION ANALYSIS 


\section{REGRESSION ANALYSIS \\ URINARY TRACT INFECTION}
Total Costs as a Function of Provider Type, Patient Age, Gender, and Chronic Disease Score

\section{ANALYSIS OF VARIANCE}

\begin{tabular}{|c|c|c|c|}
\hline Sou & $\begin{array}{l}\text { Degrees of } \\
\text { Freedom }\end{array}$ & Sum of Squares & Mean Square \\
\hline Mode & 4 & 3115851.37 & 778962.84463 \\
\hline & 2506 & 132201906.21 & 52754.15252 \\
\hline & 2510 & 135317757.59 & \\
\hline
\end{tabular}

$\begin{array}{lr}F \text { Value } & 14.7660 \\ \text { Prob }>\text { F } & 0.0001 \\ \text { Root MSE } & 299.6827 \\ \text { Dependent Mean } & 244.1085 \\ \text { R-Square } & 0.0230 \\ \text { Adjusted R-Square } & 0.0215\end{array}$

\section{PARAMETER ESTIMATES}

Variable
Intercept
Provider
Age
Gender
CDS $t$ for $\mathrm{H}_{0}$ :

Parameter Standard Parameter Estimate Error

173.73

53.49

0.79

3.74

7.74
$=0$

14.666

5.530

2.931

0.228

3.355
Prob $>t$

0.0001

0.0001

0.0034

0.8198

0.0006
Standardized

Estimate

0

0.1098

0.6118

0.0045

0.0703 


\section{REGRESSION ANALYSIS}

\section{OTITIS MEDIA}

Total Costs as a Function of Provider Type, Patient Age, Gender, and Chronic Disease Score

\section{ANALYSIS OF VARIANCE}

\begin{tabular}{lrcr} 
Source & $\begin{array}{c}\text { Degrees of } \\
\text { Freedom }\end{array}$ & $\begin{array}{c}\text { Sum of Squares } \\
\text { Mean Square }\end{array}$ & $\begin{array}{l}\text { Med } \\
\text { Model }\end{array}$ \\
Error & 4 & 10265069.03 & 2566267.2566 \\
C Total & 8249 & 162937144.88 & 19752.35118 \\
\hline & 8253 & 173202213.91 &
\end{tabular}

F Value

Prob $>$ F

Root MSE

Dependent Mean

R-Square

Adjusted R-Square
129.9220

0.0001

140.5430

175.79299

0.05930

0.05880

\section{PARAMETER ESTIMATES}

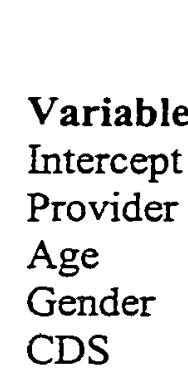

$\begin{array}{cc}\begin{array}{c}\text { Parameter } \\ \text { Estimate }\end{array} & \begin{array}{c}\text { Standard } \\ \text { Error }\end{array} \\ 108.64 & 3.85 \\ 57.62 & 3.62 \\ 1.76 & 0.12 \\ 0.53 & 3.11 \\ 7.00 & 1.03\end{array}$

$t$ for Ho:

Parameter

$=0$

28.185

15.903

15.151

0.171

6.770
Prob $>t$
0.0001
0.0001
0.0001
0.8643
0.0001

Standardized

Estimate

0

0.1767

0.1649

0.0018

0.0732 
REGRESSION ANALYSIS

SHOULDER TENDINITIS

Total Costs as a Function of Provider Type, Patient Age, Gender, and Chronic Disease Score

ANALYSIS OF VARIANCE

\begin{tabular}{lrcr} 
Source & $\begin{array}{c}\text { Degrees of } \\
\text { Freedom }\end{array}$ & Sum of Squares & $\begin{array}{r}\text { Mean Square } \\
\text { Model }\end{array}$ \\
Error & 4 & 99115.92 & 24778.98211 \\
C Total & 350 & 2077897.72 & 5936.85062 \\
\hline & 354 & 2177013.65 &
\end{tabular}

F Value

Prob $>$ F

Root MSE

Dependent Mean

R-Square

Adjusted R-Square
4.174
0.0026
77.0510
174.6237
0.0455
0.0346

\section{PARAMETER ESTIMATES}

\begin{tabular}{|c|c|c|c|c|c|}
\hline Variable & $\begin{array}{l}\text { Parameter } \\
\text { Estimate }\end{array}$ & $\begin{array}{c}\text { Standard } \\
\text { Error }\end{array}$ & $\begin{array}{c}\text { Parameter } \\
=0\end{array}$ & Prob $>t$ & $\begin{array}{l}\text { Standardize } \\
\text { d Estimate }\end{array}$ \\
\hline Intercept & 126.54 & 18.14 & 6.977 & 0.0001 & 0 \\
\hline Provider & 32.00 & 9.46 & 3.383 & 0.0008 & 0.1777 \\
\hline Age & 0.57 & 0.36 & 1.600 & 0.1106 & 0.0866 \\
\hline Gender & -6.29 & 8.29 & -0.758 & 0.4489 & -0.0399 \\
\hline CDS & 0.85 & 2.05 & 0.413 & 0.6797 & 0.0225 \\
\hline
\end{tabular}




\section{REGRESSION ANALYSIS}

\section{BRONCHITIS}

\section{Total Costs as a Function of Provider Type, Patient Age, Gender, and Chronic Disease Score}

\section{ANALYSIS OF VARIANCE}

\begin{tabular}{|c|c|c|c|}
\hline Sour & $\begin{array}{l}\text { Degrees of } \\
\text { Freedom }\end{array}$ & Sum of Squares & Mean Square \\
\hline Mode & 4 & 2462112.30 & 615528.07581 \\
\hline Erro & 1742 & 55846324.38 & 32058.73960 \\
\hline & 1746 & 58308436.69 & \\
\hline
\end{tabular}

F Value
Prob $>$ F
Root MSE
Dependent Mean
R-Square
Adjusted R-Square

$$
\begin{array}{r}
19.200 \\
0.0001 \\
179.0496 \\
232.2433 \\
0.0422 \\
0.0400
\end{array}
$$

\begin{tabular}{|c|c|c|c|c|c|}
\hline Variable & $\begin{array}{c}\text { Parameter } \\
\text { Estimate }\end{array}$ & $\begin{array}{l}\text { Standard } \\
\text { Error }\end{array}$ & $\begin{array}{l}t \text { for } H_{0}: \\
\text { Parameter } \\
=0\end{array}$ & Prob $>t$ & $\begin{array}{l}\text { Standardized } \\
\text { Estimate }\end{array}$ \\
\hline Intercept & 197.81 & 14.00 & 14.132 & 0.0001 & 0 \\
\hline Provider & 4.73 & 10.15 & 0.466 & 0.6412 & 0.0110 \\
\hline Age & 0.42 & 0.29 & 1.444 & 0.1489 & 0.0354 \\
\hline Gender & -20.74 & 8.66 & -2.395 & 0.0167 & -0.0563 \\
\hline CDS & 12.74 & 1.73 & 7.383 & 0.0001 & 0.1807 \\
\hline
\end{tabular}

\section{PARAMETER ESTIMATES}




\section{GENERAL LINEAR MODEL}

\section{OTITIS MEDIA}

\begin{tabular}{lrcr} 
Source & $\begin{array}{c}\text { Degrees of } \\
\text { Freedom }\end{array}$ & $\begin{array}{c}\text { Sum of } \\
\text { Squares }\end{array}$ & \multicolumn{1}{c}{$\begin{array}{c}\text { Mean } \\
\text { Square }\end{array}$} \\
Model & 5 & 9147334.6769 & 1829466.9353 \\
Error & 8248 & 164054879.2312 & 19890.2617 \\
Corrected Total & 8253 & 173202213.9081 &
\end{tabular}

$\begin{array}{lc}\text { F Value } & 91.98 \\ \mathbf{P}>\mathbf{F} & 0.0001 \\ \boldsymbol{R} \text { Square } & 0.0528 \\ \text { Root MSE } & 141.0328 \\ \text { Total Cost } & \$ 175.79\end{array}$

\begin{tabular}{|c|c|c|c|c|c|c|}
\hline & \multicolumn{2}{|c|}{ IM } & \multicolumn{2}{c|}{ FP } & \multicolumn{2}{c|}{ PED } \\
\hline & $\boldsymbol{M D}$ & $\boldsymbol{P A}$ & $\boldsymbol{M D}$ & $\boldsymbol{P A}$ & $\boldsymbol{M D}$ & $\boldsymbol{P A}$ \\
\hline $\mathbf{N}$ & 469 & 210 & 1029 & 733 & 4748 & 1065 \\
\hline & $\mathbf{S}$ & $\mathbf{S}$ & $\mathbf{S}$ & $\mathbf{S}$ & $\mathbf{S}$ & $\mathbf{S}$ \\
\hline $\begin{array}{c}\text { Total } \\
\text { Cost }\end{array}$ & 250.30 & 225.66 & 202.09 & 152.09 & 179.31 & 108.38 \\
\hline SD & 156.44 & 182.36 & 153.10 & 116.32 & 142.30 & 120.79 \\
\hline & & & & & & \\
\hline $\begin{array}{c}\text { Provider } \\
\text { Cost }\end{array}$ & 145.47 & 112.93 & 142.06 & 93.33 & 139.11 & 70.54 \\
\hline SD & 24.06 & 20.88 & 45.02 & 28.70 & 48.69 & 24.64 \\
\hline & & & & & & \\
\hline Lab Cost & 1.47 & 0.67 & 0.51 & 0.24 & 0.46 & 0.30 \\
\hline SD & 9.76 & 3.74 & 4.46 & 2.31 & 3.94 & 3.31 \\
\hline $\begin{array}{c}\text { Med } \\
\text { Cost }\end{array}$ & 103.36 & 112.05 & 59.52 & 58.52 & 39.74 & 37.54 \\
\hline SD & 151.45 & 181.22 & 145.79 & 112.26 & 128.68 & 115.28 \\
\hline & & & & & & \\
\hline Episodes & 1.03 & 1.04 & 1.16 & 1.15 & 1.27 & 1.27 \\
\hline SD & 0.17 & 0.19 & 0.37 & 0.35 & 0.45 & 0.44 \\
\hline
\end{tabular}


GENERAL LINEAR MODEL URINARY TRACT INFECTION

\begin{tabular}{lccr} 
Source & $\begin{array}{c}\text { Degrees of } \\
\text { Freedom }\end{array}$ & $\begin{array}{c}\text { Sum of } \\
\text { Squares }\end{array}$ & \multicolumn{1}{c}{$\begin{array}{c}\text { Mean } \\
\text { Square }\end{array}$} \\
Model & 5 & 2103561.0745 & 420712.2149 \\
Error & 2505 & 133214196.5157 & 53179.3200 \\
Corrected Total & 2510 & 135317757.5902 &
\end{tabular}

$\begin{array}{lr}\text { F Value } & 7.91 \\ \mathbf{P}>\mathbf{F} & 0.0001 \\ \boldsymbol{R} \text { Square } & 0.0156 \\ \text { Root MSE } & 320.6064 \\ \text { Total Cost } & \$ 244.11\end{array}$

\begin{tabular}{|c|c|c|c|c|c|c|}
\hline & \multicolumn{2}{|c|}{ IM } & \multicolumn{2}{|c|}{ FP } & \multicolumn{2}{|c|}{ PEDS } \\
\hline & $M D$ & $P A$ & $M D$ & $P A$ & $M D$ & $P A$ \\
\hline $\mathbf{N}$ & 572 & 269 & 615 & 542 & 446 & 67 \\
\hline & $s$ & $\$$ & $s$ & 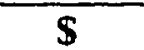 & $S$ & $\mathbf{S}$ \\
\hline $\begin{array}{l}\text { Total } \\
\text { Cost }\end{array}$ & 285.16 & 224.25 & 255.03 & 204.24 & 242.56 & 205.94 \\
\hline SD & 204.30 & 140.79 & 176.52 & 240.17 & 287.72 & 505.92 \\
\hline $\begin{array}{r}\text { Provide } \\
\text { r Cost }\end{array}$ & 157.55 & 118.49 & 140.43 & 92.07 & 126.91 & 59.84 \\
\hline SD & 45.17 & 31.07 & 43.47 & 27.37 & 40.25 & 14.75 \\
\hline $\begin{array}{l}\text { Med } \\
\text { Cost }\end{array}$ & 100.66 & 82.16 & 91.10 & 95.88 & 52.52 & 93.62 \\
\hline SD & 174.59 & 122.83 & 150.59 & 231.85 & 269.31 & 498.24 \\
\hline $\begin{array}{c}\text { Image } \\
\text { Cost }\end{array}$ & 8.73 & 4.20 & 8.85 & 3.56 & 41.31 & 30.49 \\
\hline SD & 39.54 & 25.19 & 40.19 & 24.48 & 86.73 & 95.95 \\
\hline $\begin{array}{l}\text { Lab } \\
\text { Cost }\end{array}$ & 18.23 & 19.40 & 14.65 & 12.74 & 21.83 & 21.98 \\
\hline SD & 23.27 & 20.21 & 19.46 & 18.11 & 20.73 & 17.14 \\
\hline $\begin{array}{l}\text { Episode } \\
\text { s }\end{array}$ & 1.12 & 1.09 & 1.15 & 1.13 & 1.16 & 1.08 \\
\hline SD & 0.32 & 0.29 & 0.36 & 0.34 & 0.37 & 0.27 \\
\hline
\end{tabular}




\section{GENERAL LINEAR MODEL}

\section{SHOULDER TENDINITIS}

\begin{tabular}{lrrr} 
Source & $\begin{array}{c}\text { Degrees of } \\
\text { Freedom }\end{array}$ & $\begin{array}{c}\text { Sum of } \\
\text { Squares }\end{array}$ & \multicolumn{1}{c}{$\begin{array}{c}\text { Mean } \\
\text { Square }\end{array}$} \\
Model & 4 & 147561.7303 & 36890.4326 \\
Error & 350 & 2029451.9142 & 5798.4340 \\
Corrected Total & 354 & 2177013.6445 & \\
& & & \\
& F Value & 6.36 & \\
& P $>$ F & 0.0001 & \\
& R Square & 0.0678 & \\
& Root MSE & 76.1475 & \\
& Total Cost & $\$ 174.62$ &
\end{tabular}

\begin{tabular}{|c|c|c|c|c|}
\hline & \multicolumn{2}{|c|}{ IM } & \multicolumn{2}{|c|}{ FP } \\
\hline & $M D$ & $P A$ & $M D$ & $P A$ \\
\hline $\mathbf{N}$ & 129 & 25 & 135 & 65 \\
\hline & $\$$ & $\$$ & $\$$ & $\mathbf{S}$ \\
\hline $\begin{array}{l}\text { Total } \\
\text { Cost }\end{array}$ & 191.37 & 188.37 & 175.66 & 134.96 \\
\hline SD & 70.02 & 86.34 & 58.89 & 108.86 \\
\hline $\begin{array}{c}\text { Provider } \\
\text { Cost }\end{array}$ & 158.77 & 130.55 & 131.39 & 86.56 \\
\hline SD & 46.74 & 44.41 & 32.16 & 19.75 \\
\hline Med Cost & 23.88 & 37.02 & 36.12 & 42.05 \\
\hline SD & 51.25 & 49.58 & 47.44 & 108.99 \\
\hline $\begin{array}{c}\text { Image } \\
\text { Cost }\end{array}$ & 7.16 & 18.48 & 7.82 & 6.09 \\
\hline SD & 20.61 & 35.75 & 21.41 & 19.25 \\
\hline Lab Cost & 1.56 & 2.33 & 0.33 & 0.27 \\
\hline SD & 8.07 & 11.66 & 3.78 & 2.17 \\
\hline Episodes & 1.12 & 1.20 & 1.07 & 1.06 \\
\hline $\mathrm{SD}$ & 0.33 & 0.41 & 0.26 & 0.24 \\
\hline
\end{tabular}


GENERAL LINEAR MODEL

BRONCHITIS

\begin{tabular}{lrcr} 
Source & $\begin{array}{c}\text { Degrees of } \\
\text { Freedom }\end{array}$ & $\begin{array}{c}\text { Sum of } \\
\text { Squares }\end{array}$ & \multicolumn{1}{c}{$\begin{array}{c}\text { Mean } \\
\text { Square }\end{array}$} \\
Model & 5 & 1318939.7741 & 763787.9548 \\
Error & 1741 & 56989496.9111 & 32733.7719 \\
Corrected Total & 1746 & 58308436.6852 & \\
& & & \\
& F Value & 8.06 & \\
& P $>$ F & 0.0001 & \\
& R Square & 0.0226 & \\
& Root MSE & 180.9248 & \\
& Total Cost & $\$ 232.24$ &
\end{tabular}

\begin{tabular}{|c|c|c|c|c|c|c|}
\hline & \multicolumn{2}{|c|}{ IM } & \multicolumn{2}{c|}{ FP } & \multicolumn{2}{c|}{ PED } \\
\hline $\mathbf{N}$ & $\mathbf{M D}$ & $\boldsymbol{P A}$ & $\boldsymbol{M D}$ & $\boldsymbol{P A}$ & $\boldsymbol{M D}$ & $\boldsymbol{P A}$ \\
\hline & 568 & 142 & 731 & 262 & 37 & 7 \\
\hline $\begin{array}{c}\text { Total } \\
\text { Cost }\end{array}$ & $\mathbf{S}$ & $\mathbf{S}$ & $\$$ & $\$$ & $\$$ & $\$$ \\
\hline SD & 171.40 & 183.46 & 164.18 & 174.51 & 259.60 & 960.48 \\
\hline & & & & & & \\
\hline $\begin{array}{c}\text { Provider } \\
\text { Cost }\end{array}$ & 145.48 & 110.32 & 125.67 & 83.41 & 109.27 & 55.69 \\
\hline SD & 24.09 & 12.87 & 19.97 & 12.22 & 0 & 0 \\
\hline & & & & & & \\
\hline Med Cost & 104.45 & 136.11 & 88.58 & 111.73 & 128.06 & 439.92 \\
\hline SD & 162.45 & 175.45 & 158.66 & 168.37 & 255.03 & 960.48 \\
\hline & & & & & & \\
\hline $\begin{array}{c}\text { Image } \\
\text { Cost }\end{array}$ & 4.65 & 6.97 & 2.17 & 3.53 & 5.35 & 0 \\
\hline SD & 17.35 & 20.36 & 11.77 & 14.87 & 23.99 & 0 \\
\hline & & & & & & \\
\hline Lab Cost & 1.75 & 1.54 & 1.14 & 1.51 & 0 & 0 \\
\hline SD & 9.24 & 6.51 & 7.06 & 8.41 & 0 & 0 \\
\hline & & & & & & \\
\hline Episodes & 1.03 & 1.01 & 1.03 & 1.02 & 1.00 & 1.00 \\
\hline SD & 0.17 & 0.12 & 0.16 & 0.15 & 0 & 0 \\
\hline
\end{tabular}


